\title{
Pollutant analysis using passive samplers: principles, sorbents, calibration and applications. A review
}

\author{
Klaudia Godlewska ${ }^{1}$ D $\cdot$ Piotr Stepnowski ${ }^{1} \cdot$ Monika Paszkiewicz $^{1}$
}

Received: 10 April 2020 / Accepted: 14 August 2020 / Published online: 5 September 2020

(c) The Author(s) 2020

\begin{abstract}
Passive techniques are a constantly evolving method of monitoring water pollution, allowing the simultaneous sampling and concentration of selected chemical compounds. The most popular aqueous passive samplers are those in which sorbents are used as receiving phases, including: the Polar Organic Chemical Integrative Sampler (POCIS). Originally, POCIS contained the copolymer poly(divinylbenzene)-co- $N$-vinylpyrrolidone, which allowed the collection of analytes with $0 \leq \log K_{\text {ow }} \leq 5$, The limitation of the use of conventional samplers for sampling water pollutants only with a specific polarity has resulted in the fact that innovative sorbents are used more and more in POCIS-like samplers. In recent years, application of several innovative sorbents in POCIS-like samplers, for example: mixed-mode ion exchange polymeric sorbents, ionic liquids, molecularly imprinted polymers and carbon nanotubes has been described. This is the first review in which the usability of classical and innovative sorbents used in passive techniques principles has been collected and compared, and it has been shown that the type of sorbent can significantly affect the efficiency of sampling pollutants in the aquatic environment. The major points are the following: 1) principle of operation, of passive samplers, 2) characteristics of POCIS and sorbents used as receiving phases, 3) sampler calibration methods and environmental factors affecting their operation, 4) a detailed description of the application possibilities of conventional and innovative sorbents used in POCIS-like samplers. This review shows the growing number of works on the use of innovative sorption materials to overcome limitation of originally designed POCIS, and the published results, allow us to conclude that the type of sorbent may be a key factor in increasing the applicability of POCIS-like samplers.
\end{abstract}

Keywords Passive sampling $\cdot$ POCIS $\cdot$ Innovative sorbents $\cdot$ Development of POCIS-like samplers

\begin{tabular}{|c|c|}
\hline Abbreviations & \\
\hline $\mathrm{DCM}$ & Dichloromethane \\
\hline DGT & Diffusive gradients in thin films \\
\hline DMLS & Discrete multilayer sampler \\
\hline dSPE & Dispersive solid-phase extraction \\
\hline $\mathrm{MeOH}$ & Methanol \\
\hline MESCO & Membrane-enclosed sorptive coating \\
\hline OASIS HLB & Hydrophilic-lipophilic-balanced sorbent \\
\hline Pest-POCIS & $\begin{array}{l}\text { Pesticide polar organic chemical integra- } \\
\text { tive sampler }\end{array}$ \\
\hline Pharm-POCIS & $\begin{array}{l}\text { Pharmaceutical polar organic chemical } \\
\text { integrative sampler }\end{array}$ \\
\hline PIMS & Passive integrative mercury sampler \\
\hline \multicolumn{2}{|c|}{$\begin{array}{l}\text { Klaudia Godlewska } \\
\text { klaudia.godlewska@phdstud.ug.edu.pl }\end{array}$} \\
\hline $\begin{array}{l}\text { Department o } \\
\text { of Chemistry, } \\
80-308 \text { Gdans }\end{array}$ & $\begin{array}{l}\text { Environmental Analytics, Faculty } \\
\text { Iniversity of Gdansk, ul. Wita Stwosza } 63 \text {, } \\
\text { Poland }\end{array}$ \\
\hline
\end{tabular}

$\begin{array}{ll}\text { PISCES } & \begin{array}{l}\text { Passive in situ concentration-extraction } \\ \text { sampler }\end{array} \\ \text { POCIS } & \begin{array}{l}\text { Polar organic chemical integrative } \\ \text { sampler }\end{array} \\ R_{\mathrm{s}} & \text { Sampling rate } \\ \text { SPMDs } & \text { Semipermeable membrane devices }\end{array}$

\section{Introduction}

In recent years, passive techniques have been gaining more attention, especially due to researchers looking for reliable methods of monitoring inorganic and organic substances in the natural environment. Passive samplers are economic and trustworthy devices enabling the determination of the timeweighted average concentration of target compounds and thus integrating spot pollution events (Tapie et al. 2011). The advantages of passive sampling devices also include ease of use in the field without the need for electrical power 
or special equipment, and their ability to accumulate analytes and thus to measure low and very low concentrations. This is a huge advantage over spot sampling methods, in which analyte concentrations are often below the limit of quantification and limit of detection of the chosen instrumental method, thus preventing the determination of ultratrace micropollutants in the environment (Thomatou et al. 2011). Common methods for analyte determination consist of several stages: (1) point sampling, (2) transport of samples to the laboratory, (3) extraction of analytes from the tested matrix, (4) purification and concentration of target compounds and (5) instrumental analysis. The use of such dynamic methods for monitoring environmental pollution has many shortcomings. The main disadvantage is that the sampled spot represents only those impurities that are present at the time of sampling. Episodic events, such as storm water leaks or runoff, are often overlooked because pollution can disperse before the next sampling period. Sampling several times to take into account episodic events may be difficult to perform physically, organizationally and financially, especially in remote areas (Zhang et al. 2016). Without sufficient sampling repeatability, it may not be possible to determine the time-weighted average concentrations of target compounds. In addition, passive sampling devices take samples of labile fractions, which are probably more toxicologically relevant than total concentrations in terms of bioavailability assessment (Silvani et al. 2017). For this reason, passive dosimeters are an attractive alternative to traditionally used sampling methods.

The ideal model of a passive sampler has a simple design, is cheap and easy to prepare, apply and analyze and is selective and sensitive for a wide range of chemical compounds, regardless of the medium being tested. In practice, the sampler design is developed for several purposes and no single device is suitable for all applications. The simplest passive sampling devices are single-phase polymer samplers, in which the polymer formula and surface area-to-volume ratio can be selected to increase sampler performance. In contrast, two-phase passive samplers consist of a receiving phase and diffusion membranes. The use of membranes is to lengthen the kinetic phase by slowing down the diffusion between the water phase and the receiving phase (Wennrich et al. 2003; Vrana et al. 2005; Terzopoulou and Voutsa 2016; Criquet et al. 2017; Yang et al. 2017). A wide range of devices is available for the passive sampling of pollutants in the aquatic environment, namely: semipermeable membrane devices (SPMDs) (Huckins et al. 1999, 2000; Harman et al. 2008a, b; Creusot et al. 2013), polymer sheets (Puls and Paul 1997; Vroblesky 2001), ceramic dosimeters (Bopp et al. 2005), diffusive gradients in thin-film (DGT) technique (Denney et al. 1999; Larner et al. 2006; Schintu et al. 2008), discrete multilayer sampler (DMLS) (Larner et al. 2006), membrane-enclosed sorptive coating (MESCO) sampler (Vrana et al. 2006), passive integrative mercury sampler (PIMS) (Brumbaugh et al. 2000), passive in situ concentration-extraction sampler (PISCES) (Barranger et al. 2014), Chemcatcher (Vrana et al. 2006, 2007; Aguilar-Martínez et al. 2008; Booij and Chen 2018) or passive organic chemical integrative sampler (POCIS) (Rujiralai et al. 2011; Černoch et al. 2011; Pesce et al. 2011; Charlestra et al. 2012; Miège et al. 2012; Creusot et al. 2013; Belles et al. 2014a; Kaserzon et al. 2014b; Aisha et al. 2017; Yabuki et al. 2018; Guibal et al. 2018; Rosen et al. 2018). POCIS-like samplers are some of the most frequently used passive devices in environmental analytics. Conventionally used sorbents in POCIS allow for effective sampling of chemical compounds with $0 \leq \log$ Kow $\leq 5$. These samplers were used at least 196 times to sampling water pollutants such as pharmaceuticals, pesticides, endocrine-disrupting substances, personal care products and phenols ("Hydrophilic-lipophilic-balanced sorbent (Oasis HLB)" and "Triphasic sorbent admixture" sections). However, one of the basic restrictions of commercial POCIS is the inefficient uptake of strongly hydrophilic and ionic organic compounds from water. Therefore, scientists are constantly looking for increasingly more efficient, less costly and more reliable devices for monitoring environmental micropollutants. Numerous studies, in which various constructional solutions of samplers and different types of membranes were used, or innovative sorption materials were sought, contributed to the rapid development of passive techniques. In recent years, there has been a successful application of several innovative sorbents in POCIS-like samplers, for example: Strata-X (Balaam et al. 2010), Oasis MAX (Fauvelle et al. 2012), Chromabond HRX (Fauvelle et al. 2012), Strata XAW or Oasis WAX (Kaserzon et al. 2014; Gobelius et al. 2019), Sepra ZT (Booij et al. 2013), Strata X-CW (Carpinteiro et al. 2016), ionic liquids (Caban et al. 2016), Bond-Elute Plexa sorbent (Mijangos et al. 2018a, b), molecularly imprinted polymers (Berho et al. 2017), carbon nanotubes (Jakubus et al. 2016) (Table 1).

In this paper, a review of the literature from the last 16 years, i.e., since the appearance of POCIS-like samplers in environmental analysis, has been carried out to summarize the latest knowledge on the development of passive samplers. Studies using POCIS-like samplers, depending on the sorbent used, from 2004 to 2020 have been chronologically compiled and are presented in Tables 2, 3 and 4. The work describes in detail the basics of passive techniques, sampler calibration methods and their limitations, and types of passive devices depending on the way the probe works. The possibilities of using specific sorbents in POCIS-like samplers are described in detail, as well as their advantages and disadvantages. This review proves that the use of innovative sorption materials, and various types of POCIS modifications have allowed the application of this type of passive 


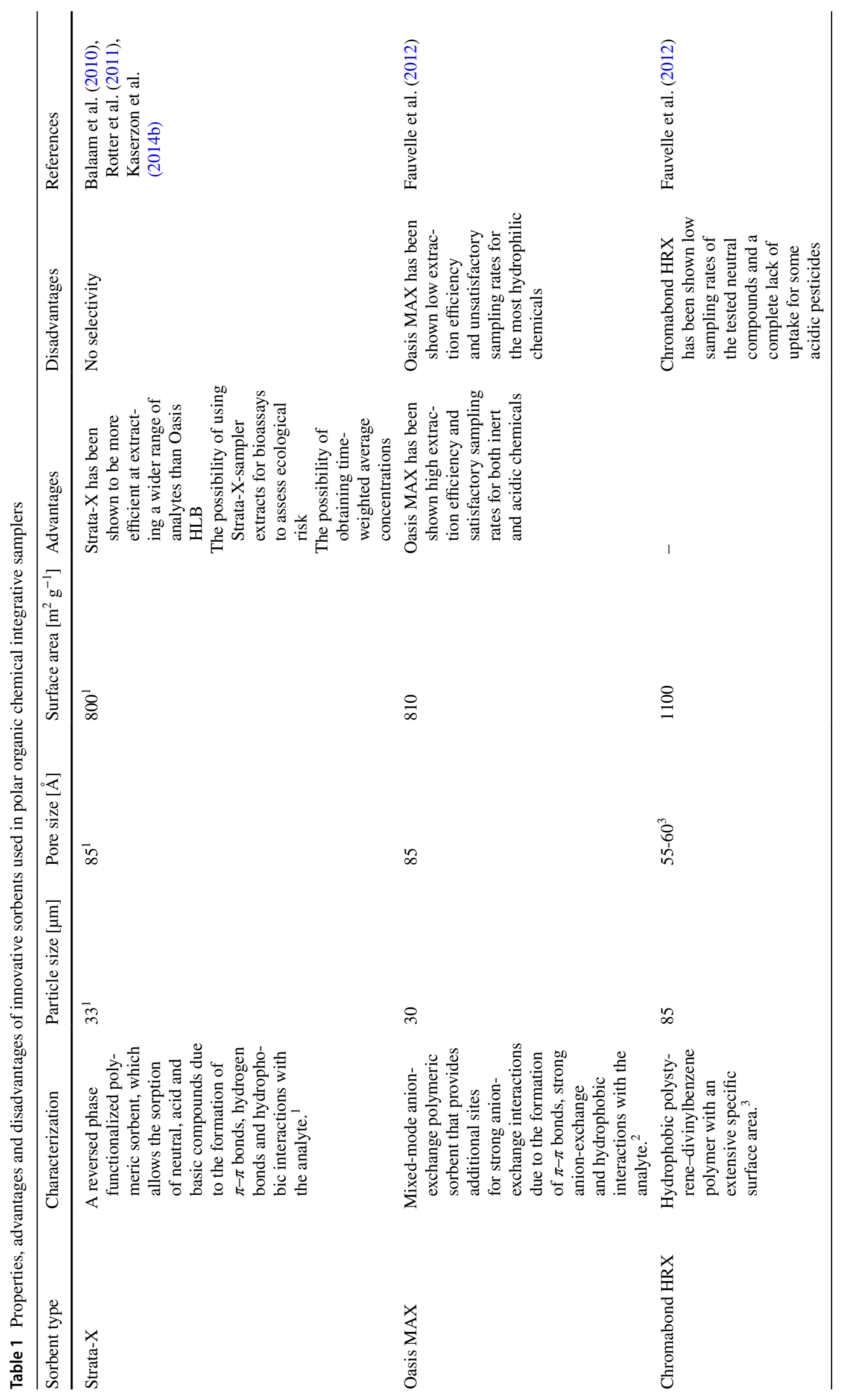




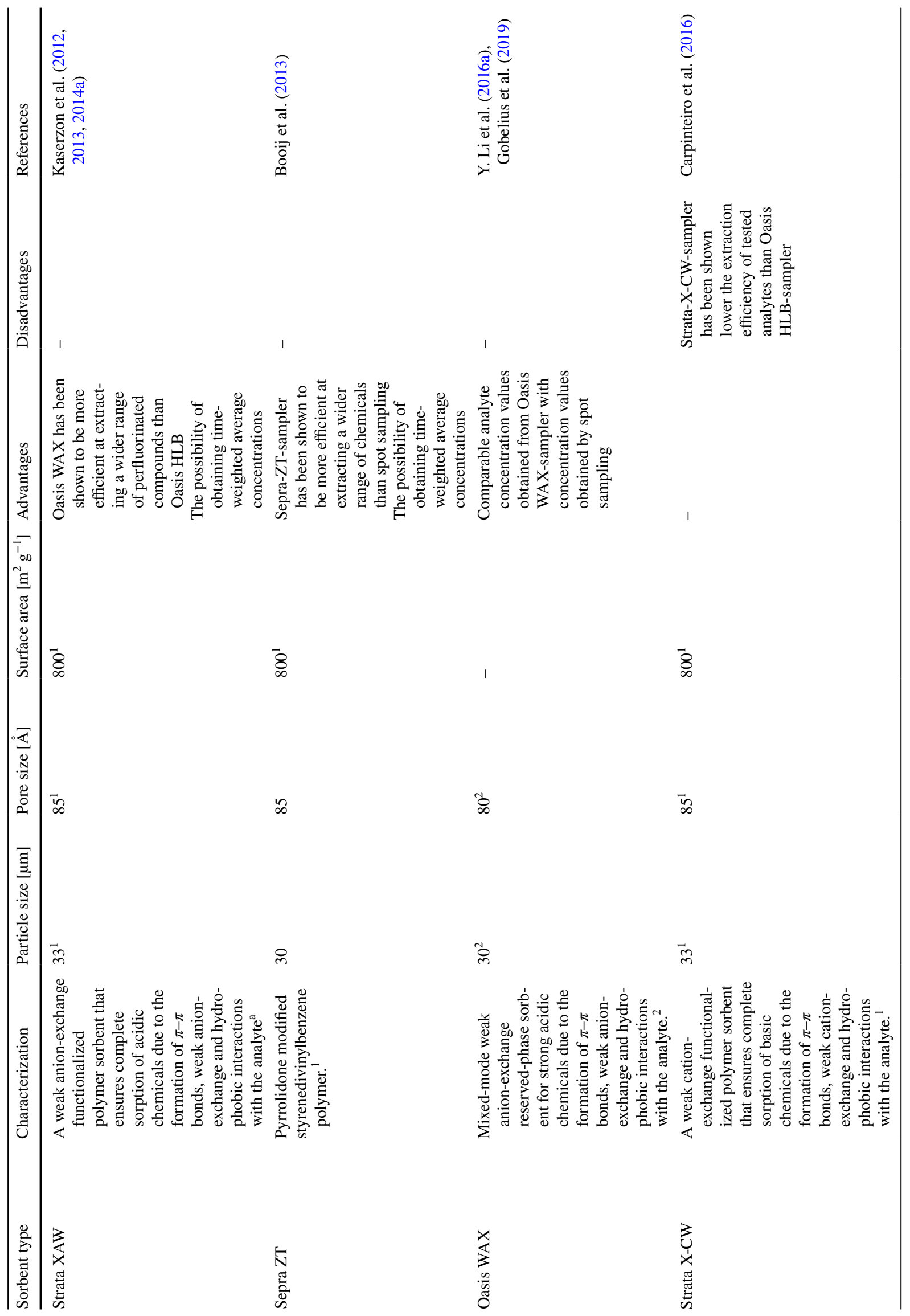




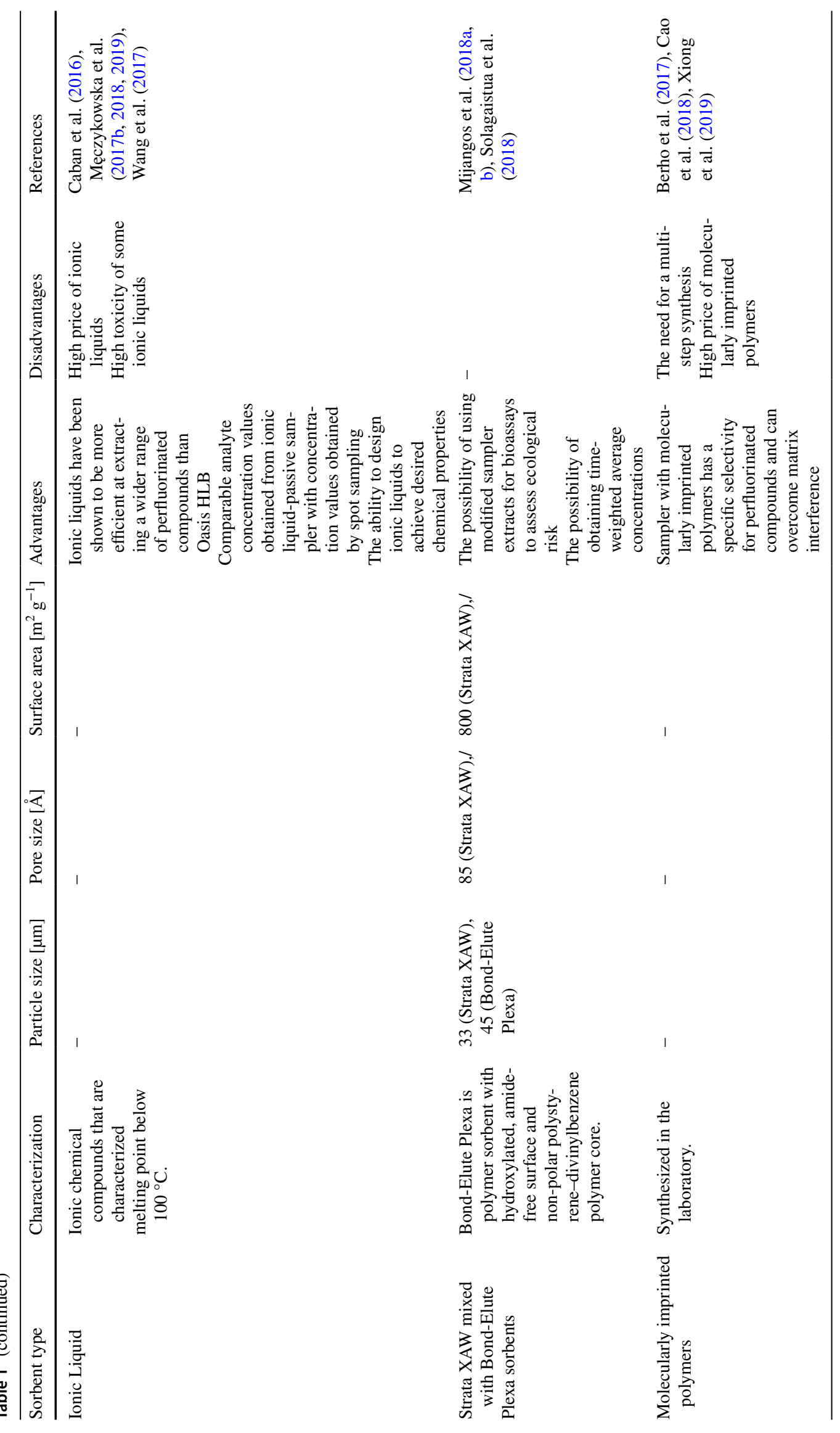




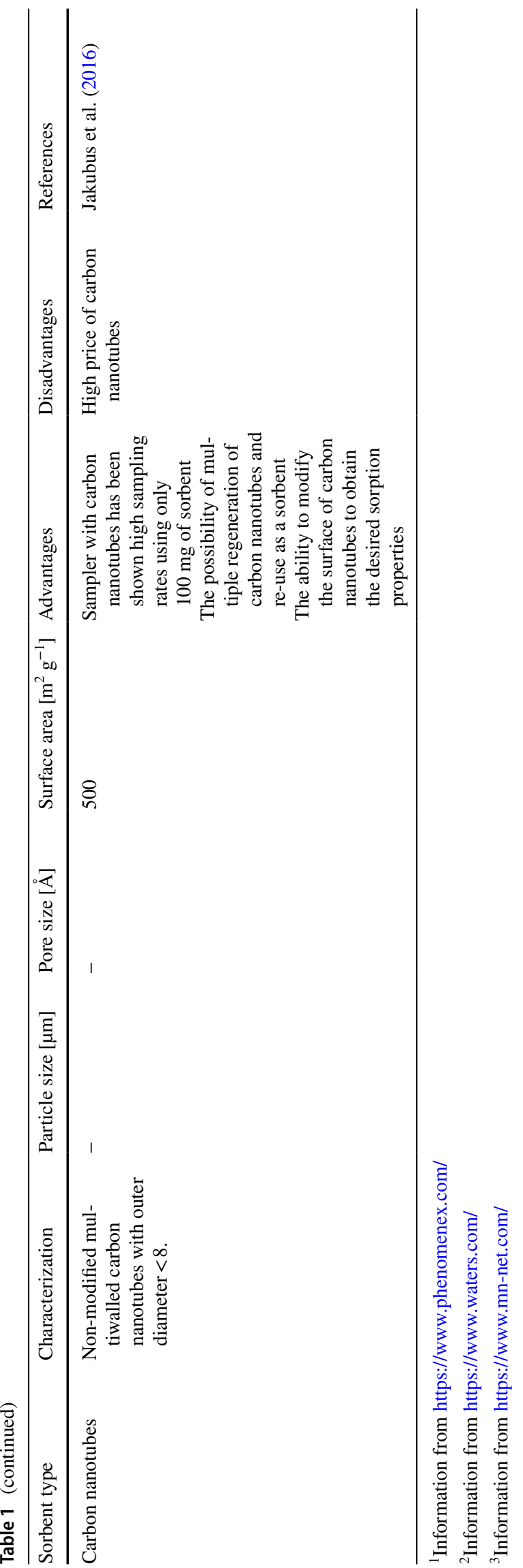

sampler to be extended ("Innovative sorbents" section and Table 1).

\section{Characteristic of selected passive samplers}

The polar organic chemical integrative sampler was developed at the Columbia Environmental Research Center (US Geological Survey) and the patent was granted in the United States in November 2002 (\# 6478961). POCIS was first used in the field in 2004 (Alvarez et al. 2004b) to monitor hydrophilic pollution of the aquatic environment $\left(\log K_{\mathrm{ow}}<4\right)$. Polar organic chemical integrative sampler (POCIS) can be both a kinetic and equilibrium sampler and consists of three parts: (1) sorbent, (2) polyethersulfone membranes and (3) two stainless steel rings (Fig. 1) (Alvarez et al. 2004a). The original configuration consisted of $100 \mathrm{mg}$ of sorbent sandwiched between two microporous (pore size $100 \mathrm{~nm}$, thickness $130 \mathrm{~mm}$ ) polyethersulfone membranes that were held together by two stainless steel washers (thickness $3.2 \mathrm{~mm}$, internal diameter $3.3 \mathrm{~cm}$, outer diameter $7.0 \mathrm{~cm}$ ) (Booij and Chen 2018). Polyethersulfone microporous membranes act as semipermeable barriers between an effective receiving phase (solid sorbent) and the external environment (aqueous phase). The pores in the membranes prevent the accumulation of solid particles, colloids, and fauna and flora with cross sections of a diameter larger than the pore size, simultaneously allowing the accumulation of target compounds (environmental micropollutants). As sorbents, Oasis HLB (hydrophilic-lipophilic-balanced copolymer [poly(divinylbenzene)-co- $N$-vinylpyrrolidone]) or 80:20 (m/m) ISOLUTE ${ }^{\circledR}$ ENV + (hydroxylated polystyrene-divinylbenzene copolymer) and Ambersorb 1500 (carbon lightly dispersed on S-X3 Biobeads) are used (Alvarez et al. 2004b). The latter sorbent mixture is commonly referred to as "Triphasic sorbent admixture." Since 2004, the original POCIS and modified POCIS (e.g., containing a different type of sorbent or membranes) have been successfully used for the monitoring of pollutants in sediment (Alvarez et al. 2012), atmosphere (Kot-Wasik et al. 2007), soil (Pignatello et al. 2010) and water (Alvarez et al. 2008). Ahrens et al. (2015) compared the usefulness of five types of passive samplers for monitoring selected chemical compounds in aquatic environments. The obtained results indicated that POCIS was characterized by the highest extraction efficiency among the tested samplers. It is not surprising then that POCIS-like samplers are some of the most frequently used passive devices in environmental analytics. The introduction and testing of new sorption materials in passive techniques are aimed both at increasing the range of chemicals that can be sampled by the sampler but also at increasing the sampling rate $\left(R_{\mathrm{s}}\right)$ and extraction efficiency. During the selection of an innovative sorbent, scientists are often 


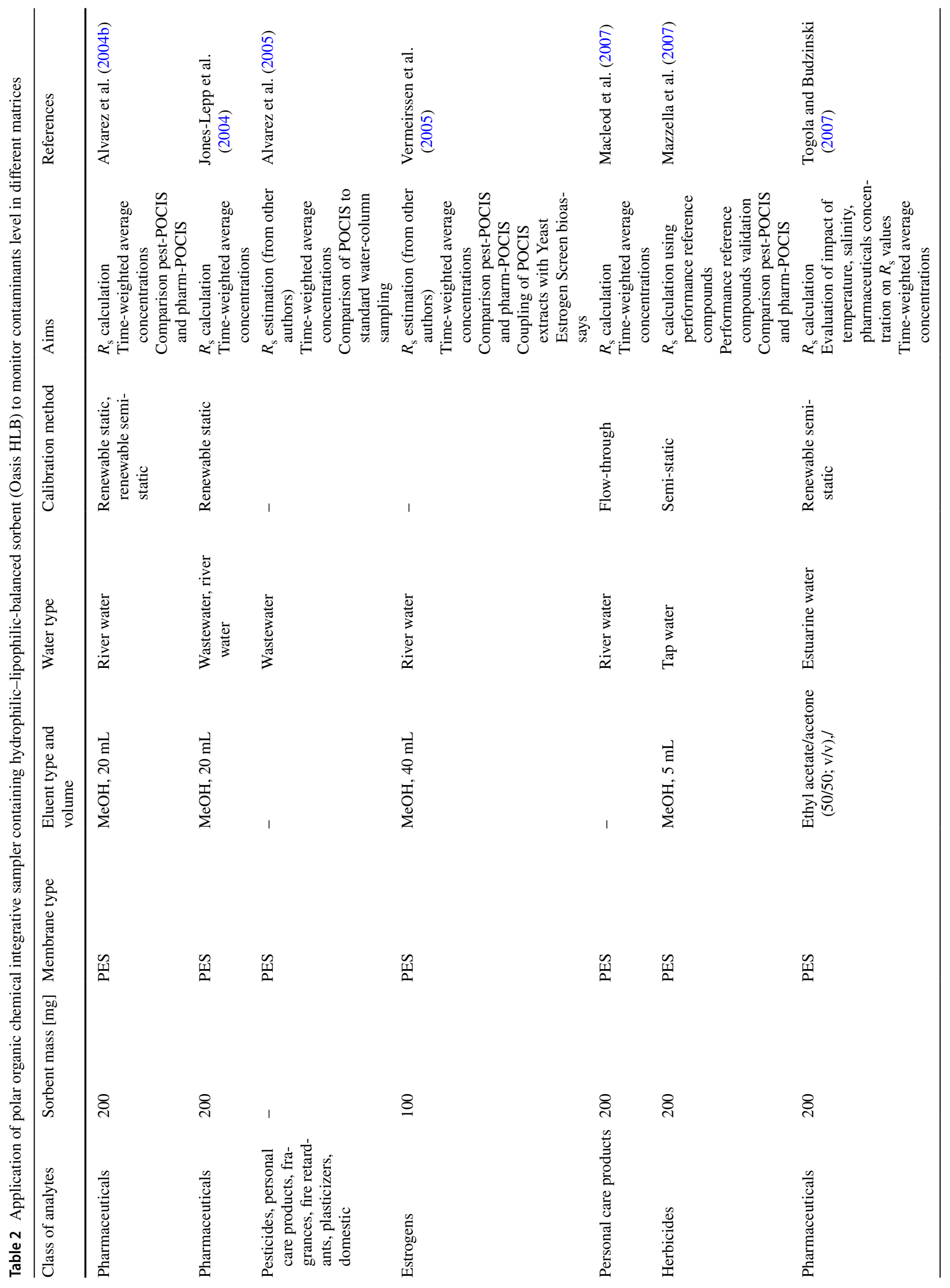




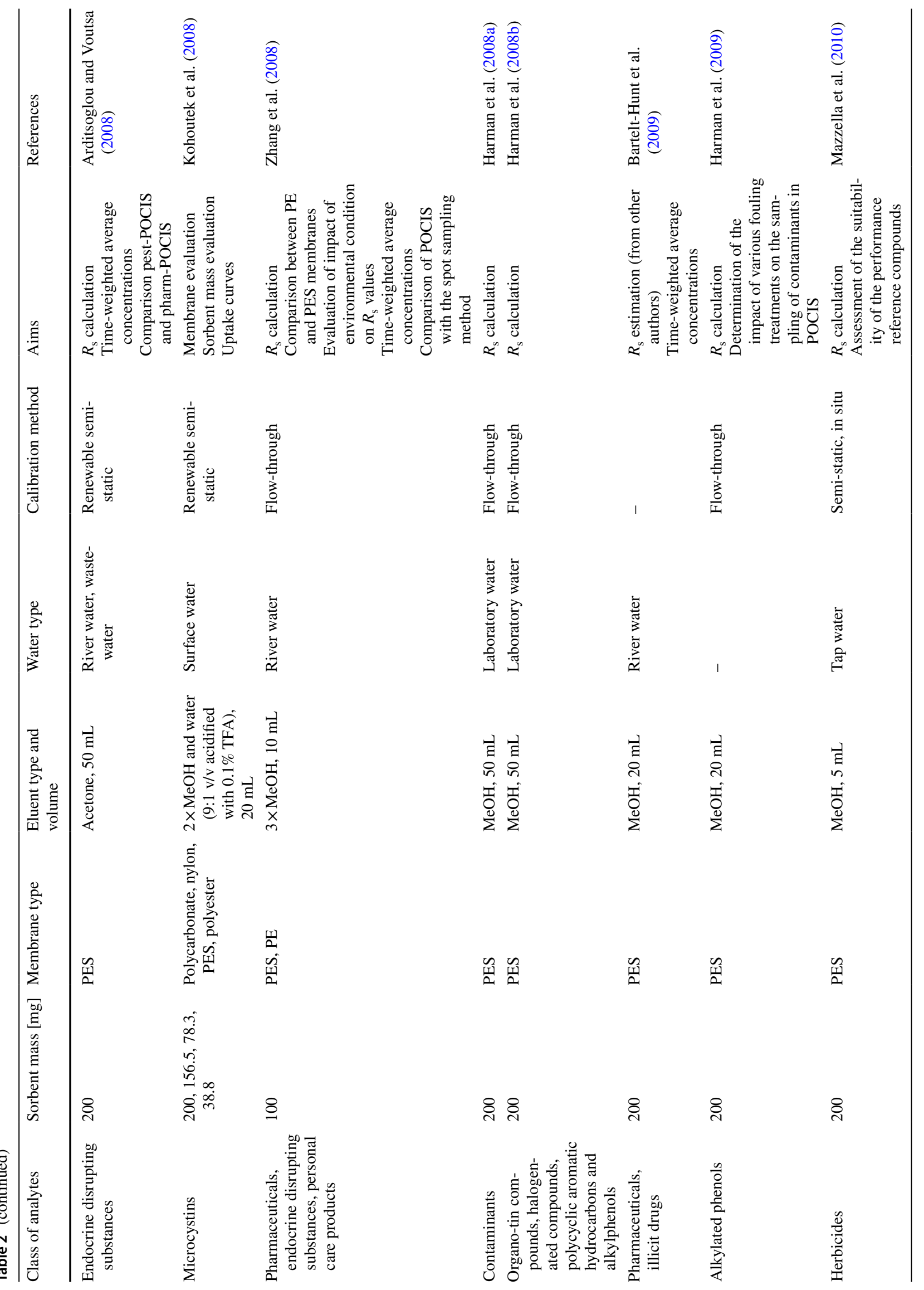




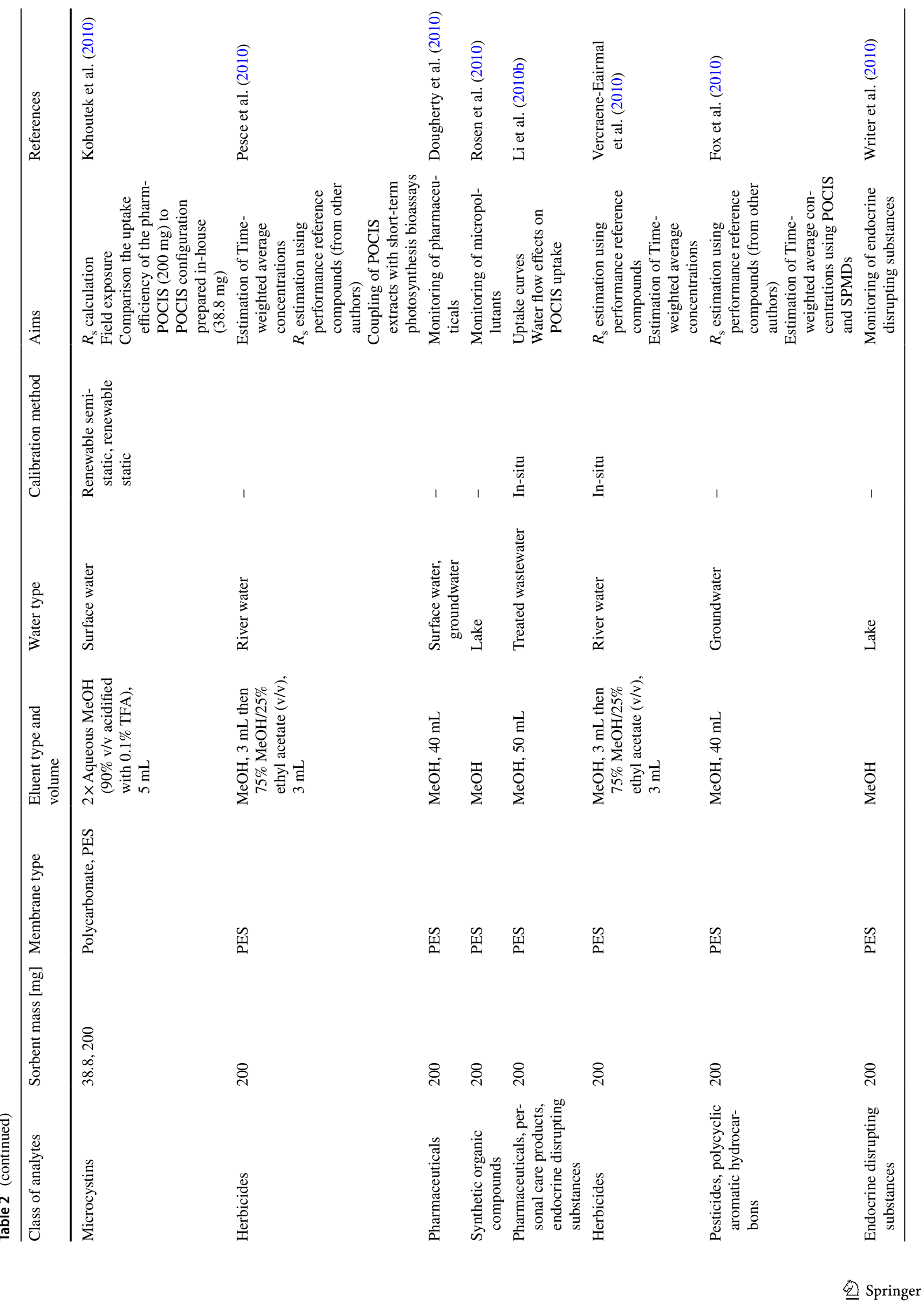




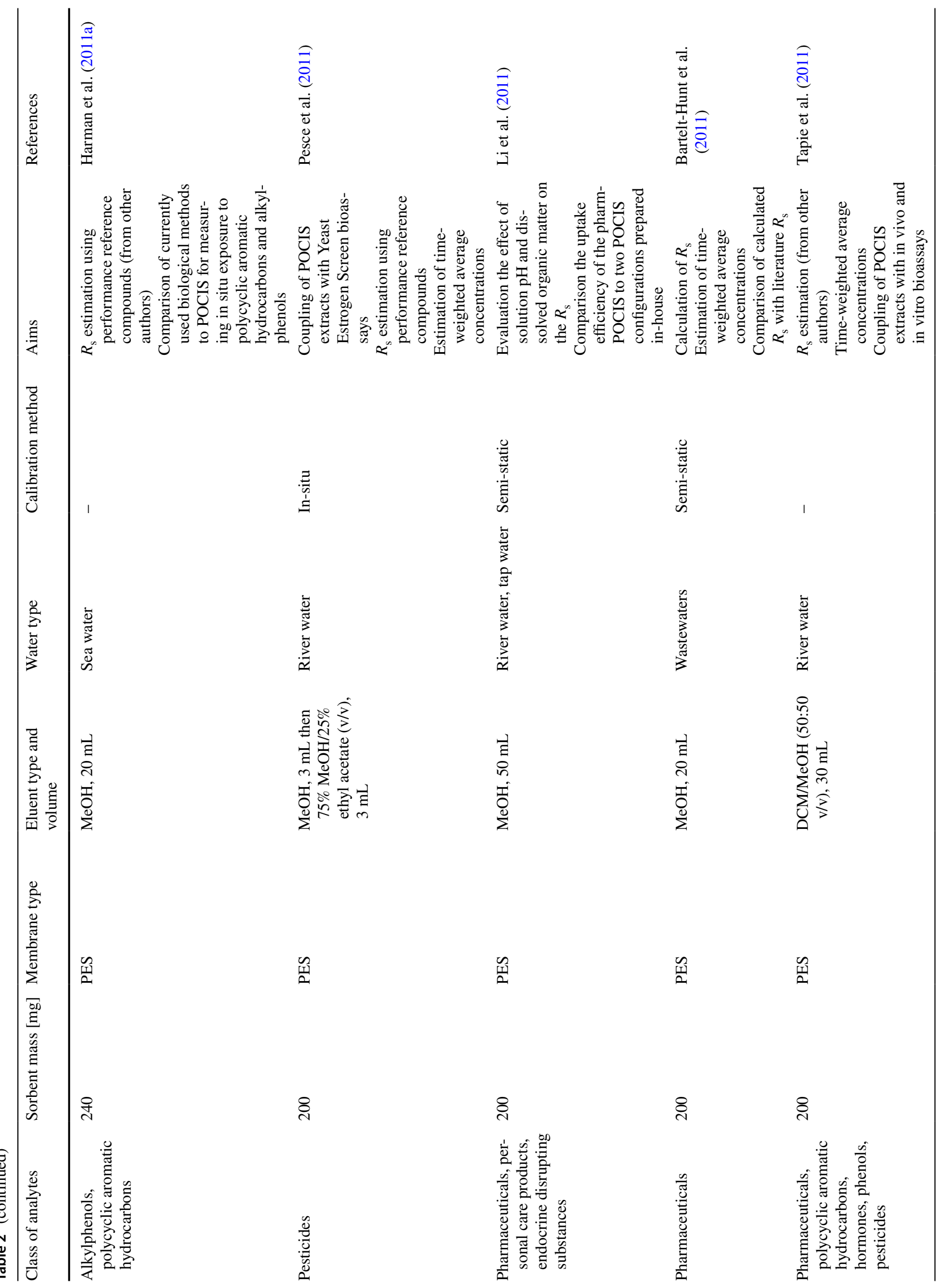




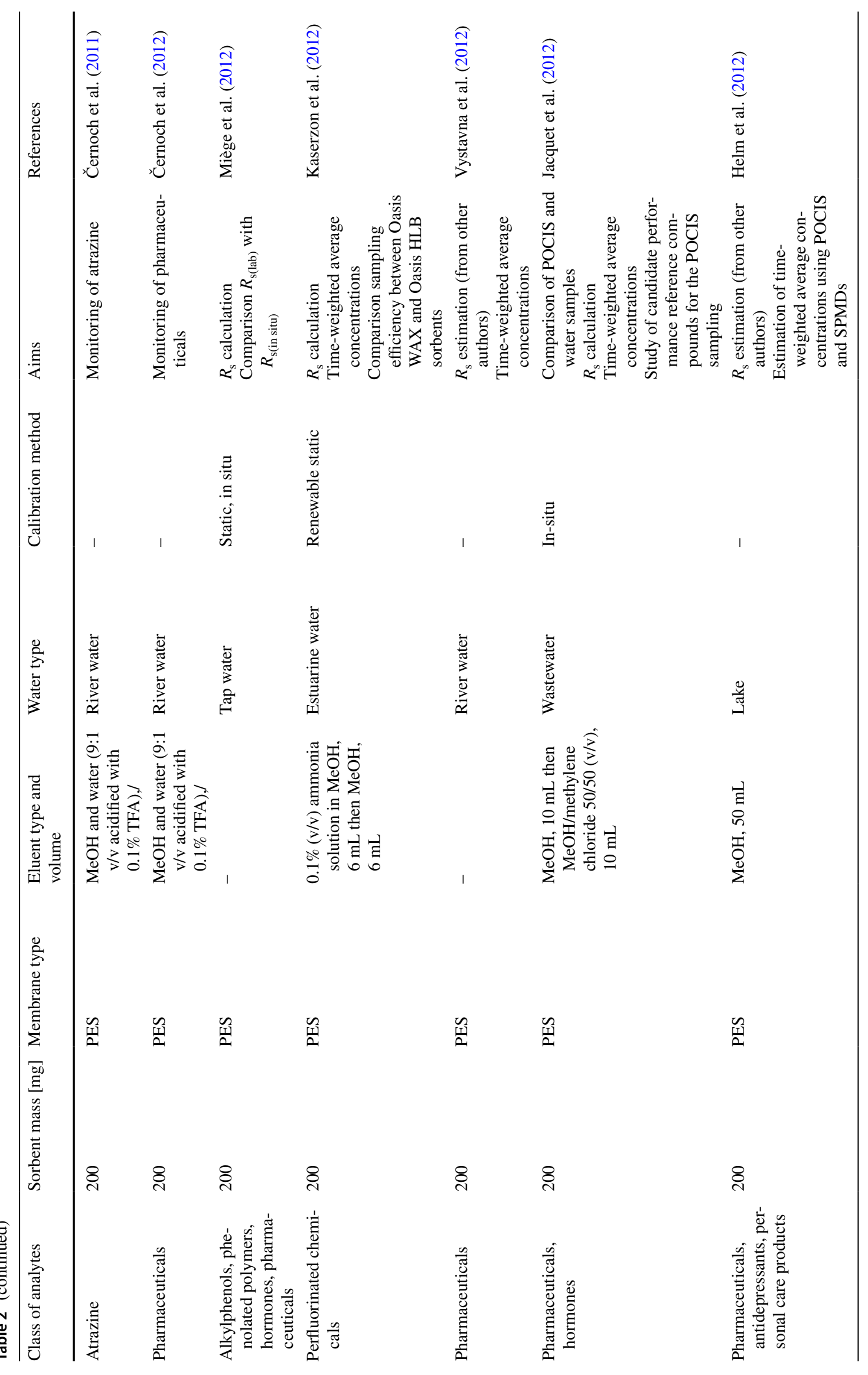




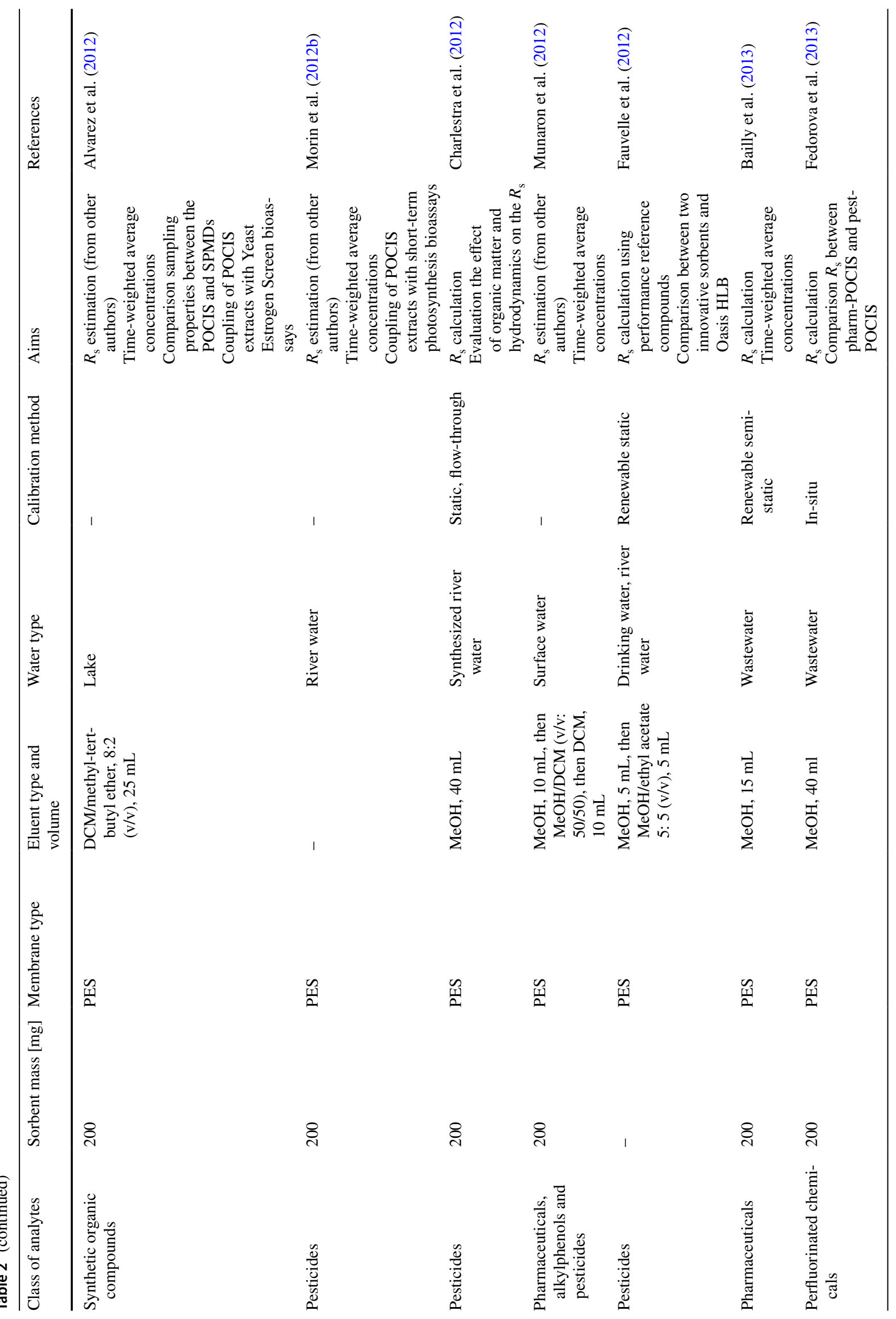




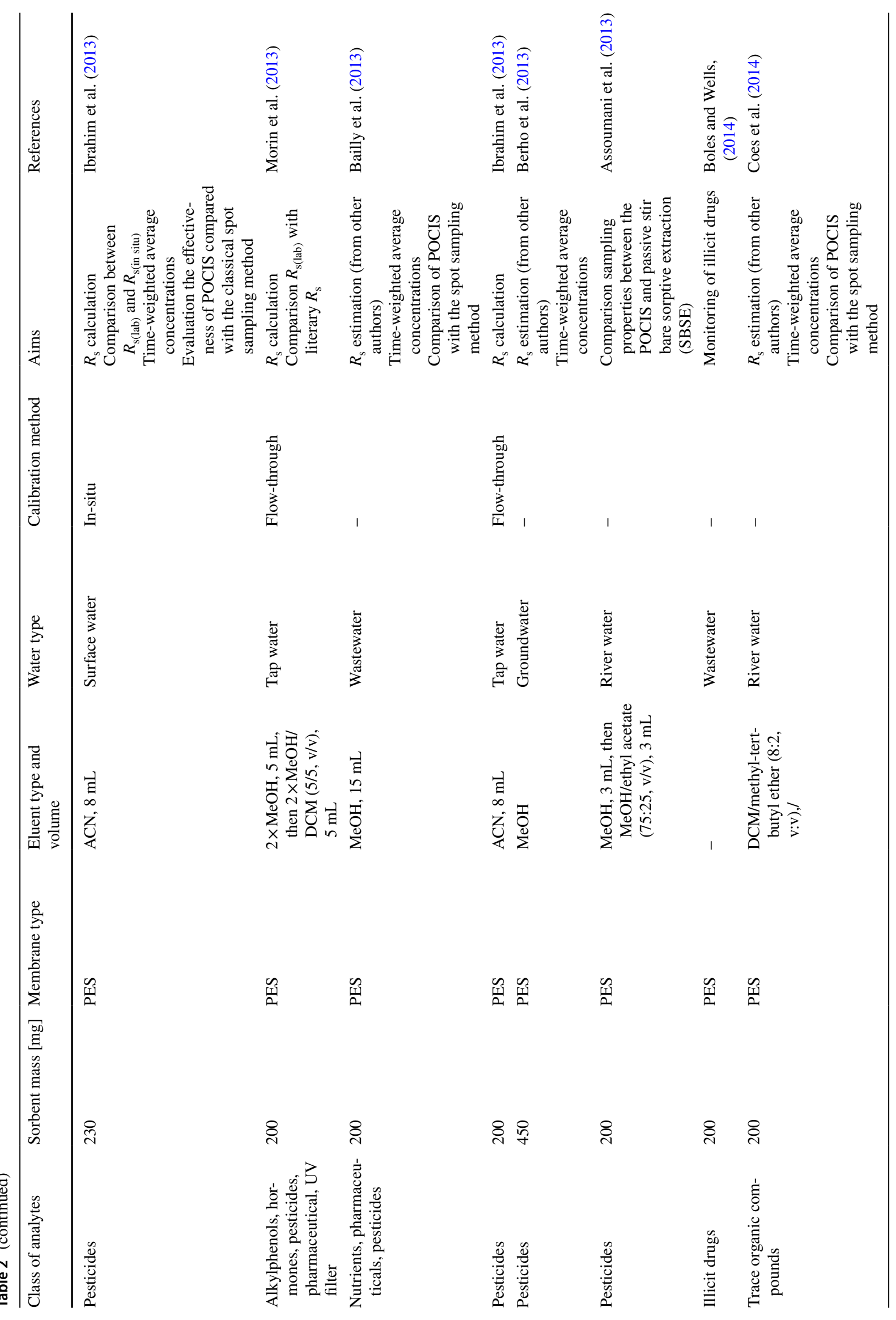




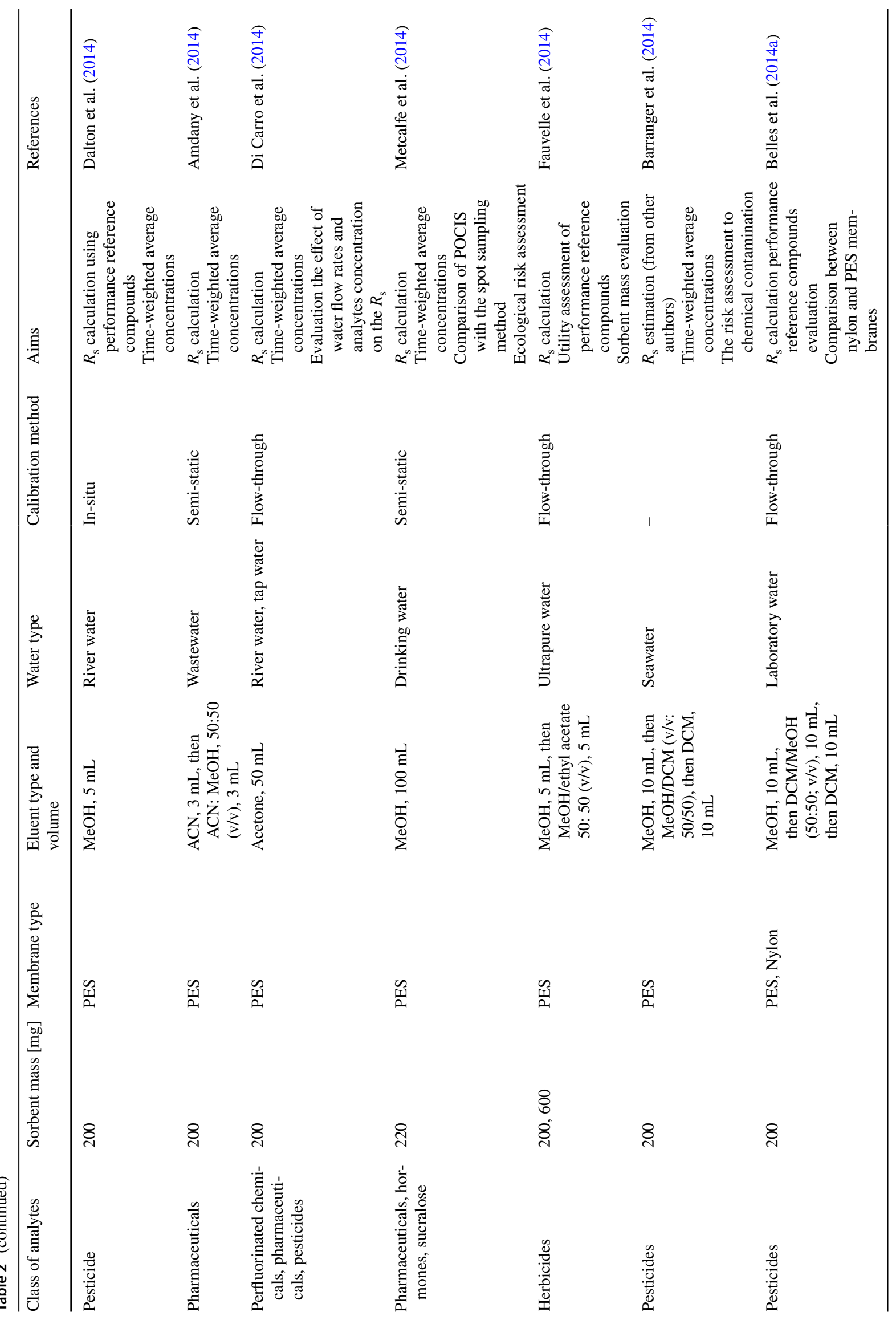




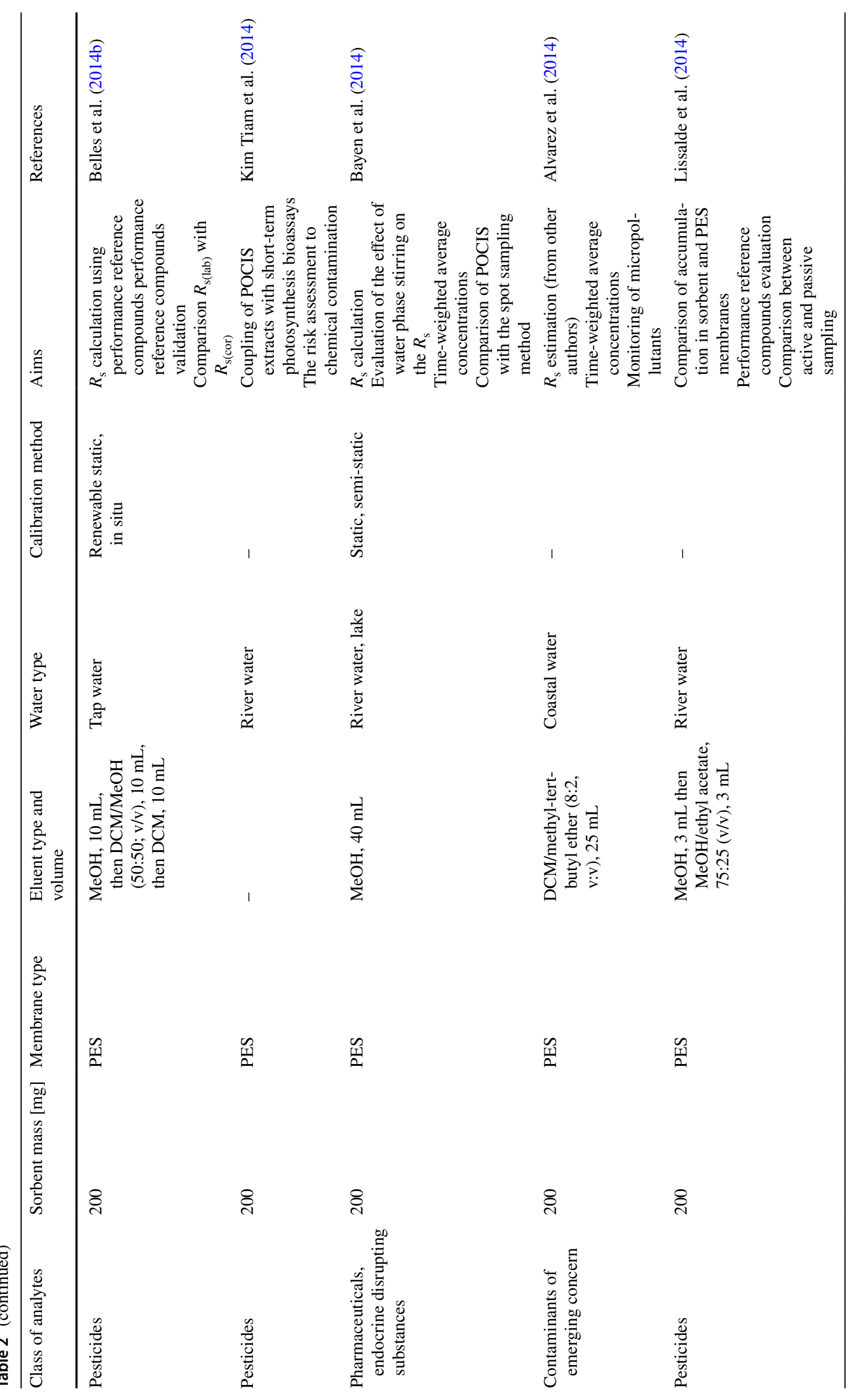




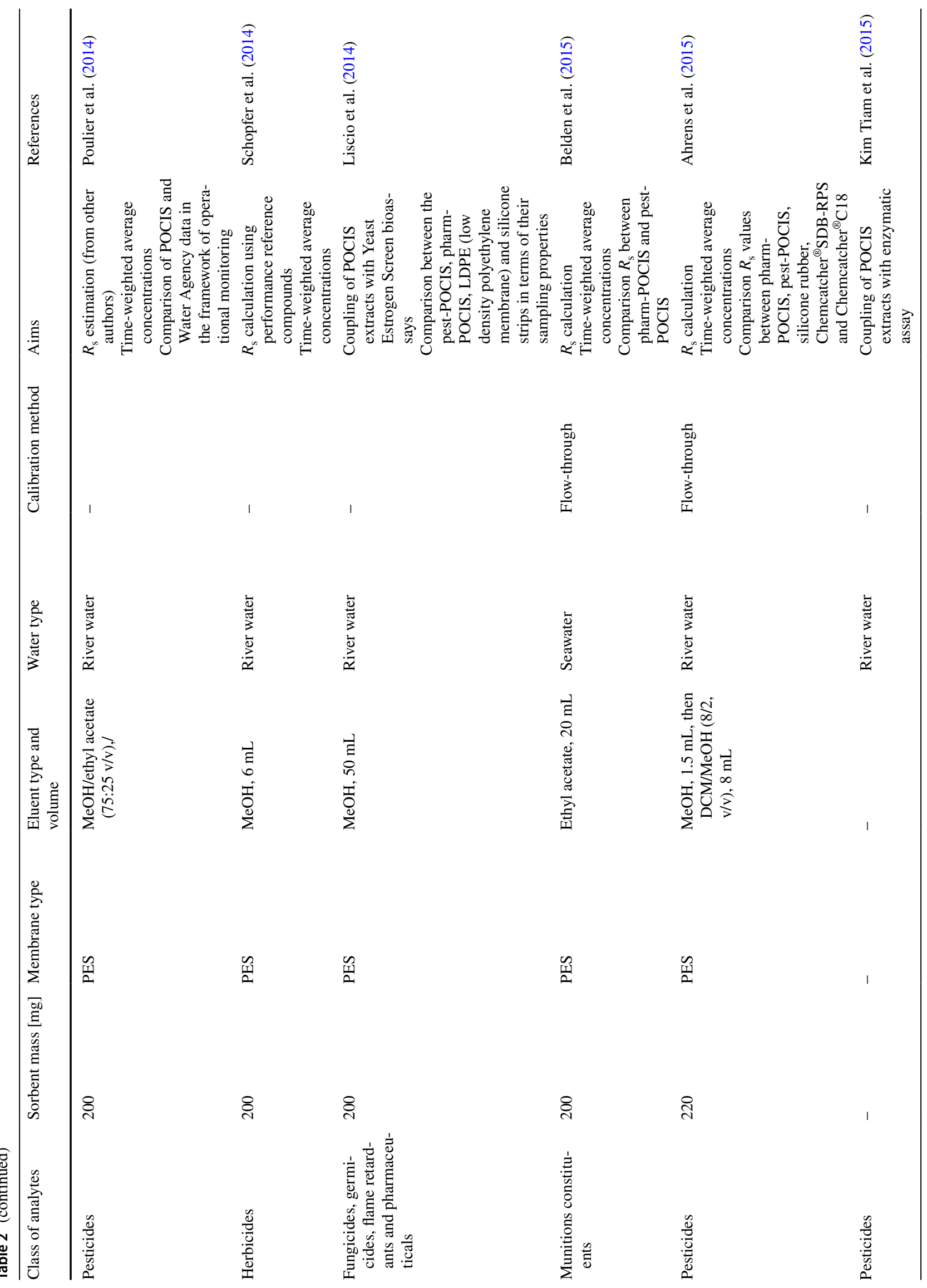




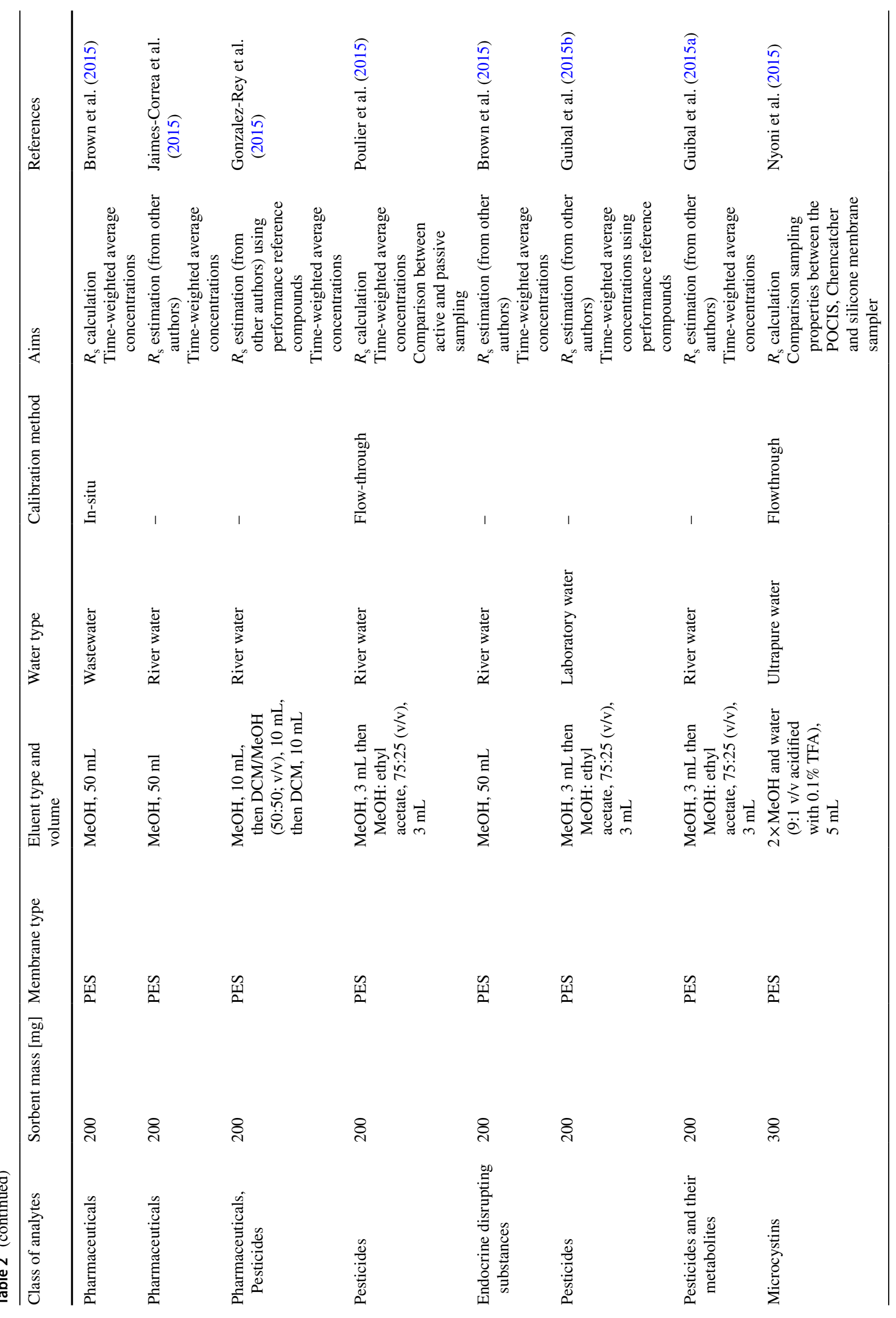




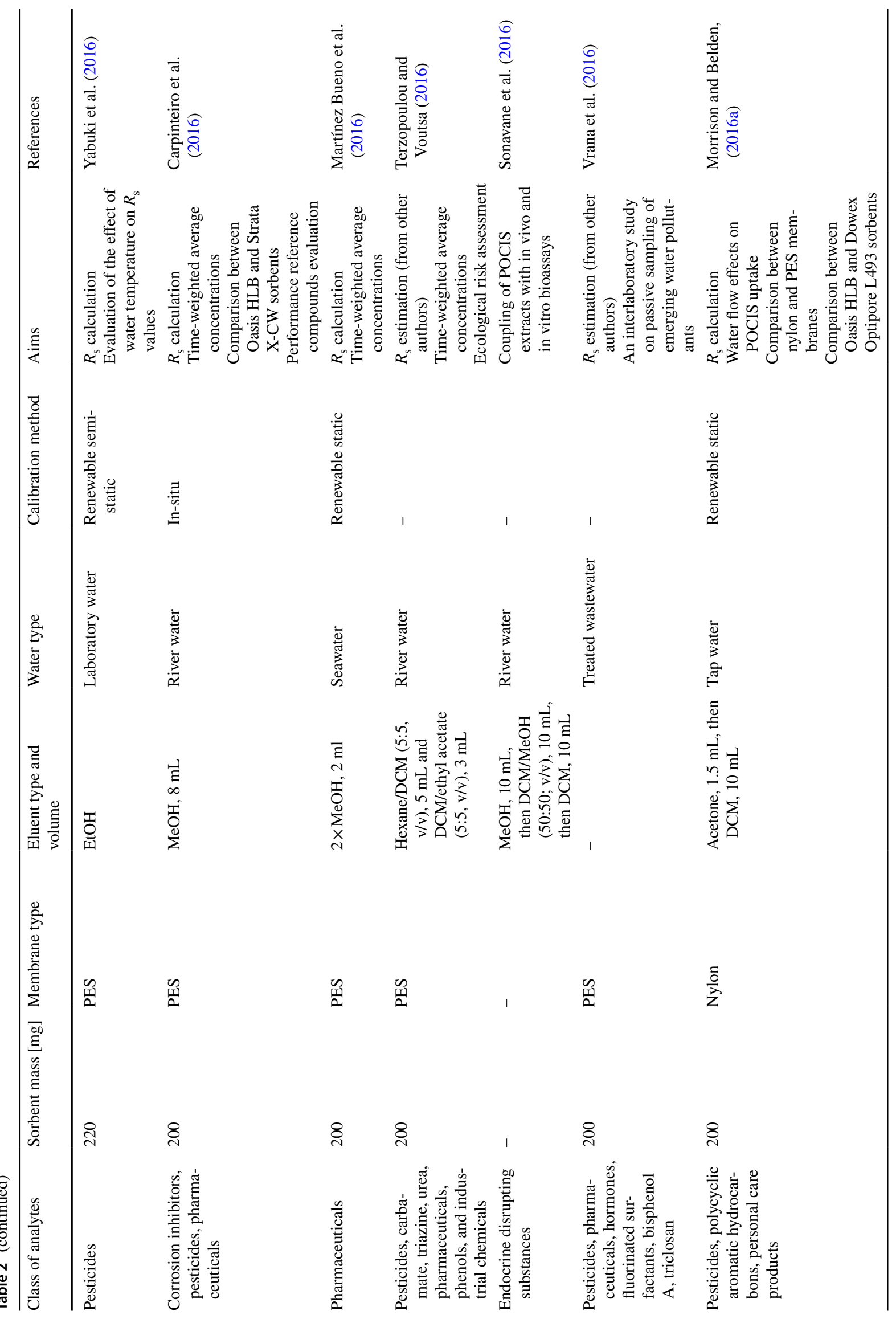




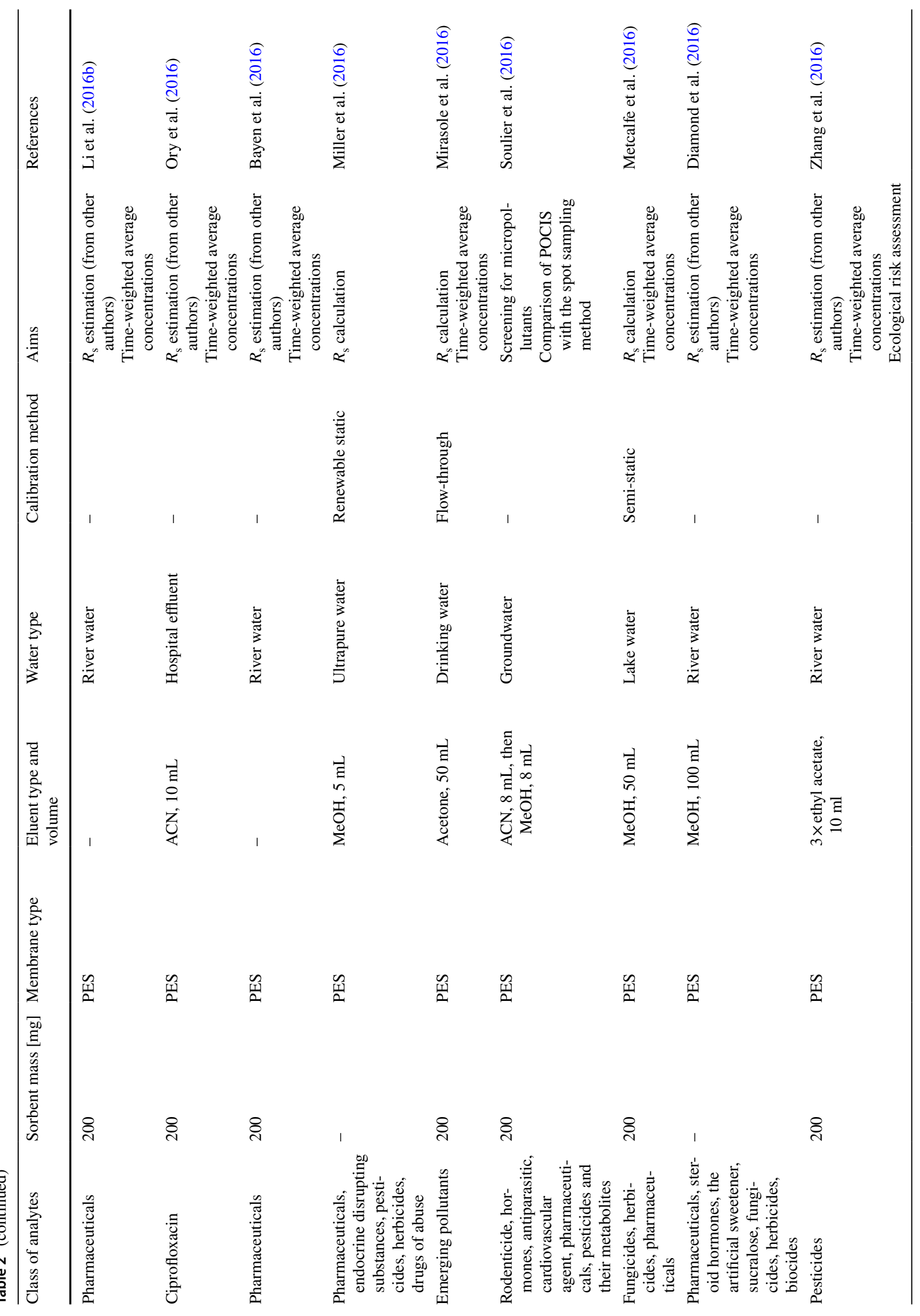




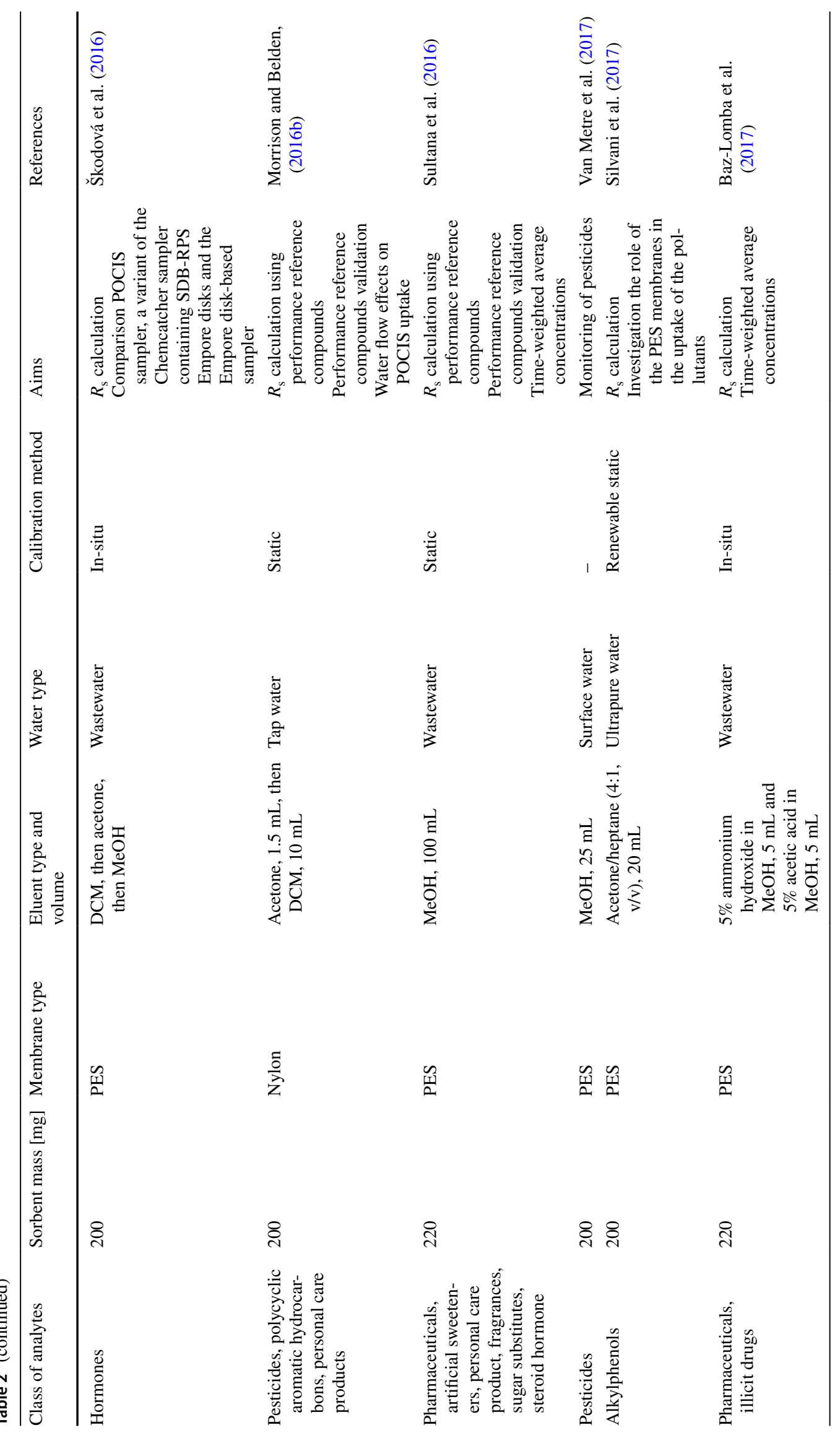




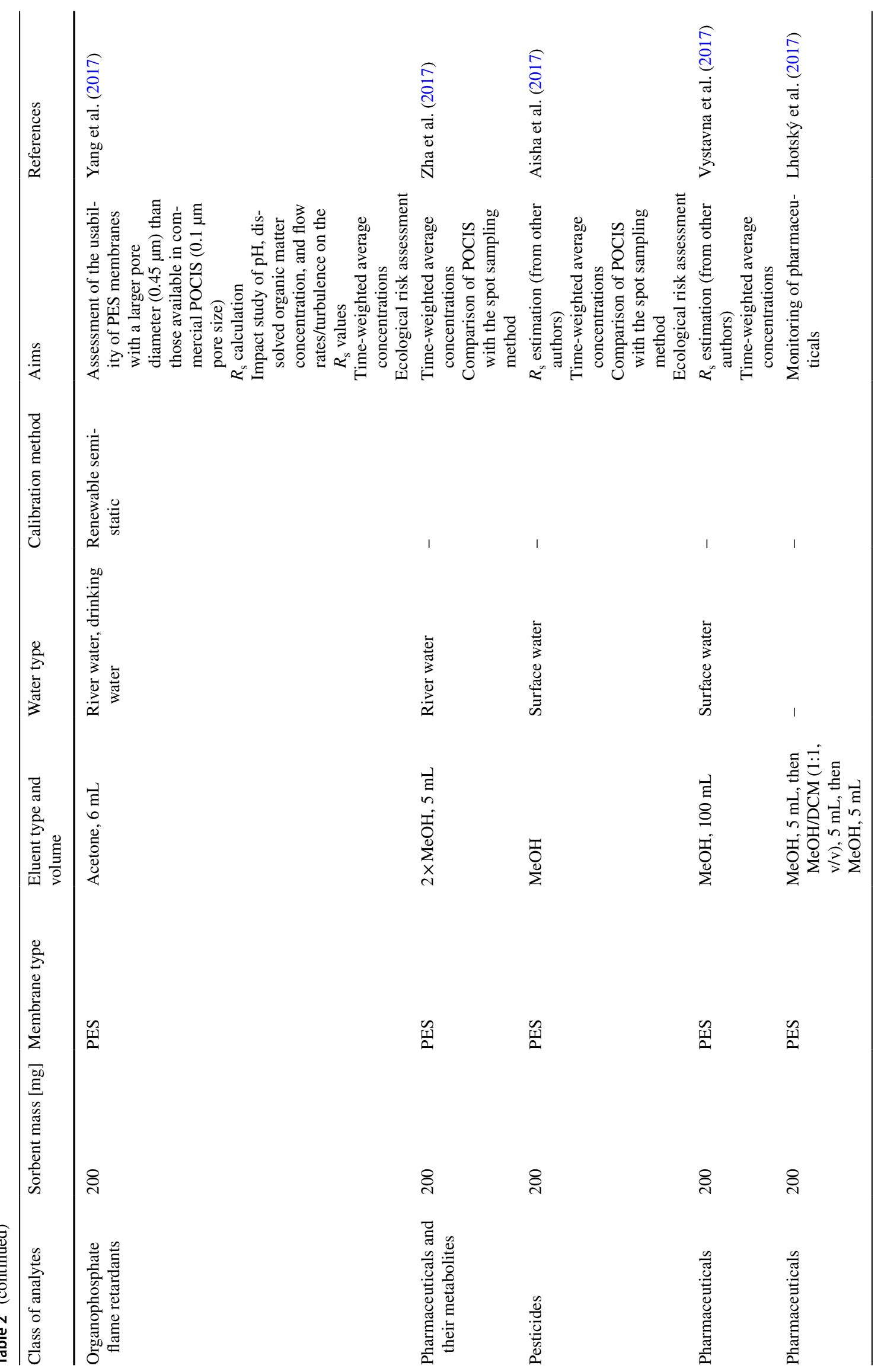




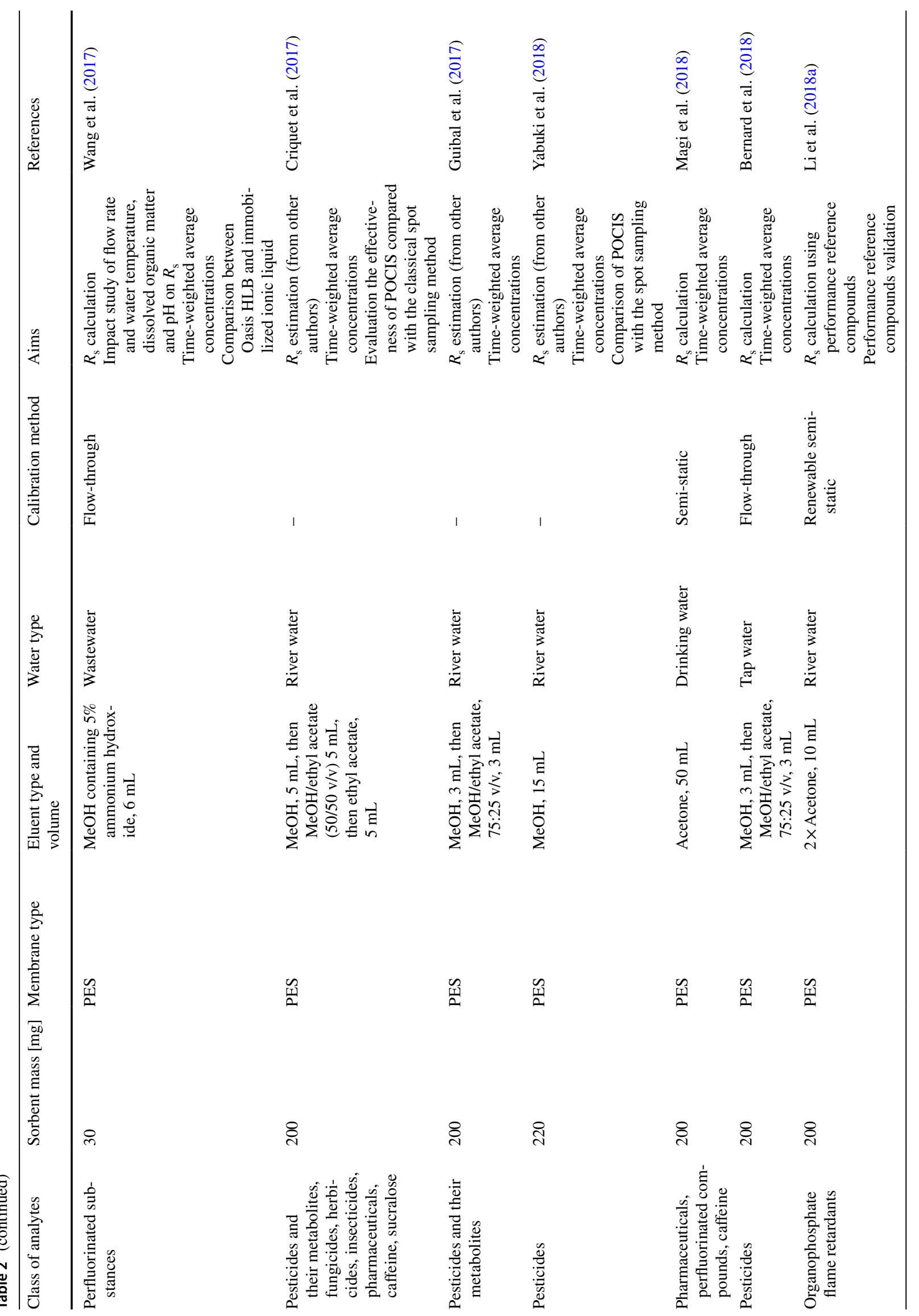




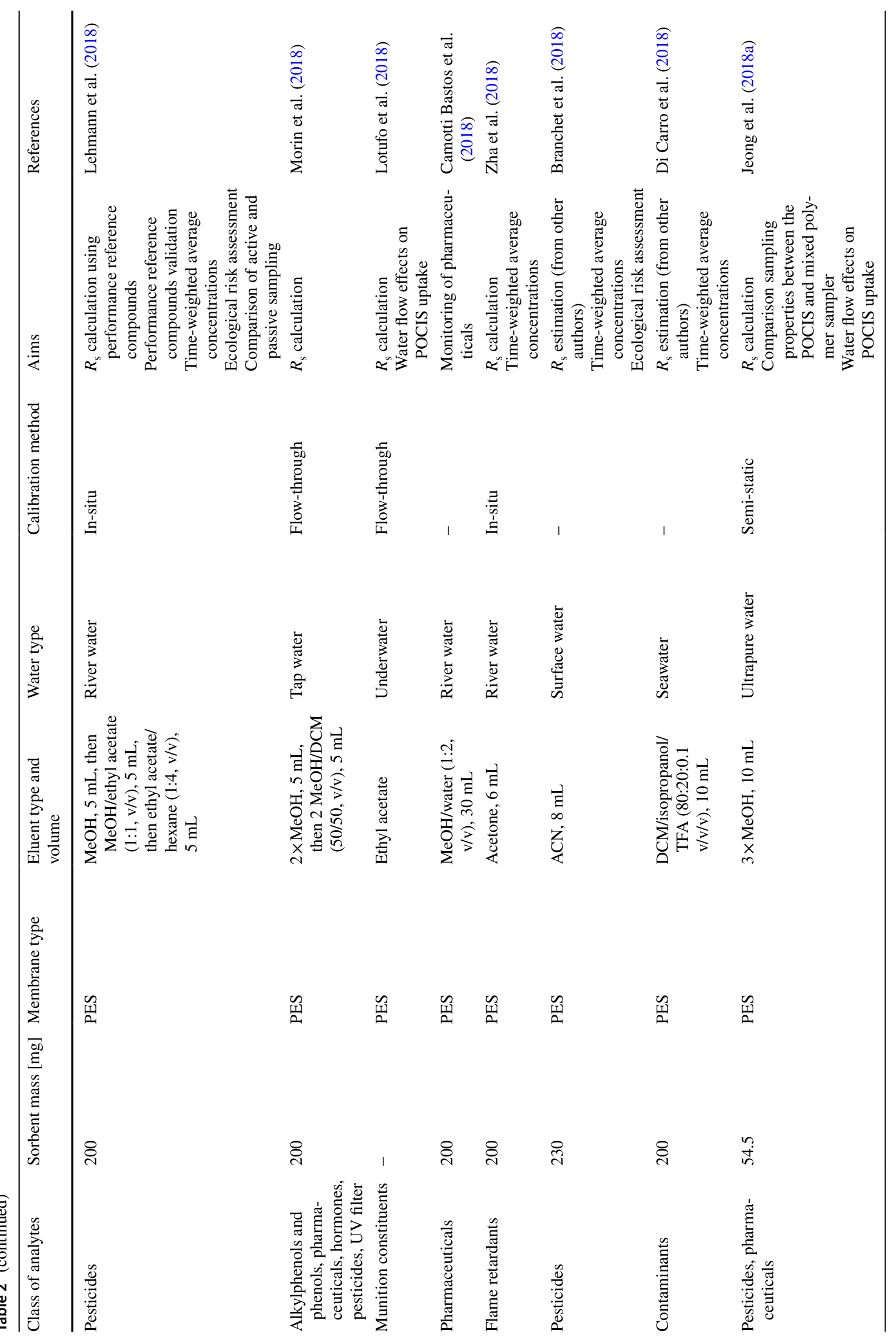




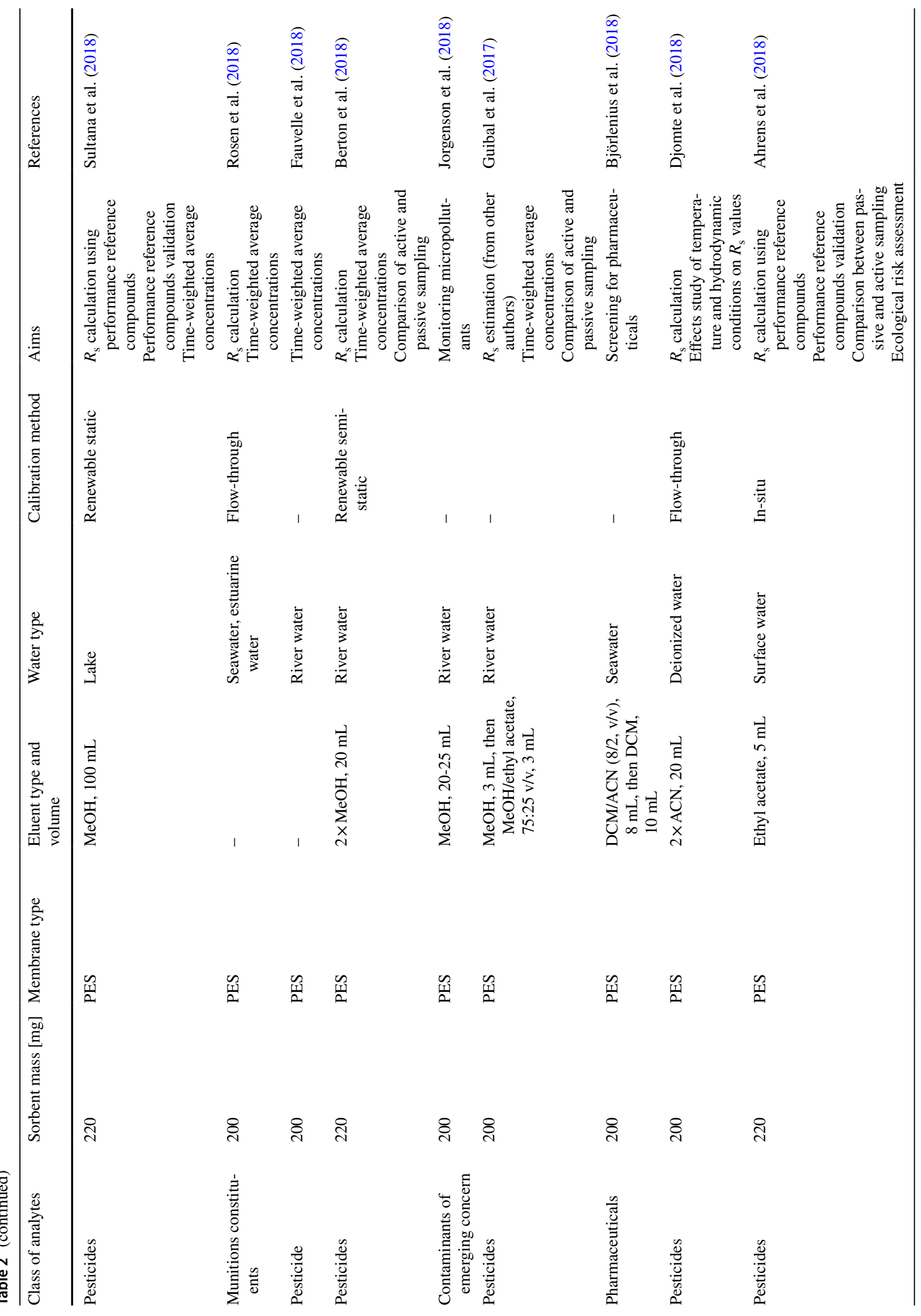




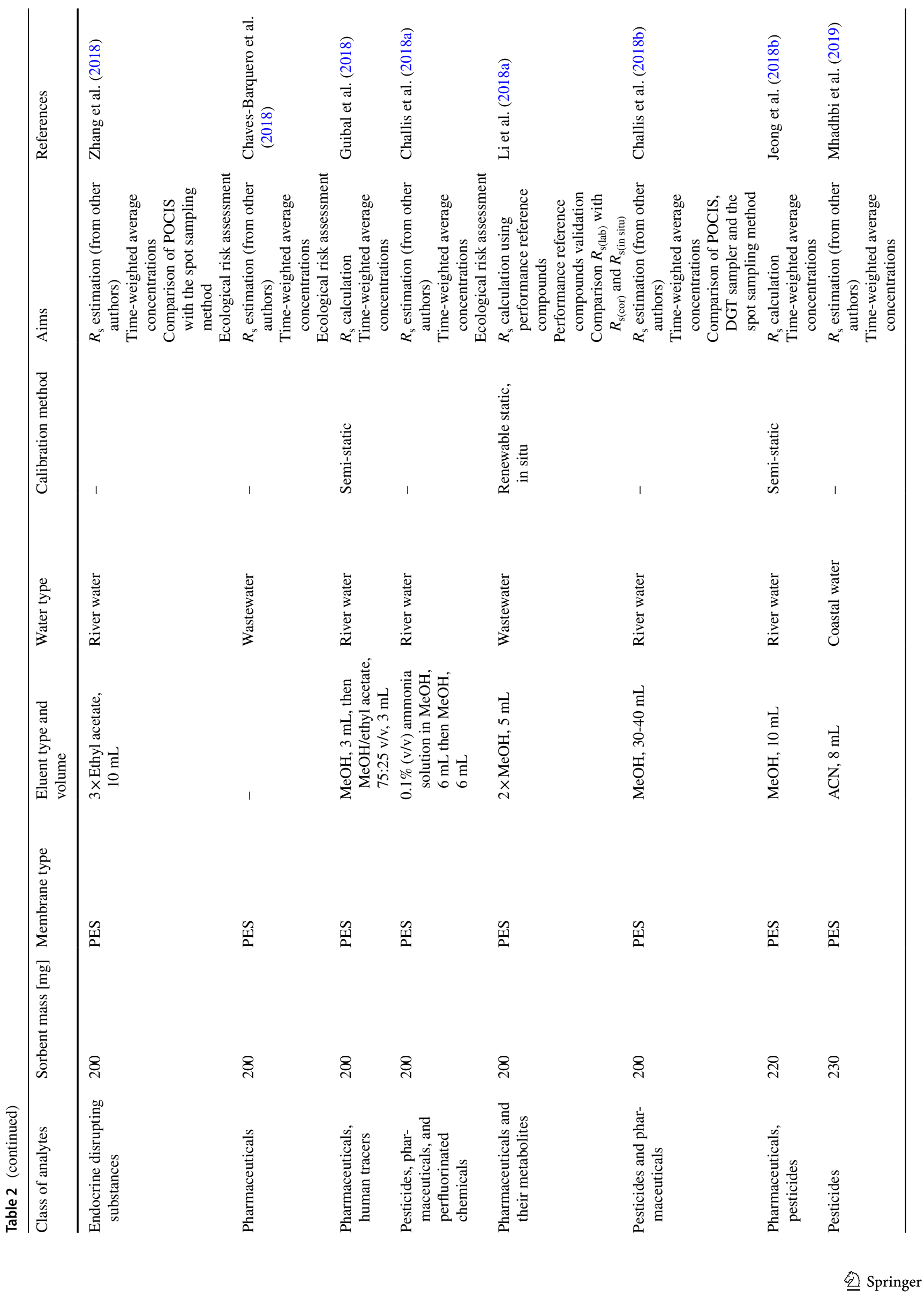




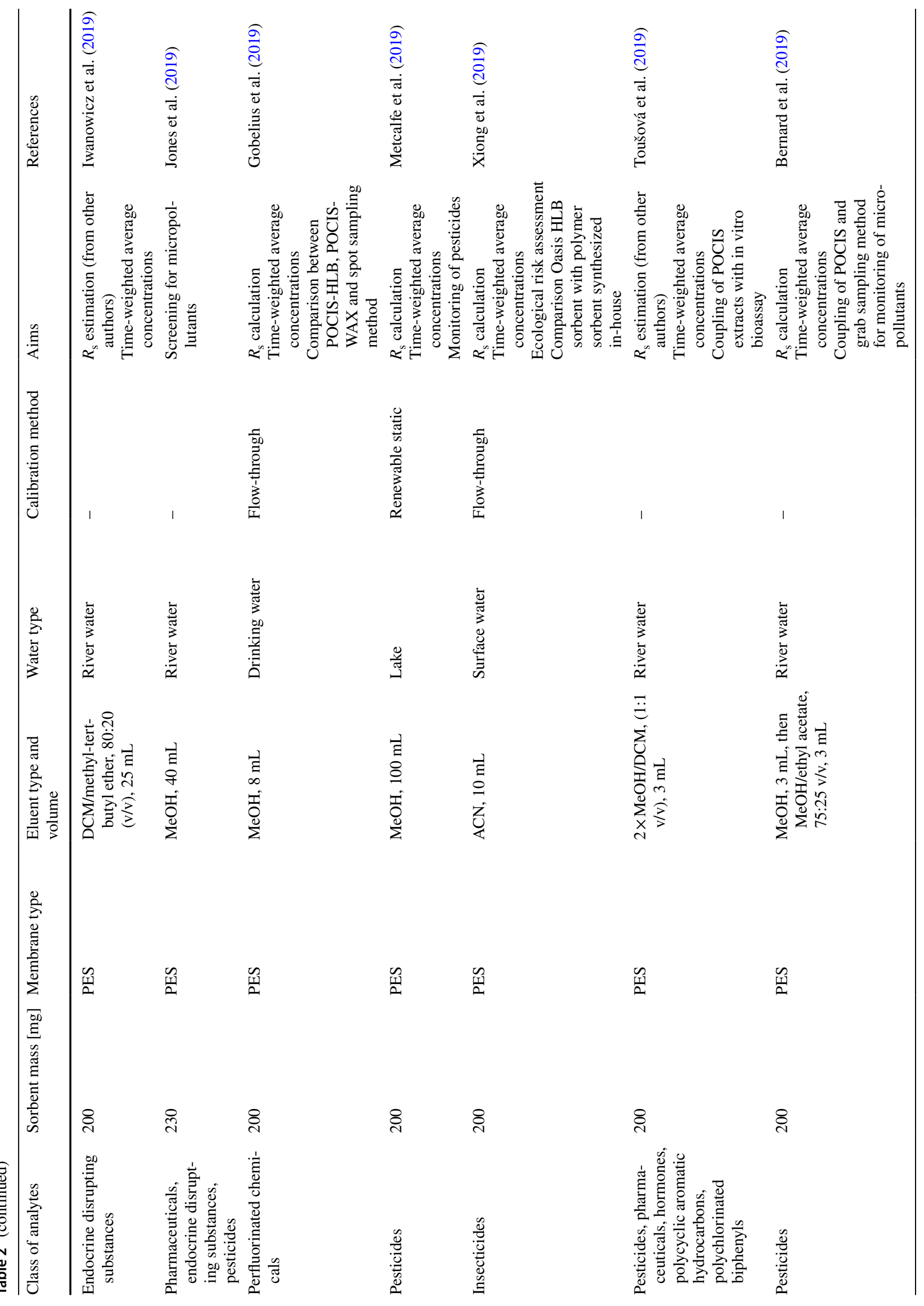




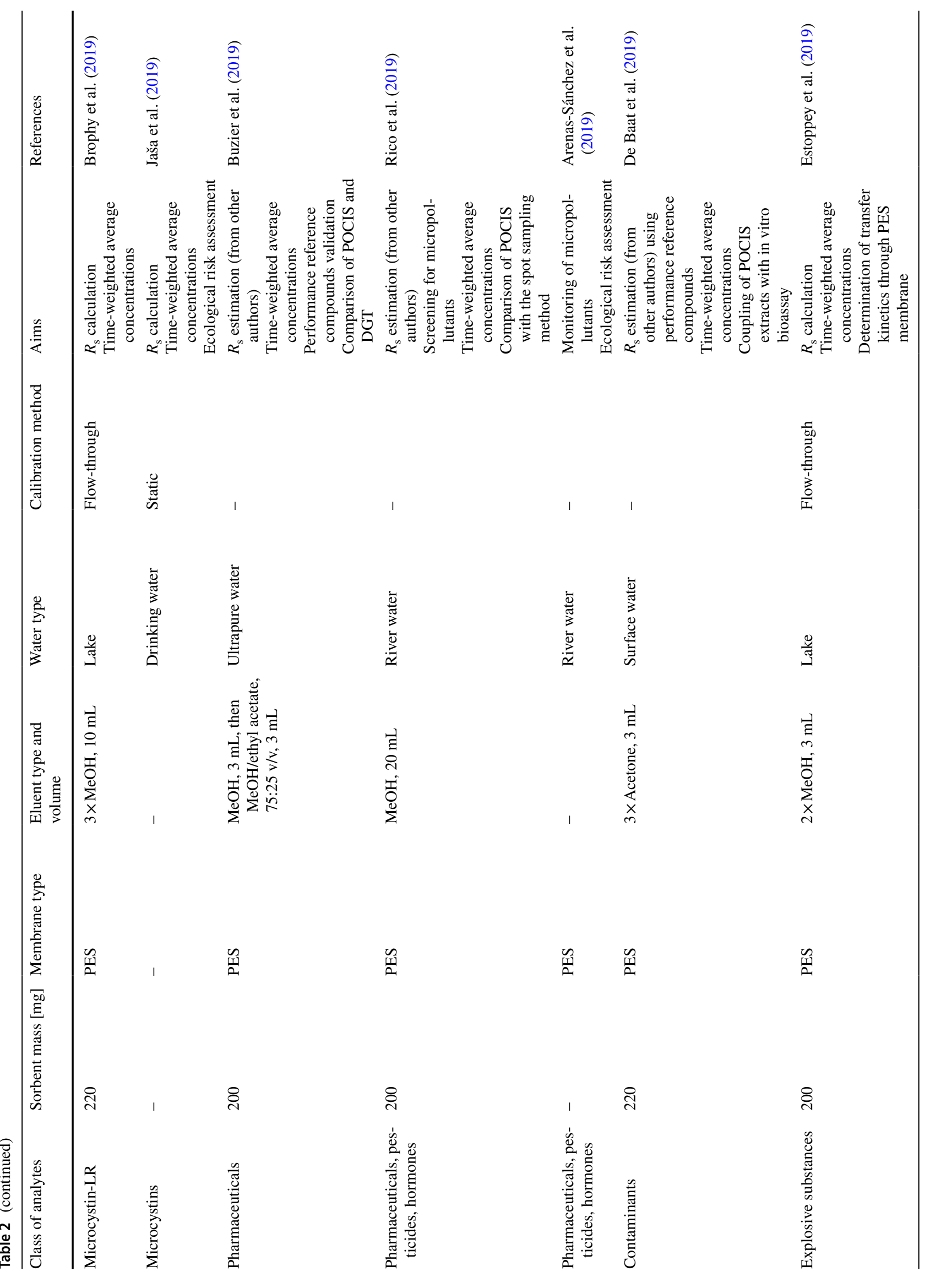




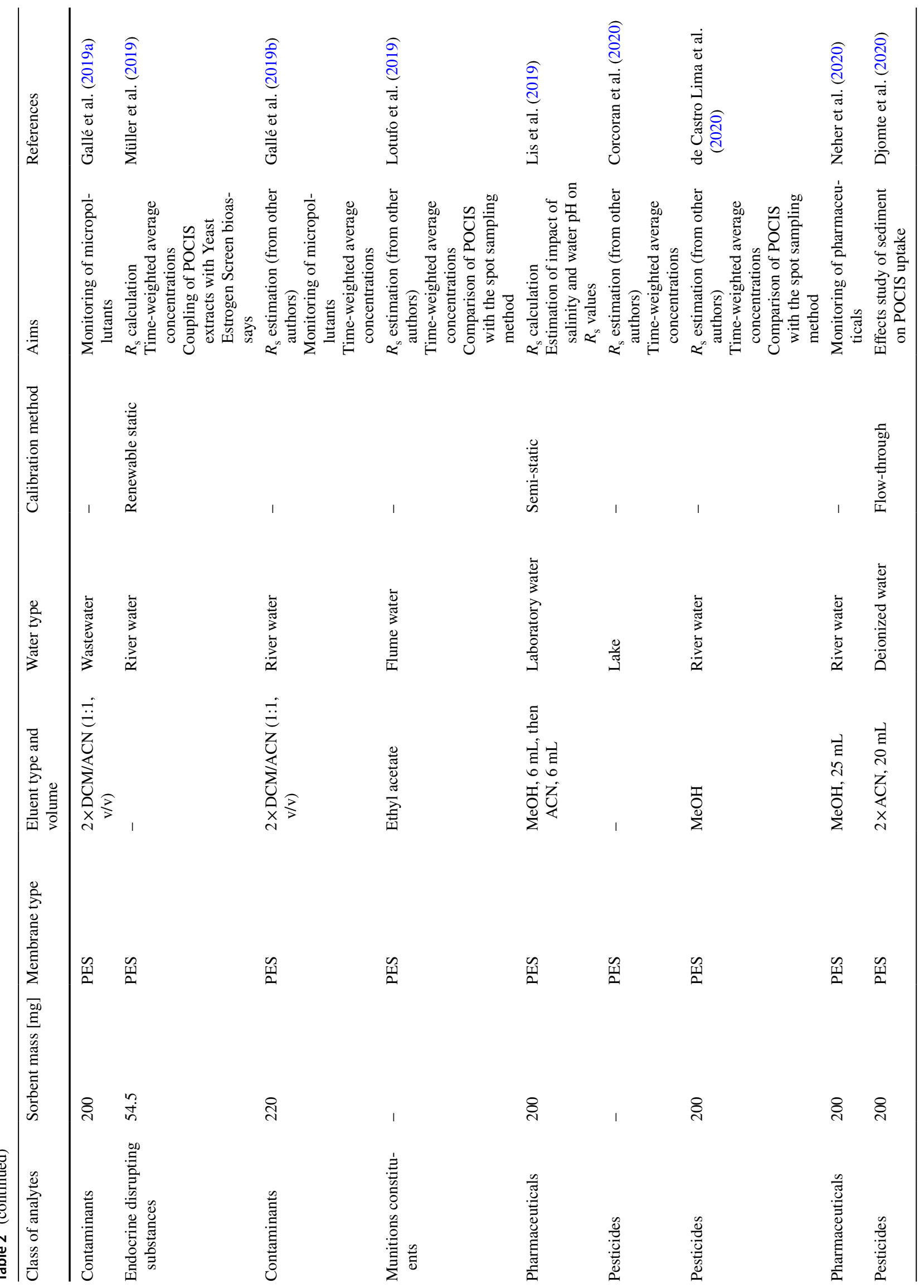




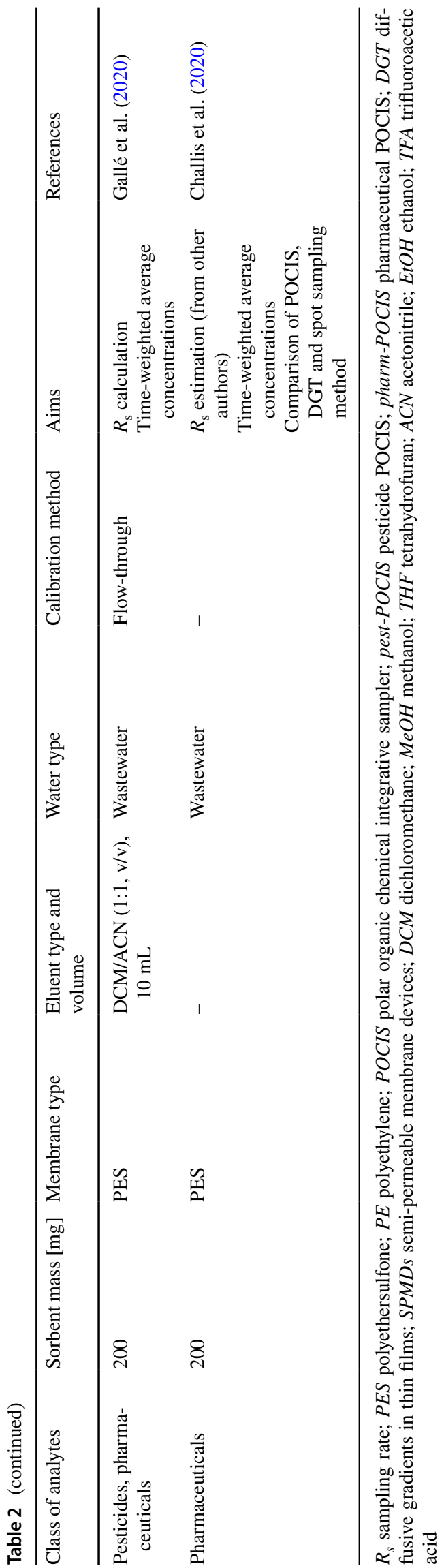

guided by the results of traditional extraction methods (e.g., solid-phase extraction). Kaserzon et al. (2012) based their selection of sorbent on the results that showed that the weak anion-exchange material Oasis WAX is a suitable sorbent in solid-phase extraction for anionic perfluorinated compounds, thanks to the modification of the Oasis HLB sorbent with piperazine groups. Based on the results that confirm similar solid-phase extraction performance when using Oasis HLB and Oasis WAX for the extraction of perfluorinated compounds (with Oasis WAX being a better sorbent for short-chain compounds) (Taniyasu et al. 2005), Kaserzon et al. (2012) decided to use this sorbent also in POCIS-like samplers. Similarly, Caban et al. (2016) based their experiments on promising studies on the use of ionic liquids in liquid-liquid extraction (Vičkačkaite and Padarauskas 2012) and interesting properties of ionic liquids (they can act as solvents for compounds that differ significantly in polarity.) They decided to use ionic liquids as the receiving phase in POCIS-like sampler for collection of a diverse range of chemical compounds (pharmaceuticals, hormones, phenols). Scientists are also guided by their own earlier research when choosing an innovative sorbent in passive techniques. Berho et al. (2017) conducted tests on the use of synthesized molecular imprinted polymer as a sorbent in solidphase extraction to isolate aminomethylphosphonic acid and glyphosate. Due to the fact that they obtained satisfactory results, they decided to use molecularly imprinted polymers as a sorbent also in POCIS-like sampler. Similarly, Jakubus et al. (2016), who were initially interested in using carbon nanotubes as the sorbent in dispersive solid-phase extraction (dSPE) (Paszkiewicz et al. 2018; Jakubus et al. 2019a, b) because of their adsorption properties, ability to $\pi-\pi$ interaction, and good thermal and chemical stability also decided to determine the effectiveness of carbon nanotubes as sorbents in POCIS-like sampler. Thanks to the use of innovative sorbents, effective sampling of analytes belonging to chemical groups such as: endocrine-disrupting substances, pesticides, perfluorinated chemicals, pharmaceuticals, corrosion inhibitors, phenols, hormones, musk compounds, personal care products and polycyclic aromatic hydrocarbons, was carried out. The characteristics of innovative sorbents used in POCIS-like samplers are presented in Table 1.

\section{Calibration of passive samplers}

During the exposure of the sampler in water, depending on the compounds present in the tested matrix, the environmental conditions and the exposure time of the passive device, the concentration of the analyte in the sampler increases linearly during phase I (kinetic). In phase II (intermediate), the accumulation kinetics are curvilinear. In contrast, phase III (equilibrium) corresponds to the equilibrium separation 


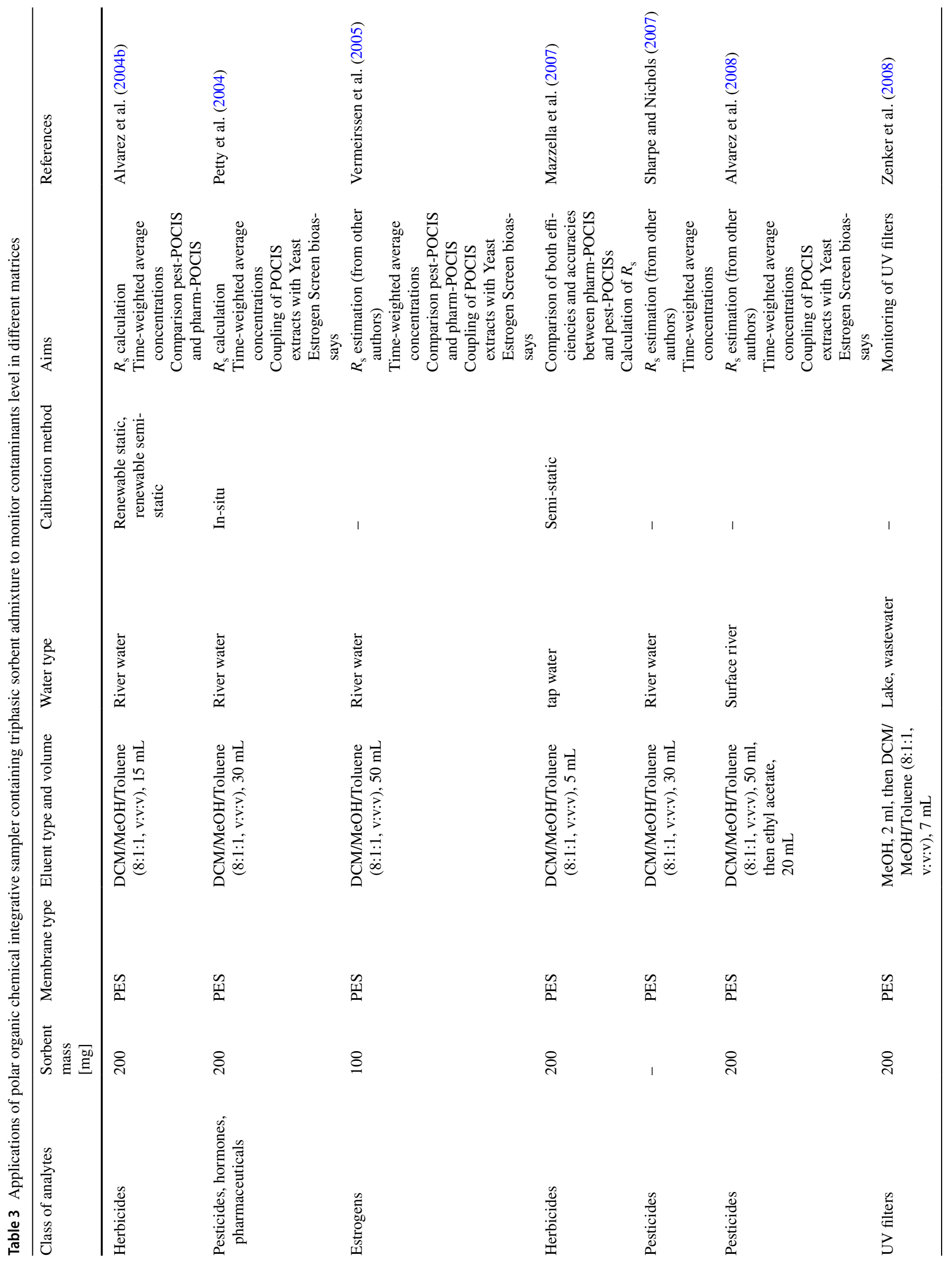




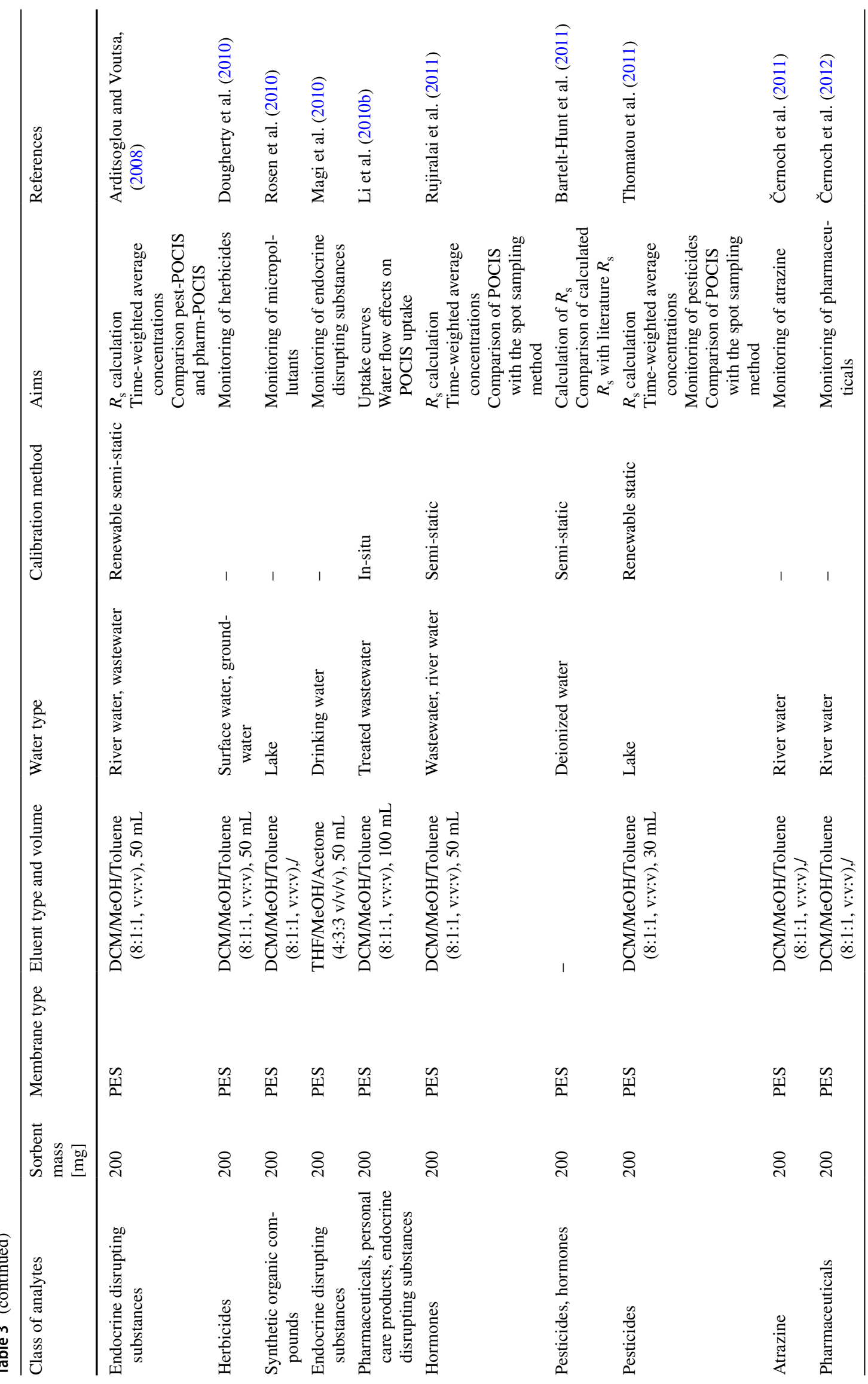




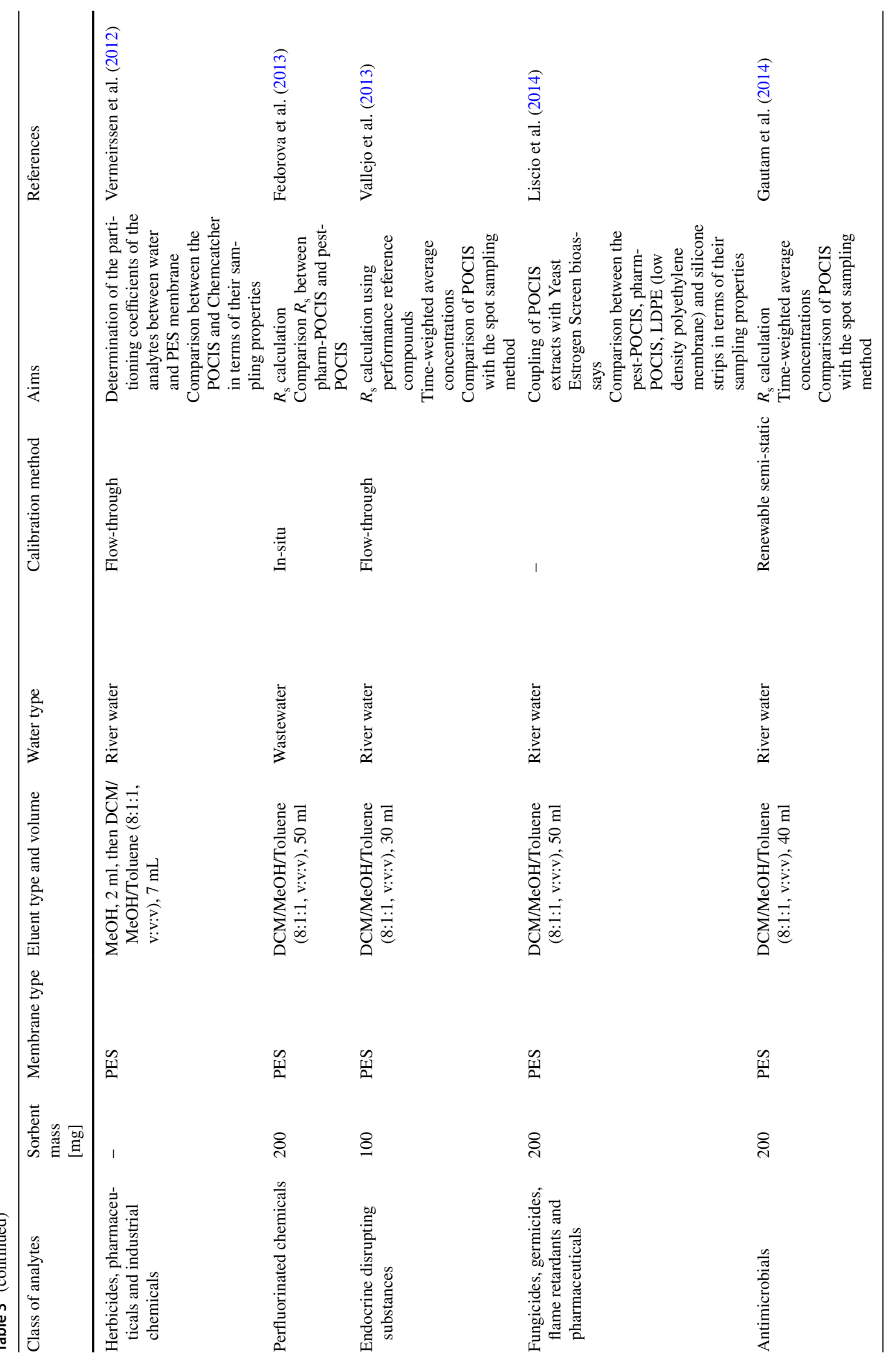




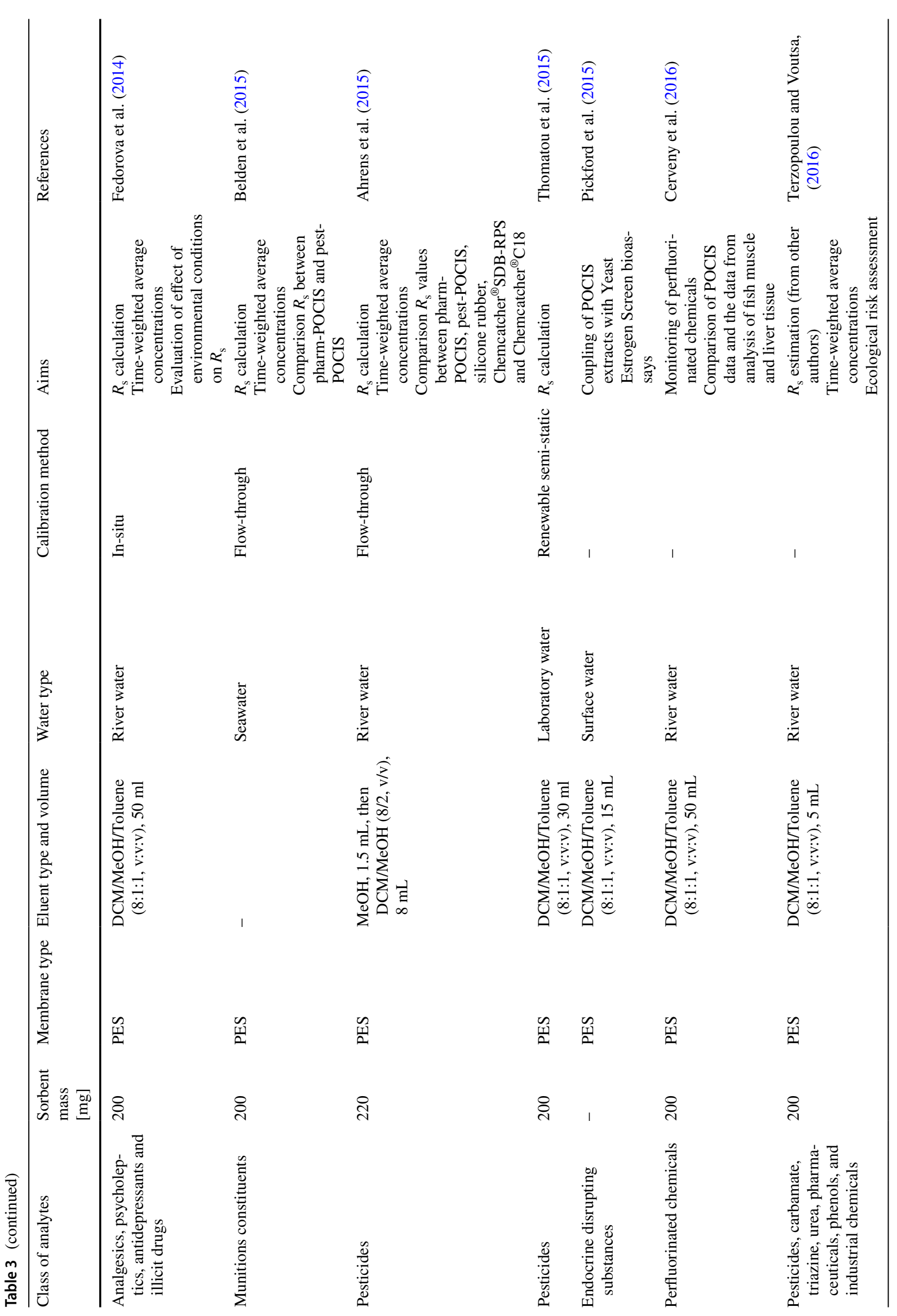


of the relationship between the receiving phase (in the sampler) and the medium surrounding the dosimeter (Kot-Wasik et al. 2007) (Fig. 2).

There are two main types of passive samplers:

- equilibrium passive sampling devices,

- kinetic passive sampling devices.

Equilibrium samplers are kept in the exposure environment until equilibrium is achieved between the analyte concentration in the receiving phase and the analyte concentration in the matrix surrounding the sampler. The principle of operation of such a device determines that when the concentration of the analyte in the exposure medium becomes constant (no further accumulation of the analyte in the receiving phase), and after reaching equilibrium the concentration of the analyte in the receiving phase will not change, the concentration of the target compound in the environment can be determined using phase-water partition coefficients $\left(K_{\mathrm{sw}}\right)$ according to the following equation (Yates et al. 2007; Pintado-Herrera et al. 2016; Smedes 2018):

$C_{\mathrm{s}}=C_{\mathrm{w}} K_{\mathrm{SW}}$

where $C_{\mathrm{s}}$ is the analyte concentration in the receiving phase at a known exposure time and $C_{\mathrm{w}}$ is the analyte concentration in the aqueous phase. The suitability of equilibrium passive sampling devices depends on the size and variability of the test compound concentration in the aqueous phase and the sampler response time, which must be shorter than the mentioned changes in analyte concentration (Huckins et al. 2000).

Kinetic passive sampling devices are designed in such a way that the accumulation of target compounds is complete over time and responds to changes in the concentration of analytes in water. These devices are used to measure the time-weighted average concentrations of tested chemicals in the environment according to the following formula (Arditsoglou and Voutsa 2008; Harman et al. 2011b; Thomatou et al. 2011; Tanwar et al. 2015):

$C_{W=\frac{C_{S} M_{s}}{R_{s} t}}$

where $R_{\mathrm{s}}\left[\mathrm{L}\right.$ day $\left.^{-1}\right]$ is the sampling rate of the analyte, $M_{s}$ $[\mathrm{kg}]$ is the mass of sorbent, $t[\mathrm{~d}]$ is the sampling period and $C_{\mathrm{s}}\left[\mathrm{g} \mathrm{kg}^{-1}\right]$ and $C_{\mathrm{w}}\left[\mathrm{g} \mathrm{L}^{-1}\right]$ are the concentrations of the target compound in the receiving phase and in the aquatic phase, respectively. To determine the time-weighted average concentration of the target compound, it is necessary to determine the $R_{\mathrm{S}}$ value (meaning the amount of water purified from a tested chemical compound per unit of time). To determine the $R_{\mathrm{s}}$ values of the analytes, the passive samplers used must be calibrated in the laboratory or in situ (Vrana 


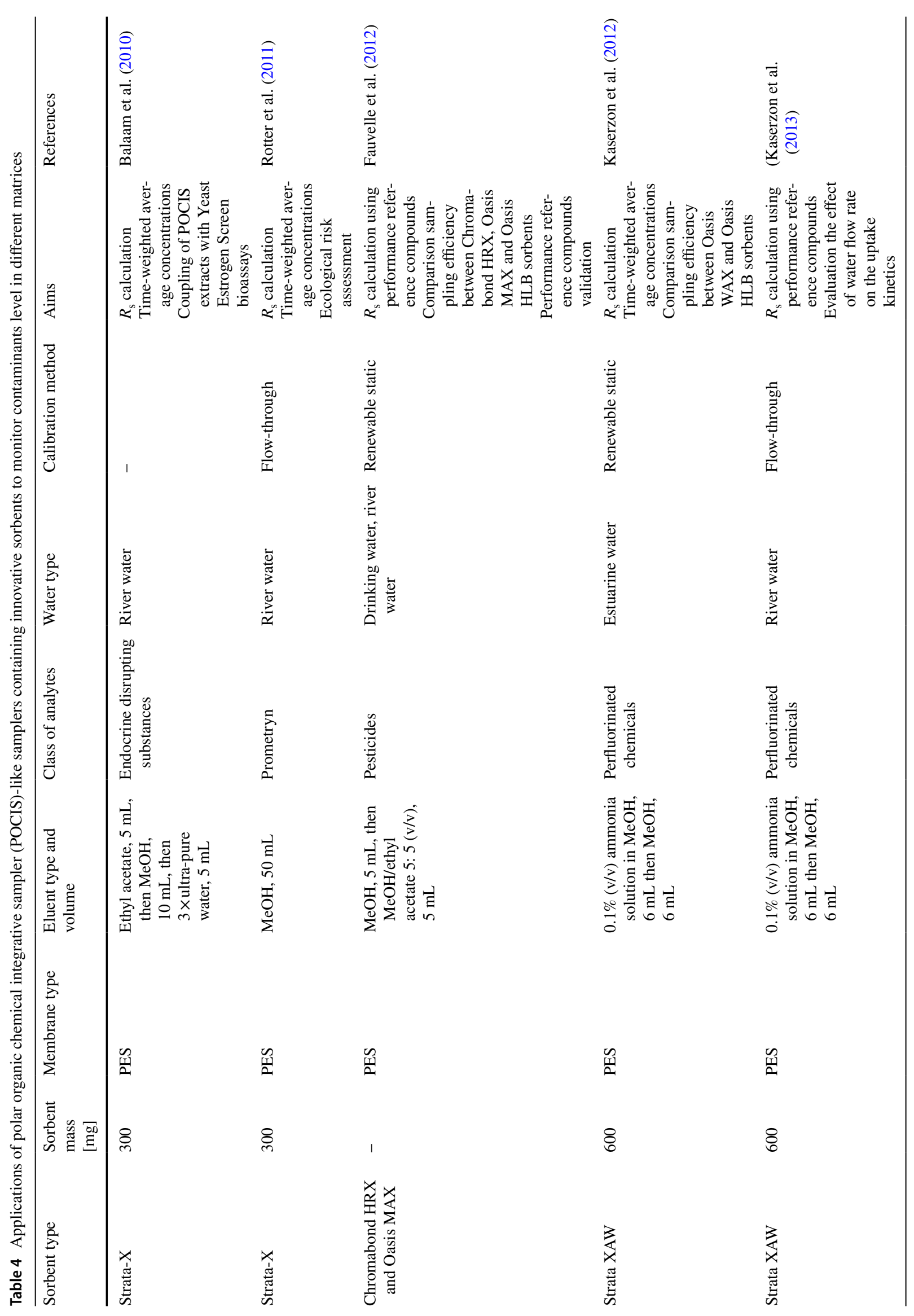




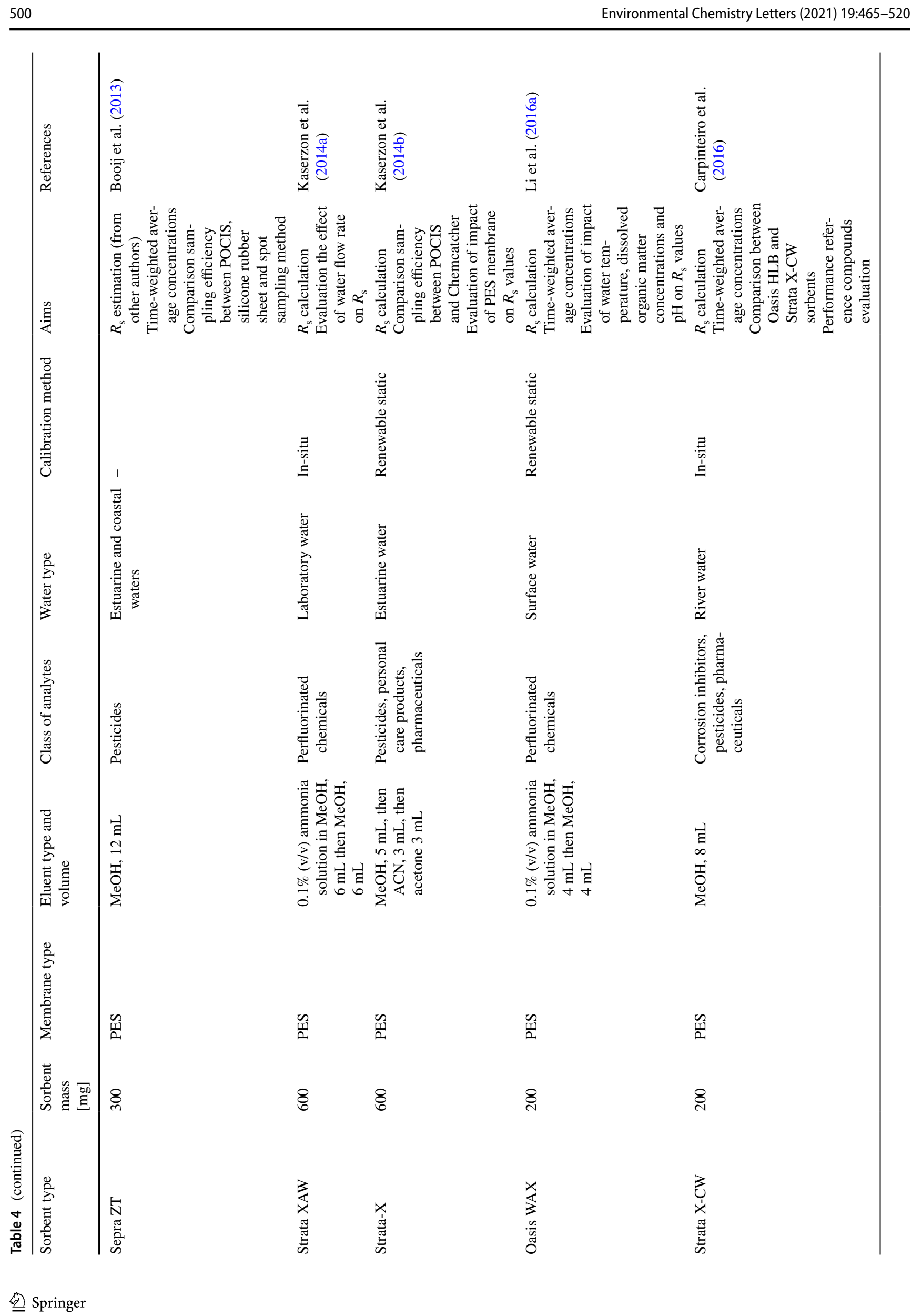


Environmental Chemistry Letters (2021) 19:465-520

501

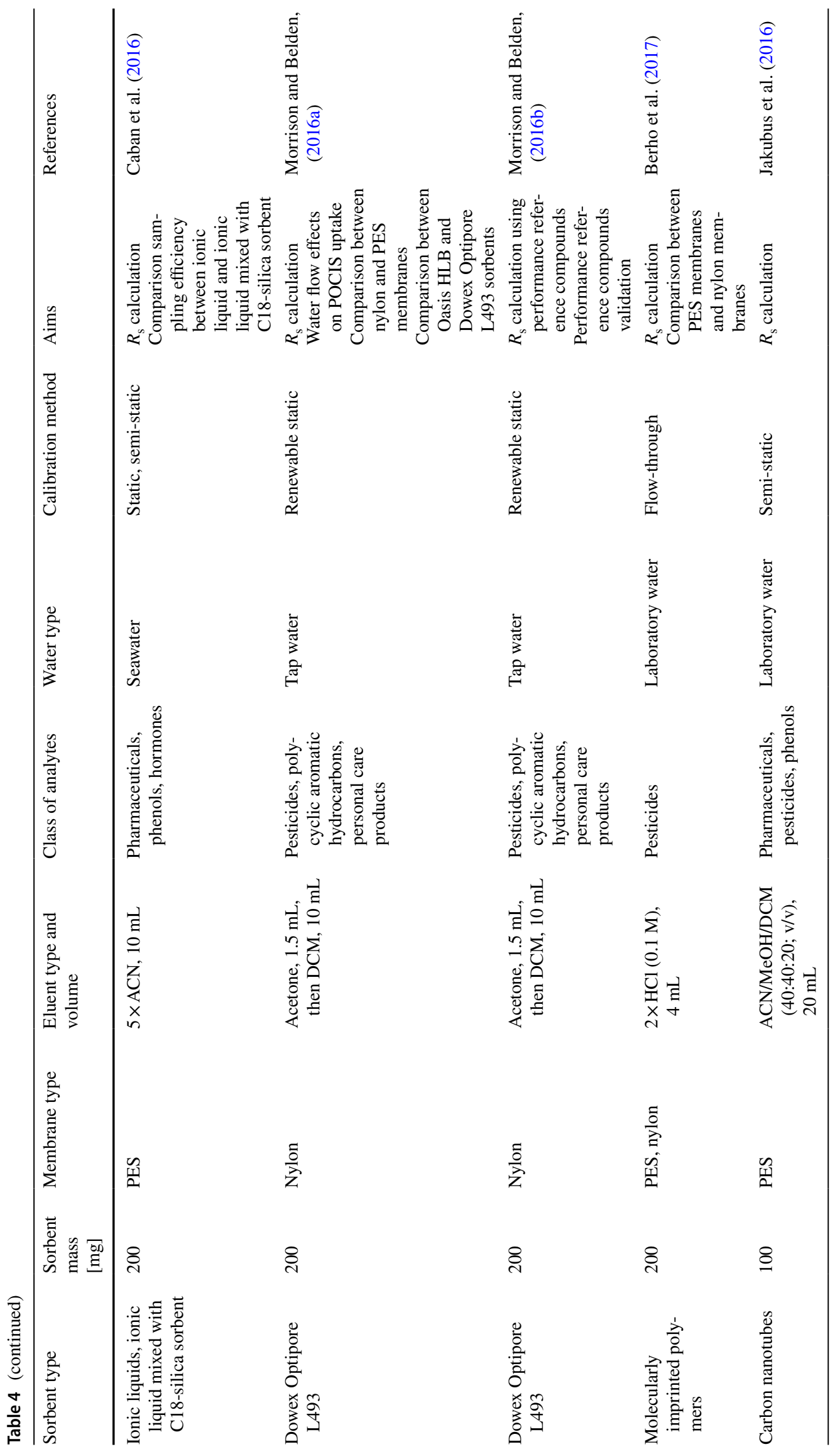

Springer 


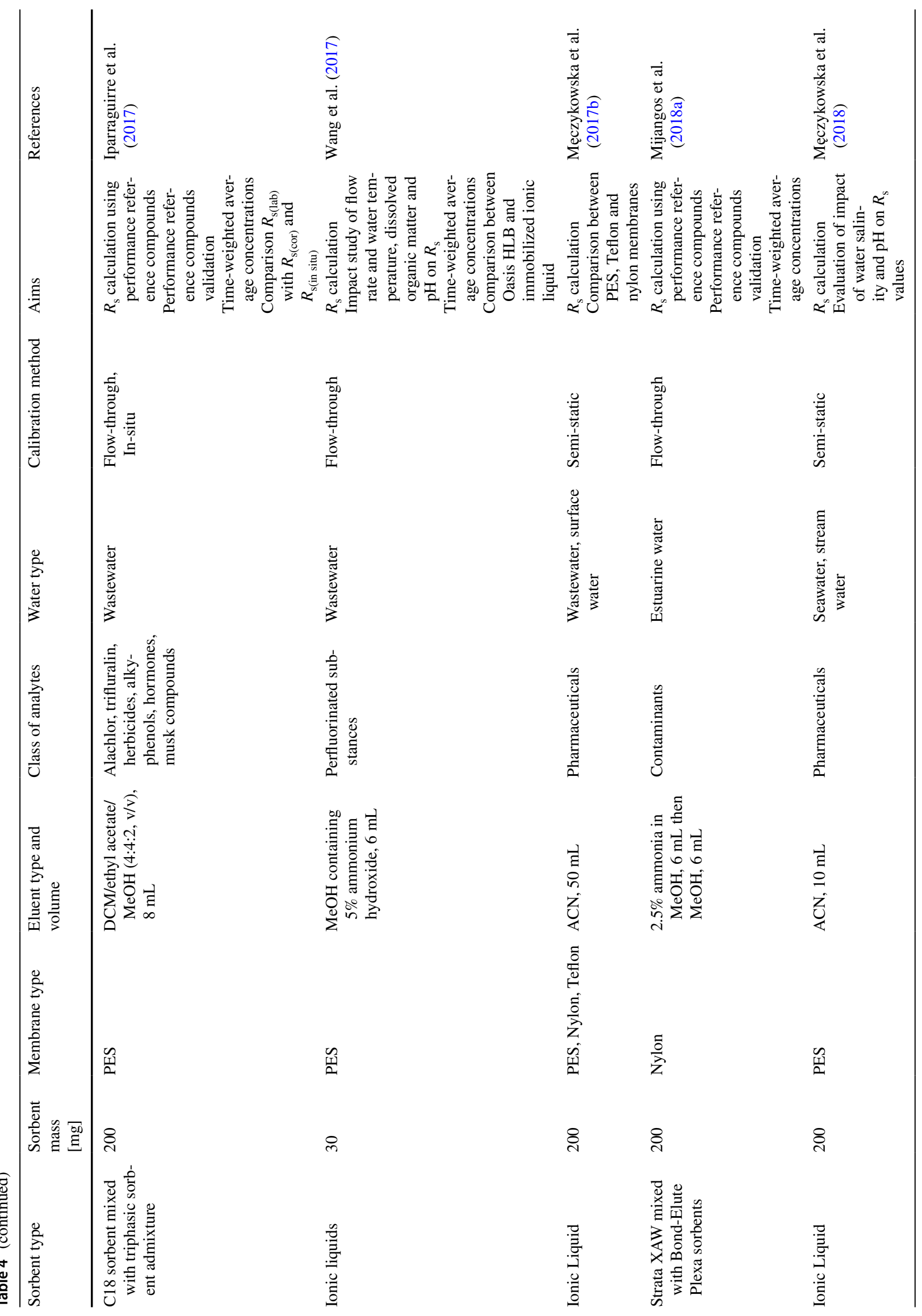




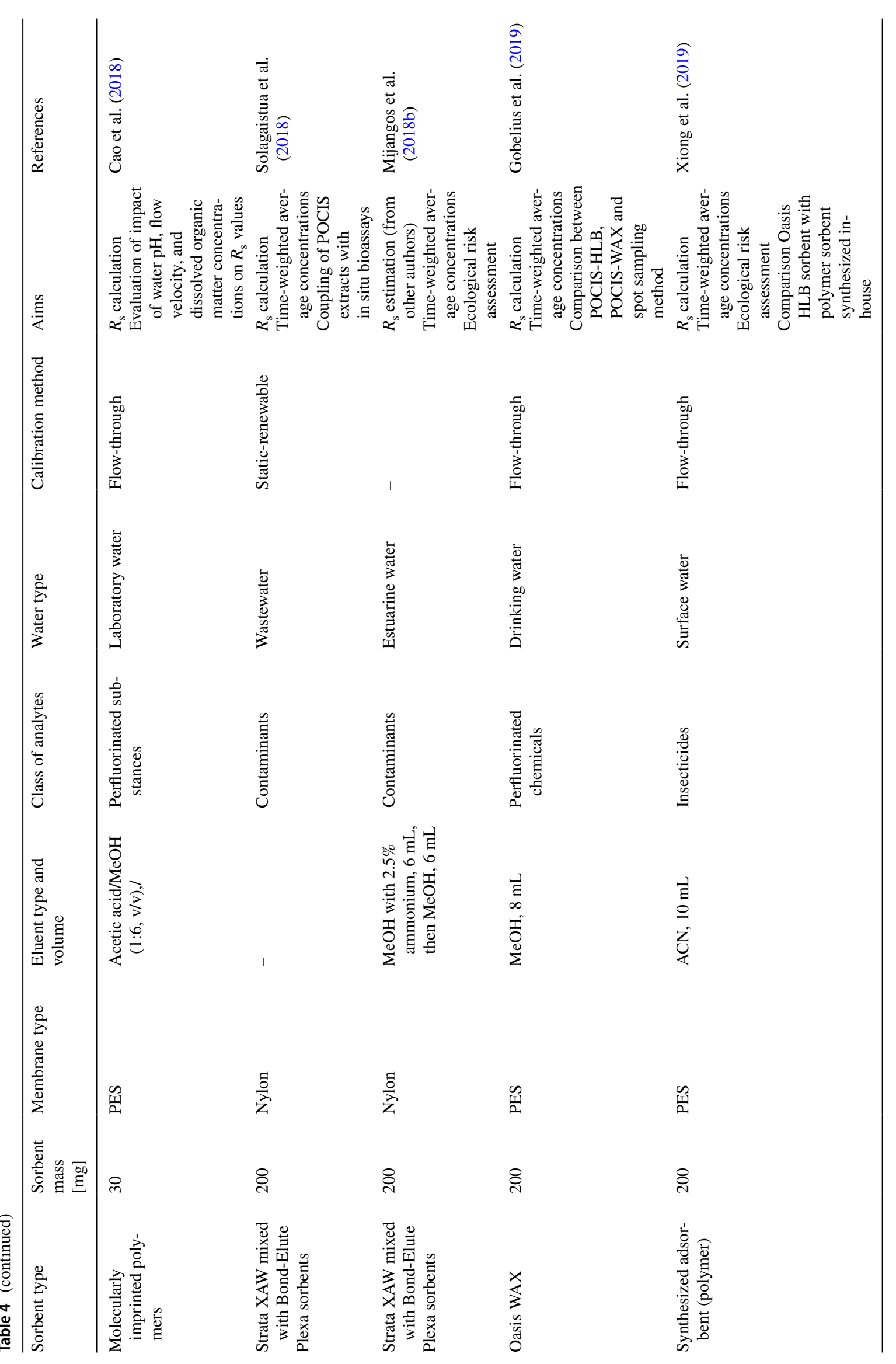



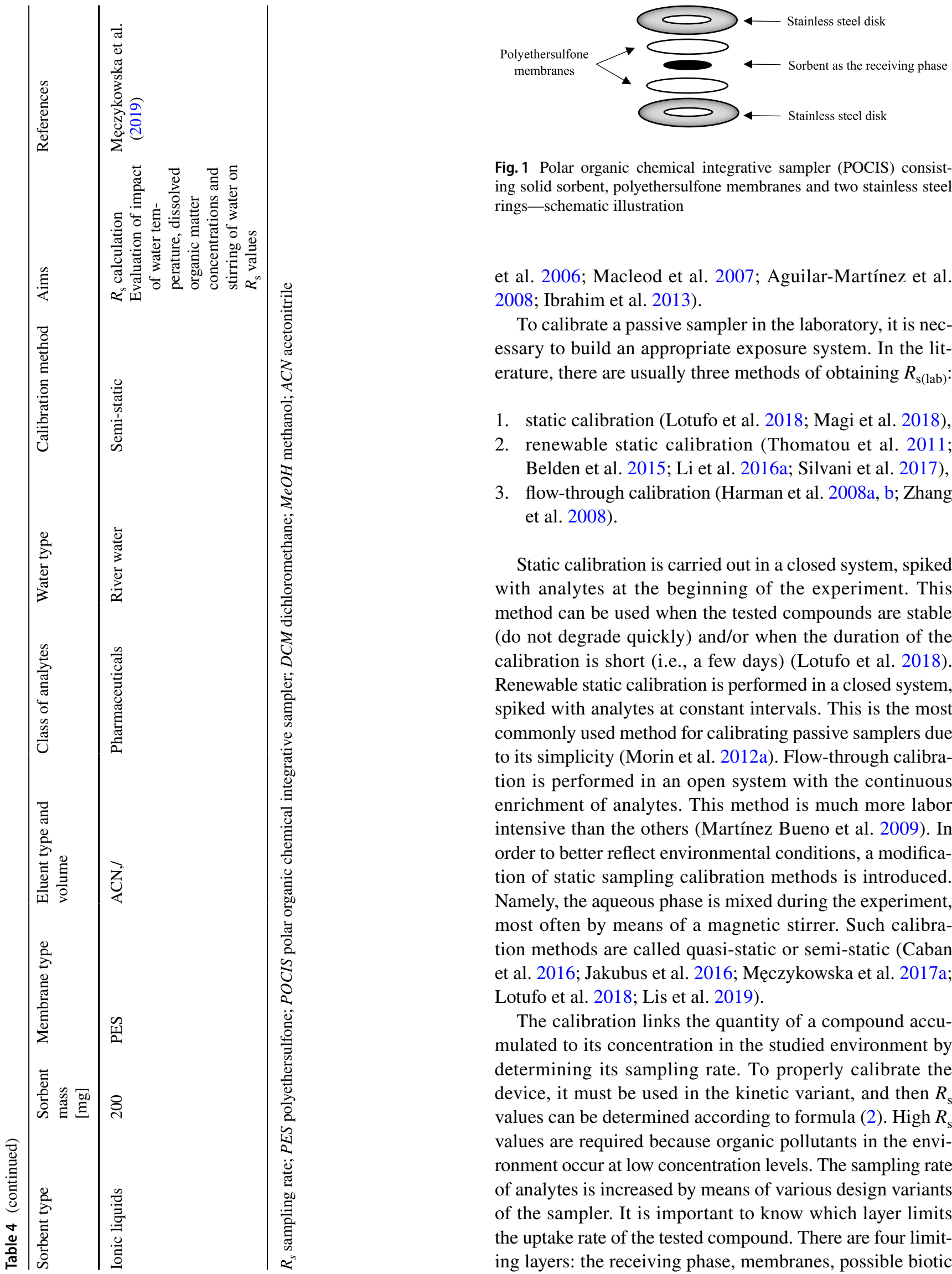

Fig. 1 Polar organic chemical integrative sampler (POCIS) consisting solid sorbent, polyethersulfone membranes and two stainless steel rings-schematic illustration

et al. 2006; Macleod et al. 2007; Aguilar-Martínez et al. 2008; Ibrahim et al. 2013).

To calibrate a passive sampler in the laboratory, it is necessary to build an appropriate exposure system. In the literature, there are usually three methods of obtaining $R_{\mathrm{s}(\mathrm{lab})}$ :

1. static calibration (Lotufo et al. 2018; Magi et al. 2018),

2. renewable static calibration (Thomatou et al. 2011; Belden et al. 2015; Li et al. 2016a; Silvani et al. 2017),

3. flow-through calibration (Harman et al. 2008a, b; Zhang et al. 2008).

Static calibration is carried out in a closed system, spiked with analytes at the beginning of the experiment. This method can be used when the tested compounds are stable (do not degrade quickly) and/or when the duration of the calibration is short (i.e., a few days) (Lotufo et al. 2018). Renewable static calibration is performed in a closed system, spiked with analytes at constant intervals. This is the most commonly used method for calibrating passive samplers due to its simplicity (Morin et al. 2012a). Flow-through calibration is performed in an open system with the continuous enrichment of analytes. This method is much more labor intensive than the others (Martínez Bueno et al. 2009). In order to better reflect environmental conditions, a modification of static sampling calibration methods is introduced. Namely, the aqueous phase is mixed during the experiment, most often by means of a magnetic stirrer. Such calibration methods are called quasi-static or semi-static (Caban et al. 2016; Jakubus et al. 2016; Męczykowska et al. 2017a; Lotufo et al. 2018; Lis et al. 2019).

The calibration links the quantity of a compound accumulated to its concentration in the studied environment by determining its sampling rate. To properly calibrate the device, it must be used in the kinetic variant, and then $R_{\mathrm{s}}$ values can be determined according to formula (2). High $R_{\mathrm{s}}$ values are required because organic pollutants in the environment occur at low concentration levels. The sampling rate of analytes is increased by means of various design variants of the sampler. It is important to know which layer limits the uptake rate of the tested compound. There are four limiting layers: the receiving phase, membranes, possible biotic 
Fig. 2 Kinetic and equilibrium uptake phases as a function of time-kinetic (phase I), intermediate (phase II) and equilibrium (phase III)

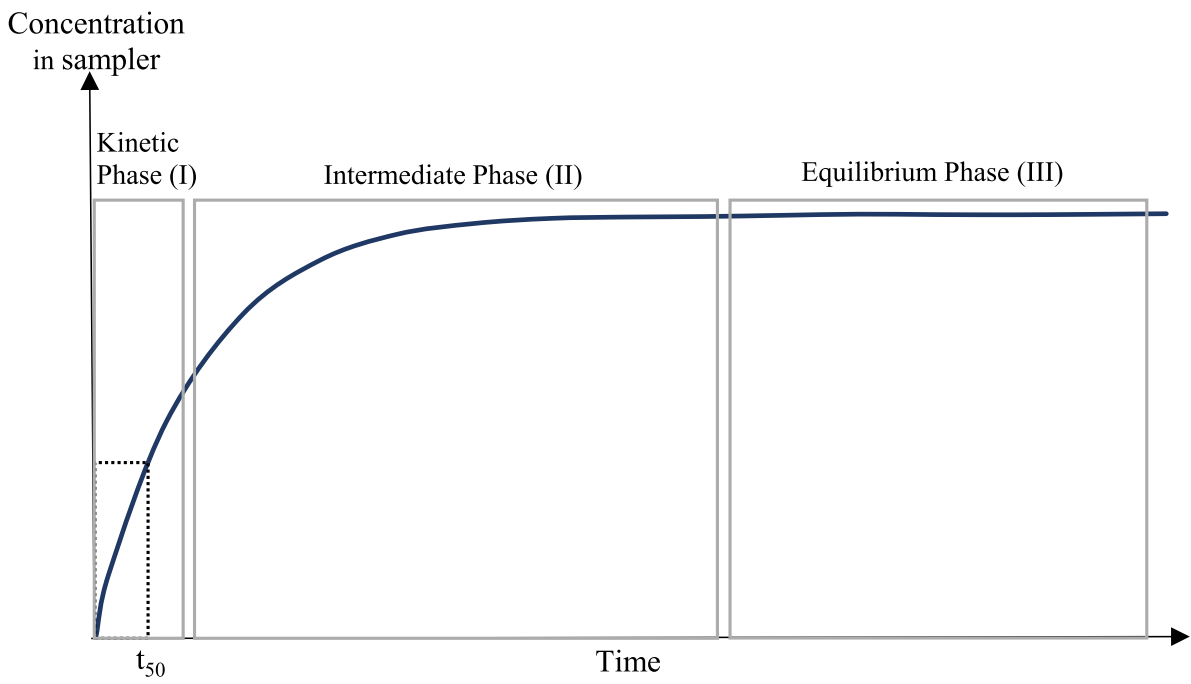

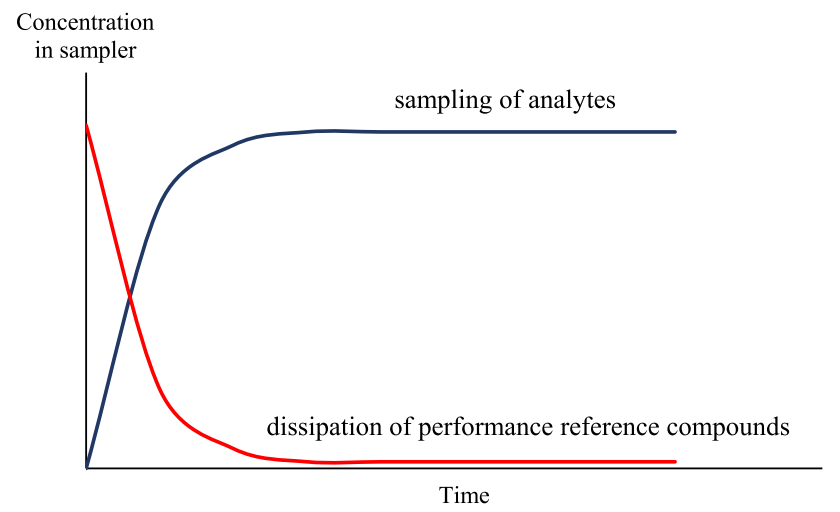

Fig. 3 Simultaneous sampling of analytes by a passive sampler and dissipation of performance reference compounds (PRCs) from the receiving phase during its exposure in the environment

contamination of the membrane and the aqueous boundary layer (Ibrahim et al. 2013; Vallejo et al. 2013; Berho et al. 2017). In addition, the $R_{\mathrm{S}}$ values may also depend on environmental conditions such as water salinity (Togola and Budzinski 2007; Bayen et al. 2014; Męczykowska et al. 2018), pH of the donor phase ( $\mathrm{Li}$ et al. 2011, 2016a; Lis et al. 2019), temperature (Ibrahim et al. 2013; Yabuki et al. 2016) and dissolved organic matter concentration ( $\mathrm{Li}$ et al. 2011; Ibrahim et al. 2013). For this reason, many scientists propose to use performance reference compounds to make the obtained $R_{\mathrm{S}}$ values more reliable.

Performance reference compounds are compounds added to the receiving phase in the sampler before its exposure which do not affect the process of sampling analytes from water. During the exposure of the passive device, the performance reference compounds are released from the sampler into the external environment. The sampling of analytes and the release of performance reference compounds are caused by the same molecular process (Fig. 3). Changes in the sampling rates of analytes due to environmental conditions (e.g., decrease in temperature, increase in salinity, decrease in $\mathrm{pH}$ ) should be reflected by the same changes in the release of performance reference compounds from the samplers (Harman et al. 2012).

The release of performance reference compounds is required to follow first-order kinetics (Carpinteiro et al. 2016):

$\ln \frac{C_{t}}{C_{0}}=k_{e} t$

where $C_{t}$ and $C_{0}$ are the concentrations in the receiving phase $\left[\mu \mathrm{g} \mathrm{g}^{-1}\right.$ ] during $\mathrm{t}$ [day] and before introduction, respectively, and $k_{e}$ is the elimination rate constant $\left[\mathrm{day}^{-1}\right.$ ]. The elimination rate constant is used to determine the corrected $R_{\mathrm{S}}\left(R_{\mathrm{s}(\mathrm{cor})}\right)$. Therefore, $R_{\mathrm{s}(\mathrm{cor})}$ can be determined by the following equation (Morin et al. 2012a):

$R_{\mathrm{s}(\mathrm{cor})}=\frac{k_{e(\mathrm{in} \mathrm{situ)}}}{k_{e(\mathrm{lab})}} R_{\mathrm{s}(\mathrm{lab})}$

where $k_{e(\mathrm{lab})}$ is the calculated elimination rate constant in the laboratory and $k_{e(\text { in situ })}$ is the elimination rate constant obtained in the field. The ratio of $k_{e(\text { in situ })}$ to $k_{e(\text { lab })}$ is called the environmental adjustment factor. According to theory, the environmental adjustment factor reflects changes in uptake rates (relative to laboratory data) due to differences in analyte properties, environmental conditions, membrane biofouling and the water phase flow rate. For instance, if the environmental adjustment factor values are relatively constant for analytes with a $\log K_{\text {ow }}$ value in the range of 4-8, then these factors will be appropriate for most hydrophobic chemicals (Męczykowska et al. 2017a). 
Performance reference compounds are compounds that are not present in the environment and may be, for example, isotopically labeled compounds $\left({ }^{2} \mathrm{H}-,{ }^{13} \mathrm{C}\right.$-labeled reference compounds can be used). The ideal solution would be if each compound had its own performance reference compounds (e.g., anthracene-d10 as the performance reference compound for anthracene). However, for practical reasons this is not possible. Performance reference compounds are usually hydrophobic compounds, successfully used in SPMDs or Chemcatcher techniques, in which hydrophobic analytes are sampled $\left(\log K_{\text {ow }} 4.5-6\right)$. In the case of hydrophilic analytes, the selection of the appropriate performance reference compounds is not easy. For instance, for pharmaceuticals, several studies used diclofenac-d4 and ibuprofen-d 3 as performance reference compounds, but the results obtained were not satisfactory (Camilleri et al. 2012; Carpinteiro et al. 2016; Lissalde et al. 2016), whereas Carpinteiro et al. (2016) conducted research to assess the usefulness of selected performance reference compounds for the determination of two corrosion inhibitors, seven pesticides and four pharmaceuticals in river water using POCIS. Of the seven potential performance reference compounds, only deisopropylatrazine-d5 and 4-methylbenzotriazol-d3 showed a significant release that was consistent with the first-order kinetic model. It was proved that these two performance reference compounds allow a significant reduction in the effect of water flow on $R_{\mathrm{s}}$, and 4-methylbenzotriazol-d 3 can be used to determine time-weighted average concentrations estimated using deisopropylatrazine-d5. Moreover, Mazzella et al. (2010) used deisopropylatrazine-d5 as a performance reference compound in the determination of polar herbicides in water using POCIS. They calibrated the samplers in situ and in the laboratory using the performance reference compound. Comparing the obtained $R_{\mathrm{s}(\mathrm{in} \text { situ })}$ and $R_{\mathrm{s}(\mathrm{cor})}$ values, they noticed no significant differences between the sampling rate values. These results confirm the potential use of deisopropylatrazine-d5 as a performance reference compound for some polar herbicides. The authors concluded that in situ calibrations are a better solution, but too costly and time-consuming. Therefore, calibration using performance reference compounds but, in the laboratory, seems to be a promising method for obtaining reliable $R_{\mathrm{s}}$ values. However, research into the selection of the appropriate performance reference compounds for the sampling of polar compounds by POCIS is still in its early stages.

\section{Impact of environmental conditions on sampling rate}

$R_{\mathrm{S}}$ values depend on the physicochemical properties of the analytes (molecular weight, hydrophobicity, solubility) and environmental conditions such as water flow, salinity, sample $\mathrm{pH}$, temperature, biofouling and dissolved organic matter concentration (Gong et al. 2018). The amount of research on determining the impact of specific external factors on the sampling rate and the efficiency of extraction of passive samplers is constantly growing.

The first environmental factor that significantly affects the sampling rate of analytes, which should be mentioned, is the $\mathrm{pH}$ of the water. Many environmental contaminants, including some pharmaceuticals and hormones, have functional groups that can be ionized at various $\mathrm{pH}$ values of water. Additionally, the water $\mathrm{pH}$ may have an effect on changing the hydrophobicity and/or solubility of the target chemicals. Avdeef et al. (2000) showed that the hydrophobicity of some drugs varies depending on the $\mathrm{pH}$ of the solution. For this reason, Li et al. (2011) conducted research on the effect of the dissolved organic matter concentration and $\mathrm{pH}$ of the solution on $R_{\mathrm{s}}$ values for POCIS (Oasis HLB as a sorbent). The sampling rates for acid pharmaceuticals were shown to decrease with increasing $\mathrm{pH}$ from 3 to 9 , while the sampling rates for basic chemicals (e.g., $\beta$-blockers) increased with increasing $\mathrm{pH}$ from 3 to 9 . More importantly, $R_{\mathrm{s}}$ values for inert drugs and phenolic compounds with high $\mathrm{pK}_{\mathrm{a}}$ values (e.g., bisphenol A) remained unchanged in the $\mathrm{pH}$ range of 3-9. Zhang et al. (2008), in their studies, also showed that $R_{\mathrm{S}}$ values for target compounds with a $\mathrm{pK}_{\mathrm{a}}$ greater than 10 remain relatively similar at $\mathrm{pH} 4-10$ with an relative standard deviation less than 5\% when using POCIS.

Another external factor that can negatively affect the sampling rate of chemicals is the presence of dissolved organic matter in the water because it can:

1. bind to target molecules,

2. dominate at adsorption sites and inhibit the adsorption capacity for some target analytes,

3. induce interference and time-consuming preparation.

Due to complexing with dissolved organic matter, the available concentration of target chemicals may decrease, and the complexes formed are difficult to disperse in the sampler. The measure of the total dissolved organic matter concentration is the dissolved organic carbon concentration, which in the aquatic environment is usually $2-10 \mathrm{mg} \mathrm{L}^{-1}$ (Yang et al. 2017). Most dissolved organic carbon in natural waters is fulvic and humic. Li et al. (2011) examined the relationship between the $R_{\mathrm{s}}$ values of selected drugs and hormones and the dissolved organic carbon concentration (3.33, 3.86 and $4.92 \mathrm{mg} \mathrm{L}^{-1}$ ) in the sample. It was shown that there is a tendency for the accumulation rate of acid, neutral and alkaline analytes to increase in POCIS with an increasing dissolved organic matter concentration in water, but these differences were not statistically significant. Charlestra et al. (2012) also investigated the impact of dissolved organic matter on the rate of pesticide uptake from water by POCIS. They proved that the dissolved organic matter concentration 
in the water phase in the range of $0.1-5 \mathrm{mg} \mathrm{L}^{-1}$ does not significantly affect the $R_{\mathrm{s}}$ values of the target compounds. At the same time, the authors emphasize the need for further research using higher dissolved organic matter concentrations to completely exclude the effect of dissolved organic matter on $R_{\mathrm{s}}$ values.

Salinity is an environmental factor that can strongly affect the sampling rate of compounds, especially from seawater. Salinity values of environmental waters are in a wide range of 0-35 PSU (1 practical unit of salinity corresponds to $1 \mathrm{~g}$ of salt per kg of solution), depending on the type of water reservoir, but also on temperature, precipitation, melting glaciers, etc. Many literature sources indicate that the solubility of most organic pollutants in water decreases with increasing salt concentration due to the so-called salting effect. This effect should theoretically increase their sorption efficiency in the sampler. On the other hand, complexing organic chemicals with polyvalent cations can inhibit and delay the sampling of target organic pollutants. Togola and Budzinski (2007) proved that water salinity showed little effect on the accumulation of acid compounds in POCIS, while the $R_{\mathrm{s}}$ values of basic compounds decreased with increasing salinity. Shi et al. (2014) conducted POCIS calibrations to determine antibiotics and hormones in coastal waters. The effect of sample salinity $\left(0 \%, 14 \%\right.$ o, 35\%o) on the $R_{\mathrm{s}}$ values of target analytes was investigated. It was shown that an increase in water salinity caused an increase in the sampling rate of all the tested compounds excluding estriol, with the highest $R_{\mathrm{s}}$ values observed at $14 \%$ o salinity. This complex relationship indicates that POCIS should be thoroughly tested for various environmental conditions before use in the field.

In addition to the factors mentioned above, the water flow also has an important impact on the sampling rate. In the case of an integral (kinetic) passive sampler, there is a strong relationship between sampling and the boundary layer with water on the membrane. Therefore, increasing the flow rate of the solution should reduce the thickness of the water/ membrane boundary, which is equivalent to increasing the sampling rate of analytes by the passive kinetic sampler. Di Carro et al. (2014) examined the relationship between the water flow $\left(2,5.1,10.2\right.$ and $\left.15.3 \mathrm{~cm} \mathrm{~s}^{-1}\right)$ and the sampling rate during flow-through calibration. POCIS passive samplers were used with Oasis HLB sorbent as the receiving phase, and the analytes were pesticides, pharmaceuticals and perfluorinated compounds. It was proved that increasing the flow rate of the water phase affects the $R_{\mathrm{s}}$ values, although increasing the flow velocity was not always synonymous with an increase in $R_{\mathrm{s}}$ values. However, in the research of Charlestra et al. (2012) both water flow and mixing were shown to significantly increase the uptake rate of target analytes, which is closely related to the reduction of the diffusion boundary layer.
Temperature is another important factor that can affect the sampling rate of analytes by passive samplers. In theory, an increase in the temperature of the aqueous phase should increase the mobility of the analyte and accelerate the mass transfer from the water to the receiving phase in the sampler. Moreover, in membrane processes, the solvent flow through the membrane depends on its chemical potential, which grows with increasing temperature (Djomte et al. 2018). Yabuki et al. (2016) studied the relationship between temperature $\left(18,24\right.$ and $\left.30^{\circ} \mathrm{C}\right)$ and the sampling rate of 48 pesticides by POCIS. The results confirmed that for most analytes, the uptake rate increases with increasing temperature. Similar conclusions were drawn by Li et al. (2010a), who studied the effect of temperature $\left(5,15\right.$ and $\left.25^{\circ} \mathrm{C}\right)$ on the sampling rate for 29 different pharmaceuticals. They also showed that the highest $R_{\mathrm{s}}$ values of analytes were obtained for the highest temperature $-25{ }^{\circ} \mathrm{C}$. However, it should be remembered that the presented examples do not confirm that the temperature increase-increase $R_{\mathrm{S}}$ relationship will take place for all types of pollution.

The last environmental factor which should be taken into consideration when calibrating passive samplers is biofouling. Biofouling is a membrane growth caused by microorganisms, animals, plants or algae and the formation of a biofilm layer on the membrane or directly in the receiving phase. The growing biofilm at the top of the membrane reduces the surface for the passive extraction of water pollutants. The permeability of the membrane becomes less, which reduces the efficiency of the passive process (Męczykowska et al. 2017a). An idea to minimize the effect of biofouling is to cover the receiving phase with membranes. Schäfer et al. (2008) proved that biofouling on a naked disk (in a passive Chemcatcher ${ }^{\circledR}$ sampler) causes a decrease in the sampling rate. Polyethersulfone membranes, used in POCIS, are characterized by a higher resistance to biofouling due to their polarization. Lissalde et al. (2014), in their research on the sampling of pesticides from water by POCIS, proved that biofouling is not a factor which limits the accumulation of analytes in the sampler sorbent.

Considering the fact that so many environmental factors can (in many ways) affect the sampling rate of analytes from water reservoirs, in situ calibration or laboratory calibration using performance reference compounds, with a simultaneous assessment of the impact of environmental conditions is justified. 


\section{Sorbents used in passive organic chemical integrative samplers}

\section{Hydrophilic-lipophilic-balanced sorbent (Oasis HLB)}

Oasis HLB sorbent (specific surface area $-800 \mathrm{~m}^{2} \mathrm{~g}^{-1}$ ) is one of the most commonly used sorption materials in both active and passive methods of extracting water pollutants. The HLB polymer contains both hydrophobic (i.e., benzene and aliphatic chains) and hydrophilic (i.e., pyrrolidone) fragments. This unusual structure contributes to the good water wettability and high sorption capacity of hydrophobic and hydrophilic compounds. Commercially available pharmaceutical POCIS devices containing Oasis HLB (200 or $220 \mathrm{mg} /$ POCIS) as the receiving phase are provided by companies such as Environmental Sampling Technologies, Exposmeter AB and E\&H Services. However, many scientists buy the sorbent separately and create home-made samplers to reduce or increase the amount of sorbent used in POCIS (Table 2). Researchers are constantly striving to reduce the costs of the sampling, preparation and final analysis of environmental samples. For this reason, the most common attempts to reduce the weight of the receiving phase while maintaining good sampling efficiency are of an economic nature. On the other hand, scientists who increase the amount of Oasis HLB used in the sampler aim at increasing the sampling rate and the efficiency of collecting aqueous pollutants, and the use of Oasis HLB sorbent can be a costeffective approach in environmental analysis.

Fauvelle et al. (2014) performed a laboratory calibration of passive samplers to compare the uptake of both polar and acid herbicides for 20 days in POCIS devices containing 200 and $600 \mathrm{mg}$ Oasis HLB (POCIS-200 and POCIS-600). A significant increase in $R_{\mathrm{s}}$ values between POCIS-200 and POCIS-600 was observed for the uptake of compounds in the kinetic phase. Moreover, Kohoutek et al. (2008) conducted research to develop and evaluate the use of a passive sampler for microcystins and to compare the ability of different configurations (membranes and sorbent mass) to effectively accumulate these analytes. They applied three ratios of the sorbent mass to the membrane surface area $\left(2.75,5.55\right.$ and $\left.11.10 \mathrm{mg}\left(\mathrm{cm}^{2}\right)^{-1}\right)$, using an Oasis HLB sorbent sampling device and a polycarbonate membrane. The obtained results proved that the sampling rate decreased along with an increase of the sorbent mass-to-surface area ratio. The researchers stated that this could be related to changes in diffusion velocity. The lower effective thickness (at a lower sorbent mass) caused a higher speed of the water sample through the sorbent layer, which leads to a more efficient accumulation of microcystins. Other researchers also obtained high extraction efficiency and satisfactory sampling rates, using, e.g., $100 \mathrm{mg}$ (Vermeirssen et al. 2005; Zhang et al. 2008), $30 \mathrm{mg}$ (Wang et al. 2017) or $54.5 \mathrm{mg}$ (Jeong et al. 2018a; Müller et al. 2019) Oasis HLB. Considering the above, it can be concluded that the increase in sorbent mass will not always increase the uptake rate of the target chemical compounds.

In research conducted by Kohoutek et al. (2008), polyethersulfone, polyester, nylon and polycarbonate membranes were tested, between which Oasis HLB sorbent (200 mg) was placed. It was determined that chemicals can migrate to the sorbent layer through the membrane in two ways, i.e., dissolution and migration through the polymer matrix of the membrane, and migration through the pores filled with water. These two modes control the accumulation of analytes to the passive sampler. Assuming the constant exposure conditions used in the experiments of Kohoutek et al. (2008), the most important features affecting accumulation were the effective membrane thickness and the open pore volume. Among the tested membranes, the polycarbonate membrane showed the highest microcystin uptake rate as well as similar uptake frequencies for two different microcystin variants (microcystin-RR and microcystin-LR). The polycarbonate membrane is a thin membrane $(5-25 \mu \mathrm{m})$, ensuring rapid diffusion and analyte collection at medium flow rates. They also obtained very similar results for polyethersulfone membranes, which are durable, resistant and tensile and have a large volume of open pores. However, the relatively large thickness of this microporous membrane $(110-150 \mu \mathrm{m})$ can lead to the stagnation of the water boundary layer, which extends the diffusion pathway for target compounds. Less effective accumulation was found for the hydrophilic nylon66 membrane, which is relatively thick $(65-125 \mu \mathrm{m})$ with an average pore volume. In contrast, the polyester membrane, which is naturally hydrophilic, resistant and of small thickness $(5-11 \mu \mathrm{m})$, accumulated only microcystin-RR and no microcystin-LR was found. Belles et al. (2014a, b) proposed replacing polyethersulfone membranes with nylon membranes in POCIS (Oasis HLB as a sorbent) in order to be able to collect hydrophobic compounds and improve the accumulation of other pollutants. The $R_{\mathrm{s}}$ values of each hydrophobic analyte were higher in the POCIS-Nylon configuration than in POCIS-Polyethersulfone. This is mainly due to the fact that the pores in nylon membranes are larger than in polyethersulfone membranes, which contributes to a reduction in the mass transfer resistance and increases the accumulated amounts of various chemical compounds in the sampler. Nonetheless, for very polar compounds, changing the membrane type did not affect the amount of compound in the receiving phase.

However, regardless of the sorbent mass or membrane type used, each passive sampler should be calibrated before use in the field. For pharm-POCIS, all known sampler calibration methods are used (Table 2). Interestingly, the most common are the flow-through or in situ methods, despite 
them being time-consuming and complicated. As previously mentioned, in situ calibration is the most reliable method for determining $R_{\mathrm{s}}$ values. However, by using other methods, many researchers focus on developing the performance reference compounds-based approach to improve the accuracy of passive sampler calibration. Jacquet et al. (2012), in their studies, tested three deuterated beta-blockers and four deuterated hormones as potential performance reference compounds. Unfortunately, only deuterated atenolol showed significant dispersion from the POCIS sorbent. Sultana et al. (2016) also tested four deuterated beta-blockers (atenolol-d7, metoprolol-d6, sotalol-d6 and propranolold7) as performance reference compounds in POCIS-Oasis HLB during laboratory and in situ calibration. Of the tested compounds, metoprolol-d6 and propranolol-d7 showed significant and comparable elimination rates from sorbent in laboratory and field experiments and therefore were used as performance reference compounds in the further calibration of POCIS. But Li et al. (2018a, b) tested several different deuterated compounds (acetaminophen-d3, antipyrine-d3, sulfamethoxazole-d4, carbamazepine-d10, diclofenac acid$\mathrm{d} 4$, clofibric acid-d4, bezafibrate-d6, ibuprofen-d3 and naproxen-d3) as potential performance reference compounds. In this case, only antipyrine-d3, carbamazepine-d10 and sulfamethoxazole-d4 showed dispersion with POCIS according to first-order kinetics. As can be seen, finding the right performance reference compounds that could be used successfully in pharm-POCIS is not easy, but more and more work is being done on this subject (Table 2) to provide the necessary knowledge for a better understanding of the performance reference compounds-based approach.

An important step in the procedure for determining pollutants using POCIS is the extraction of analytes retained on the surface of the sorbent. According to Table 2, methanol $(\mathrm{MeOH})$ is the most common elution solvent used in POCISOasis HLB. It is also a widely used eluent in active extraction methods; thus, it is not surprising that $\mathrm{MeOH}$ has been successfully used for the desorption of compounds from Oasis HLB, such as pharmaceuticals (Alvarez et al. 2004b; Jones-Lepp et al. 2004), hormones (Vermeirssen et al. 2005), pesticides (Mazzella et al. 2007), endocrine disrupting products (Zhang et al. 2008), personal care products (Li et al. 2010b), polycyclic aromatic hydrocarbons (Harman et al. 2008), alkylphenols (Harman et al. 2009), nutrients (Bailly et al. 2013), flame retardants (Liscio et al. 2014), artificial sweeteners (Diamond et al. 2016) and explosive substances (Estoppey et al. 2019). $\mathrm{MeOH}$, despite the ability to elute many organic compounds, is not always sufficient to obtain an effective extraction. Therefore, scientists create various types of elution mixtures by adding e.g. ethyl acetate, acetone, dichloromethane (DCM), methylene chloride, etc. to methanol to increase the elution efficiency of analytes from Oasis HLB (Table 2). In addition, the literature provides information on the use of different volumes of selected eluents ranging from $4 \mathrm{~mL}$ of $\mathrm{MeOH}$ (Martínez Bueno et al. 2016) to $100 \mathrm{~mL}$ of $\mathrm{MeOH}$ (Metcalfe et al. 2014). For the sampling of chemicals that differ significantly in hydrophilicity, step elution is often used with two or more solvents (Morin et al. 2018).

In some papers, scientists compare the sampling properties of different types of passive samplers (Table 2). Škodová et al. (2016) carried out calibrations of POCIS-Oasis HLB, Chemcatcher-SDB-RPS (styrene divinylbenzene-reversed phase sulfonated) Empore disk and an Empore disk-based sampler to determine the $R_{\mathrm{s}}$ values and the efficiency of hormone extraction from water. The results showed that only POCIS containing Oasis HLB was able to integrate sampling for up to one month. For Chemcatcher, kinetic sampling was only possible for one week. In addition, the authors emphasized that the practical advantage of POCIS over the Chemcatcher design used is its low pollution during manipulation. Liscio et al. (2009) compared the sampling properties of POCIS, low-density polyethylene sampler and silicone strips. Their results also confirm the best suitability of POCIS for the sampling of endocrine disrupting compounds.

Although pharm-POCIS was mainly developed for the accumulation of pharmaceuticals, this sampler has been used so far to monitor: pharmaceuticals, pesticides (biocides, herbicides, insecticides, fungicides), personal care products, fragrances, fire retardants, plasticizers, domestics, microcystins, endocrine-disrupting substances, polycyclic aromatic hydrocarbons, phenols, UV filters, stimulants, anticorrosive substances, antidepressants, perfluorinated chemicals, surfactants, drugs of abuse, artificial sweeteners, sucralose, munition constituents and more (Table 2). According to the collected data, pharm-POCIS is most often exposed in rivers but also in wastewater, seawater, groundwater, drinking water and lakes (Table 2). Interestingly, pharm-POCIS has been used in many pesticide-monitoring studies for which POCIS containing another sorbent was originally developed (pest-POCIS containing a triphasic sorbent admixture). Mazzella et al. (2007) conducted a study in which they compared the herbicide uptake efficiency of two commercially available POCIS configurations (pharm-POCIS and pestPOCIS). They noticed that pharm-POCIS is more efficient and more accurate for sampling most analytes. It should be mentioned that their experiments lasted only 5 days and it is not certain whether the same effect would be obtained during long-term exposure. On the other hand, Vermeirssen et al. (2005) showed that the use of pest-POCIS and pharm-POCIS allowed the determination of very similar time-weighted average concentrations values for estrogen concentrations in river waters (excluding one sampling site, where pest-POCIS showed better sampling properties than pharm-POCIS). In addition, they proved that pestPOCIS is more suitable for combining with bioassays than 
pharm-POCIS. This shows that despite the fact that Oasis HLB is widely used as a sorbent in POCIS, it is not always the best choice, which leads to a constant search for innovative sorption materials.

\section{Triphasic sorbent admixture}

ISOLUTE $^{\circledR}$ ENV+ is a polymer polystyrene sorbent used to isolate a wide range of polar pollutants from water. Commercially available pesticide POCIS devices containing a triphasic sorbent admixture (200 or $220 \mathrm{mg} /$ POCIS) as the receiving phase are supplied by companies such as: Exposmeter AB and E\&W Services. Pest-POCIS was originally created to monitor pesticides in the aquatic environment, but scientists successfully used this sampler to also collect such compounds as pharmaceuticals (Černoch et al. 2012), hormones (Rujiralai et al. 2011), UV filters (Černoch et al. 2012), phenols (Terzopoulou and Voutsa 2016), perfluorinated compounds (Cerveny et al. 2018), personal care products ( $\mathrm{Li}$ et al. 2010b), endocrine disrupting substances (Magi et al. 2010), flame retardants (Liscio et al. 2014), munitions constituents (Belden et al. 2015) (Table 3). According to the collected data, POCIS containing ISOLUTE ${ }^{\circledR}$ ENV+ is most often exposed in rivers (as well as POCIS-Oasis HLB) but also in sewage, seawater, groundwater, drinking water and lakes. The mass of the triphasic sorbent admixture used as the sorbent is usually $200 \mathrm{mg}$. However, Vermeirssen et al. (2005) proved that by using half the weight of this sorbent, it is also possible to sample analytes from water. Comparing the concentrations of pollutants obtained after POCIS exposure with those obtained from spot sampling, no significant differences were observed. Similar results were obtained by Vallejo et al. (2013), who successfully used $100 \mathrm{mg}$ of the triphasic sorbent admixture in POCIS to sample endocrine-disrupting substances from the aquatic environment, and the time-weighted average concentrations obtained were similar to those obtained from spot sampling. This proves the potential of the triphasic sorbent admixture to be termed an economic sorbent.

In the same studies, the use of equilin-d4, estradiol-d3, prostaglandin- $\mathrm{d} 9$ and bisphenol A-d12 as performance reference compounds was evaluated. Linear elimination was noted only for equilin-d4 and estradiol-d3, and it was these compounds that were successfully used as performance reference compounds when determining the time-weighted average concentrations of endocrine-disrupting substances in water. These are the only studies, summarized in Table 3, that used the performance reference compound approach in pest-POCIS

Considering the eluent used to extract the retained analytes from the sorbent, it was most often a mixture of dichloromethane, methanol and toluene. This elution mixture was successfully used to elute pesticides, hormones, pharmaceuticals, endocrine-disrupting substances, industrial chemicals, perfluorinated chemicals and phenols, retained on the surface of the triphasic sorbent admixture. Interestingly, no studies used only $\mathrm{MeOH}$ as the eluent, which often occurred during the extraction of analytes from Oasis HLB. Several literature reports mention the use of step elution to increase the extraction efficiency of target compounds (Zenker et al. 2008; Ahrens et al. 2015; Spirhanzlova et al. 2019). In contrast, the volumes used in the elution from pest-POCIS ranged from 5 to $70 \mathrm{~mL}$ (Table 3 ).

In the research of Fedorova et al. (2013), for the first time, the calibration of pest-POCIS and pharm-POCIS, used for the sampling of perfluorinated compounds from water, was performed. After an instrumental analysis of POCIS extracts, ten of the 15 target chemicals were found. Perfluorinated compounds with the longest alkyl chains have not yet been detected in any type of POCIS, which highlights the need to look for alternative sorbents that will increase the range of POCIS applicability. Absorption curves were plotted and sampling rates calculated for the compounds that could be detected. The results indicate that pest-POCIS has a better ability to accumulate perfluorinated compounds compared to pharm-POCIS. On the other hand, Arditsoglou and Voutsa (2008) studied the efficiency of endocrine-disrupting substances extraction from water for pest-POCIS and pharmPOCIS. They proved that both types of POCIS had similar extraction efficiency and sampling rates.

\section{Innovative sorbents}

According to Table 4, Balaam et al. (2010), as the first in 2010, used a different sorbent in POCIS-like samplers than those used for years, i.e., a functionalized polymeric sorption material that contains $N$-vinylpyrrolidone (Strata-X), which allows stronger interactions to be achieved between the analyte and the sorbent. The researchers were inspired by active extraction research where Strata- $X$ has been shown to be more effective in retaining a wider range of chemicals than Oasis HLB. They created samplers similar to those described by Alvarez et al. (2004b), where they used $300 \mathrm{mg}$ Strata-X. The modified and calibrated POCIS was used to determine the time-weighted average concentrations of endocrine distributing substances in river water. After the exposure of the probes in the environment, the analytes retained on the sorbent surface were eluted and the extracts obtained were combined with bioassays to assess the environmental risk. Comparing the results, it was proved that Strata-X is more effective at sampling endocrine-disrupting substances than Oasis HLB.

Two years later, Fauvelle et al. (2012) proposed testing two sorbents: Chromabond HRX and Oasis MAX. Chromabond is a polystyrene-divinylbenzene polymer with an 
extensive specific surface area and Oasis MAX is a mixedmode anion-exchange sorbent that provides additional sites for strong anion-exchange interactions. They introduced passive samplers into drinking water and rivers to monitor pesticides. The classic POCIS-Oasis HLB was also used to compare the sampling efficiency between samplers. It turned out that despite the large specific surface area, Chromabond HRX showed low sampling rates of the tested inert compounds and a complete lack of uptake for some acidic pesticides, which may be closely related to the hydrophobic nature of this sorbent. In the case of POCIS-Oasis HLB, a high efficiency of uptake of moderately polar compounds, and some restrictions on the sampling of highly polar and acid analytes were demonstrated. In contrast, the samplers containing Oasis MAX were characterized by high extraction efficiency and satisfactory sampling rates of both neutral and acidic chemicals, except for the most hydrophilic, inert pesticides. The obtained results confirmed the usefulness of the Oasis MAX sampler for sampling acidic compounds from water.

In 2012, Kaserzon et al. (2012) used $600 \mathrm{mg}$ of Oasis WAX (weak anion-exchange sorbent) to increase the uptake of perfluorinated compounds by passive samplers. Comparing the extraction efficiency of POCIS-Oasis HLB and POCIS-Oasis WAX, they were similar, but POCIS-Oasis WAX sampled short-chain perfluorinated compounds more efficiently. This shows that classic POCIS can be used in monitoring perfluorinated compounds, but with a more limited range of analytes than a POCIS-like sampler containing a weak anion-exchange sorbent. Later studies also confirm the usefulness and advantages of Oasis WAX over Oasis HLB used in samplers for the uptake of perfluorinated compounds (Kaserzon et al. 2013, 2014a). In 2016, Li et al. $(2016 \mathrm{a}, \mathrm{b})$ successfully managed to use only $200 \mathrm{mg}$ of this sorbent for the effective extraction of perfluorinated compounds from surface water, which makes WAX sorbents even more attractive from an economic point of view.

Another sorbent proposed in the literature was Strata $\mathrm{X}$-CW-cation-exchange mixed-mode sorbent, which was placed in a POCIS-like sampler. Carpinteiro et al. (2016) used this probe to determine the sampling rates of corrosion inhibitors, pesticides and pharmaceuticals in river water. Comparative studies showed that the extraction efficiency of the tested analytes was always higher (with one exception) for traditional POCIS-Oasis HLB than for POCIS-Strata $\mathrm{X}-\mathrm{CW}$, which excluded the usefulness of this ion exchange sorbent in passive techniques.

In 2016, ionic liquids were closed between polyethersulfone membranes for the first time and an innovative POCIS-like sampler was created. Caban et al. (2016) used the following ionic liquids in their research: 1-hexyl3-methylimidazolium bis[(tri-fluoromethyl)sulfonyl] amide ([C6MIM][TFN]), trihexyl(tetradecyl)phosphonium dicyanamide ([P666-14][N(CN) 2$])$, tributyl(tetradecyl) phosphonium $p$-dodecylbenzenesulfonate ([P444-14] [DDBS] ) and tributyl(ethyl)phosphonium diethylphosphate ([P2444][(2O $\left.\left.)_{2} \mathrm{PO}_{2}\right]\right)$. They compared the sampling efficiency of pharmaceuticals, hormones and phenol derivatives between samplers containing only ionic liquids and samplers containing, as a sorbent, a mixture of an ionic liquid and $C_{18}$-silica sorbent. The mixture of the ionic liquid ([P666-14] $\left.\left[\mathrm{N}(\mathrm{CN})_{2}\right]\right)$ and $C_{18}$ sorbent used in the sampler was characterized by the highest extraction efficiency of the tested analytes and the best behavior in a developed sampler. The presented research proved the possibility of using ionic liquids as the receiving phase in passive techniques for the sampling of compounds with a wide range of polarity. These conclusions were also confirmed in later studies by Wang et al. (2017) who used only $30 \mathrm{mg}$ of an imidazole ionic liquid in a POCIS-type sampler to accumulate perfluorinated compounds. Comparative studies showed that probes containing ionic liquids displayed a higher extraction capacity for short-chain perfluorinated compounds than POCIS-Oasis HLB and ensured kinetic uptake within 21 days. The calculated time-weighted average concentration for most analytes was consistent with that obtained from active sampling. The obtained results contributed to the creation of further studies on the development of POCIS-like samplers with ionic liquids (Męczykowska et al. 2017b, 2018, 2019).

In 2017 Berho et al. (2017) successfully used molecularly imprinted polymers as a sorbent in a POCIS-like sampler for sampling glyphosate and aminomethylphosphonic acid. A year later, Cao et al. (2018) also used such a modified sampler, this time to accumulate perfluorinated compounds, and compared its extraction efficiency with the previously developed POCIS-WAX. It was proved that POCIS with molecularly imprinted polymers used as a sorbent has a specific selectivity for the tested perfluorinated compounds and can overcome matrix interference. However, such a sampler has not yet been used directly in the aquatic environment to monitor pollution.

In 2017, carbon nanotubes were also used for the first time as a promising sorption material in passive samplers. Jakubus et al. (2016), in their research, proved that the use of carbon nanotubes as the receiving phase allows higher $R_{\mathrm{s}}$ values of the tested analytes (pharmaceuticals, hormones, phenols) to be achieved than when using conventional sorbents. The weight of the sorbent in traditional POCIS is generally $200 \mathrm{mg}$. But, Jakubus et al. (2016) successfully developed POCIS-like sampler, which used half the amount of sorbent $(100 \mathrm{mg})$. In addition, the carbon nanotubes can be reused as a sorption material. Based on the work of López-Feria et al. (2009), carbon nanotubes can be used as a sorbent at least 100 times with the same efficiency. Considering the facts mentioned above, carbon nanotubes are 
Fig. 4 Summary of the number of studies in 2004-2019 years on the POCIS-like sampler depending on the type of sorbents used

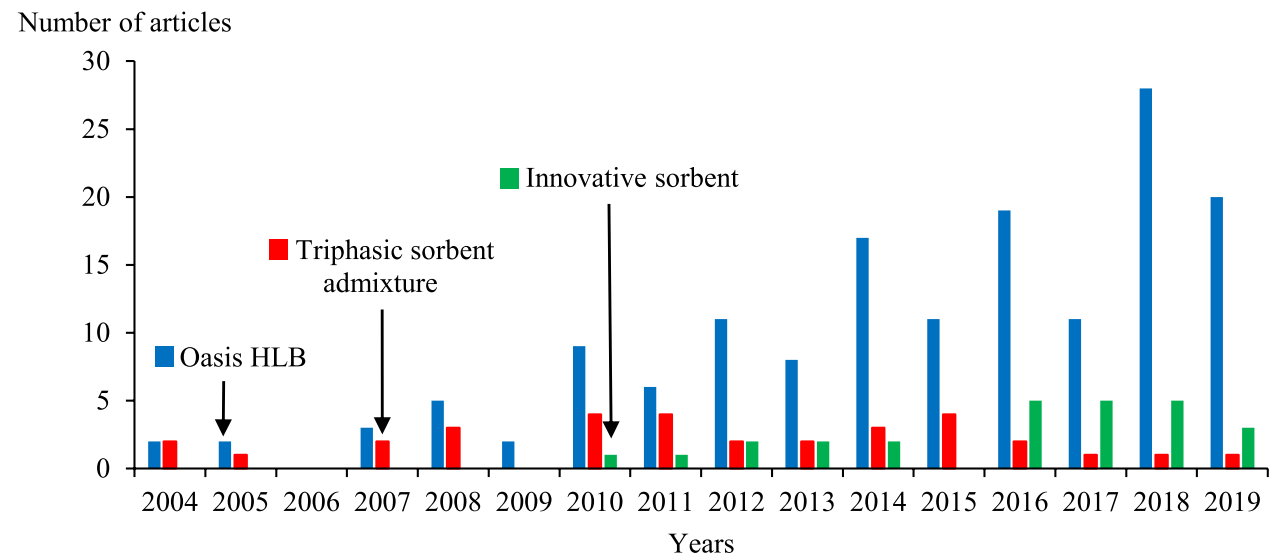

an interesting sorbent in POCIS, not only in analytical but also economic terms.

\section{Conclusion}

This review describes in detail the possibilities and restrictions on the use of traditional sorbents in POCIS. Since the introduction of the POCIS sampler in 2004, these devices have gained more and more popularity and interest, which is clearly shown in Fig. 4, which shows the amount of research on POCIS over the past 17 years. As can be seen, the huge advantage of the Oasis HLB sorbent over the triphasic sorbent admixture is that it was used in POCIS-like samplers between 2004 and 2020 at least 160 times, compared to 33 times for the admixture (according to the collected literature).

The following uses of POCIS have been identified in the existing literature (Tables 2, 3 and 4):

1. Carrying out the calibration and performance testing of the sampler,

2. Determining the impact of environmental factors (temperature, water $\mathrm{pH}$, dissolved organic matter concentration, mixing the receiving phase, water flow, salinity) on the sampling rate of target compounds,

3. Determining the impact of the type of membrane and/or sorbent used on the sampling efficiency of analytes,

4. Comparing the extraction efficiency of different passive samplers,

5. Screening/monitoring water pollution,

6. Calculating time-weighted average concentrations,

7. Testing various chemical compounds that can perform the function of performance reference compounds in POCIS,

8. Comparing the concentrations of analytes obtained from POCIS with those obtained from spot sampling,
9. Combining POCIS extracts with bioassays to assess environmental risk.

As Fig. 4 shows, the current number of studies that are performed using POCIS-like samplers is about six times greater than the number of tests performed in the first years since the appearance of POCIS in environmental analysis. The amount of literature collected in this review confirms the huge potential of these samplers as potentially reliable devices for monitoring the aquatic environment, and for other important applications. Scientists are constantly developing this extraction technique to minimize its disadvantages and expand its applicability. Attempts to modify the type of sorbent and/or its amount in POCIS-like samplers have repeatedly ended in success and the possibility of using this device to collect strongly polar and ionic compounds, by increasing the extraction efficiency (Table 4). However, Oasis HLB, which is easily available and inexpensive, is still the most popular sorption material. In contrast, the use of a triphasic sorbent admixture has been, over the last few years, small, even smaller than the use of POCIS-like samplers with innovative sorbents (Fig. 4).

One of the basic restrictions of commercial POCIS is the inefficient uptake of strongly hydrophilic and ionic organic compounds from water. The growing number of works on the use of innovative sorption materials to overcome this limitation and the published results allow us to conclude that the type of sorbent may be a key factor in increasing the applicability of POCIS-like samplers. It should be emphasized that the majority of research into new sorption materials for POCIS is in the early stages and further tests, ideas and solutions are needed to develop a reliable sorbent that will allow the sampling of a wide range of chemical compounds.

Acknowledgements Financial support was provided by the National Science Center under grant UMO-2019/33/N/ST4/01376. 
Open Access This article is licensed under a Creative Commons Attribution 4.0 International License, which permits use, sharing, adaptation, distribution and reproduction in any medium or format, as long as you give appropriate credit to the original author(s) and the source, provide a link to the Creative Commons licence, and indicate if changes were made. The images or other third party material in this article are included in the article's Creative Commons licence, unless indicated otherwise in a credit line to the material. If material is not included in the article's Creative Commons licence and your intended use is not permitted by statutory regulation or exceeds the permitted use, you will need to obtain permission directly from the copyright holder. To view a copy of this licence, visit http://creativecommons.org/licenses/by/4.0/.

\section{References}

Aguilar-Martínez R, Palacios-Corvillo MA, Greenwood R et al (2008) Calibration and use of the Chemcatcher® passive sampler for monitoring organotin compounds in water. Anal Chim Acta 618:157-167. https://doi.org/10.1016/j.aca.2008.04.052

Ahrens L, Daneshvar A, Lau AE, Kreuger J (2015) Characterization of five passive sampling devices for monitoring of pesticides in water. J Chromatogr A 1405:1-11. https://doi.org/10.1016/j. chroma.2015.05.044

Ahrens L, Daneshvar A, Lau AE, Kreuger J (2018) Concentrations, fluxes and field calibration of passive water samplers for pesticides and hazard-based risk assessment. Sci Total Environ 637638:835-843. https://doi.org/10.1016/j.scitotenv.2018.05.039

Aisha AA, Hneine W, Mokh S et al (2017) Monitoring of 45 pesticides in Lebanese surface water using polar organic chemical integrative sampler (POCIS). Ocean Sci J 52:455-466. https:// doi.org/10.1007/s12601-017-0041-4

Alvarez D, Jones-Lepp T, Stackelberg P et al (2004a) Water quality monitoring of pharmaceuticals and personal care products using passive samplers. In: The American Chemical Society, p 617

Alvarez DA, Petty JD, Huckins JN et al (2004b) Development of a passive, in situ, integrative sampler for hydrophilic organic contaminants in aquatic environments. Environ Toxicol Chem 23:1640-1648. https://doi.org/10.1897/03-603

Alvarez DA, Stackelberg PE, Petty JD et al (2005) Comparison of a novel passive sampler to standard water-column sampling for organic contaminants associated with wastewater effluents entering a New Jersey stream. Chemosphere 61:610-622. https://doi. org/10.1016/j.chemosphere.2005.03.023

Alvarez DA, Cranor WL, Perkins SD et al (2008) Chemical and toxicologic assessment of organic contaminants in surface water using passive samplers. J Environ Qual 37:1024-1033. https:// doi.org/10.2134/jeq2006.0463

Alvarez DA, Rosen MR, Perkins SD et al (2012) Bottom sediment as a source of organic contaminants in Lake Mead, Nevada, USA. Chemosphere 88:605-611. https://doi.org/10.1016/j.chemospher e.2012.03.040

Alvarez DA, Maruya KA, Dodder NG et al (2014) Occurrence of contaminants of emerging concern along the California coast (200910) using passive sampling devices. Mar Pollut Bull 81:347-354. https://doi.org/10.1016/j.marpolbul.2013.04.022

Amdany R, Chimuka L, Cukrowska E (2014) Determination of naproxen, ibuprofen and triclosan in wastewater using the polar organic chemical integrative sampler (POCIS): a laboratory calibration and field application. Water SA 40:407. https://doi. org/10.4314/wsa.v40i3.3

Arditsoglou A, Voutsa D (2008) Passive sampling of selected endocrine disrupting compounds using polar organic chemical integrative samplers. Environ Pollut 156:316-324. https://doi. org/10.1016/j.envpol.2008.02.007
Arenas-Sánchez A, Rico A, Rivas-Tabares D et al (2019) Identification of contaminants of concern in the upper Tagus river basin (central Spain). Part 2: spatio-temporal analysis and ecological risk assessment. Sci Total Environ 667:222-233. https://doi. org/10.1016/j.scitotenv.2019.02.286

Assoumani A, Lissalde S, Margoum C et al (2013) In situ application of stir bar sorptive extraction as a passive sampling technique for the monitoring of agricultural pesticides in surface waters. Sci Total Environ 463-464:829-835. https://doi.org/10.1016/j. scitotenv.2013.06.025

Avdeef A, Berger CM, Brownell C (2000) pH-metric solubility. 2: correlation between the acid-base titration and the saturation shake-flask solubility-pH methods. Pharm Res 17:85-89. https ://doi.org/10.1023/A:1007526826979

Bailly E, Levi Y, Karolak S (2013) Calibration and field evaluation of polar organic chemical integrative sampler (POCIS) for monitoring pharmaceuticals in hospital wastewater. Environ Pollut 174:100-105. https://doi.org/10.1016/j.envpol.2012.10.025

Balaam JL, Grover D, Johnson AC et al (2010) The use of modelling to predict levels of estrogens in a river catchment: how does modelled data compare with chemical analysis and in vitro yeast assay results? Sci Total Environ 408:4826-4832. https://doi. org/10.1016/j.scitotenv.2010.07.019

Barranger A, Akcha F, Rouxel J et al (2014) Study of genetic damage in the Japanese oyster induced by an environmentally-relevant exposure to diuron: evidence of vertical transmission of DNA damage. Aquat Toxicol 146:93-104. https://doi.org/10.1016/j. aquatox.2013.10.032

Bartelt-Hunt SL, Snow DD, Damon T et al (2009) The occurrence of illicit and therapeutic pharmaceuticals in wastewater effluent and surface waters in Nebraska. Environ Pollut 157:786-791. https:// doi.org/10.1016/j.envpol.2008.11.025

Bartelt-Hunt SL, Snow DD, Damon-Powell T et al (2011) Quantitative evaluation of laboratory uptake rates for pesticides, pharmaceuticals, and steroid hormones using POCIS. Environ Toxicol Chem 30:1412-1420. https://doi.org/10.1002/etc.514

Bayen S, Segovia E, Loh LL et al (2014) Application of polar organic chemical integrative sampler (POCIS) to monitor emerging contaminants in tropical waters. Sci Total Environ 482-483:15-22. https://doi.org/10.1016/j.scitotenv.2014.02.082

Bayen S, Estrada ES, Juhel G et al (2016) Pharmaceutically active compounds and endocrine disrupting chemicals in water, sediments and mollusks in mangrove ecosystems from Singapore. Mar Pollut Bull 109:716-722. https://doi.org/10.1016/j.marpo lbul.2016.06.105

Baz-Lomba JA, Harman C, Reid M, Thomas KV (2017) Passive sampling of wastewater as a tool for the long-term monitoring of community exposure: illicit and prescription drug trends as a proof of concept. Water Res 121:221-230. https://doi. org/10.1016/j.watres.2017.05.041

Belden JB, Lotufo GR, Biedenbach JM et al (2015) Application of POCIS for exposure assessment of munitions constituents during constant and fluctuating exposure. Environ Toxicol Chem 34:959-967. https://doi.org/10.1002/etc.2836

Belles A, Pardon P, Budzinski H (2014a) Development of an adapted version of polar organic chemical integrative samplers (POCISNylon). Anal Bioanal Chem 406:1099-1110. https://doi. org/10.1007/s00216-013-7286-2

Belles A, Tapie N, Pardon P, Budzinski H (2014b) Development of the performance reference compound approach for the calibration of "polar organic chemical integrative sampler" (POCIS). Anal Bioanal Chem 406:1131-1140. https://doi.org/10.1007/s0021 6-013-7297-z

Berho C, Togola A, Coureau C et al (2013) Applicability of polar organic compound integrative samplers for monitoring pesticides 
in groundwater. Environ Sci Pollut Res 20:5220-5228. https:// doi.org/10.1007/s11356-013-1508-1

Berho C, Claude B, Coisy E et al (2017) Laboratory calibration of a POCIS-like sampler based on molecularly imprinted polymers for glyphosate and AMPA sampling in water. Anal Bioanal Chem 409:2029-2035. https://doi.org/10.1007/s00216-016-0150-4

Bernard M, Boutry S, Tapie N et al (2018) Lab-scale investigation of the ability of polar organic chemical integrative sampler to catch short pesticide contamination peaks. Environ Sci Pollut Res. https://doi.org/10.1007/s11356-018-3391-2

Bernard M, Boutry S, Lissalde S et al (2019) Combination of passive and grab sampling strategies improves the assessment of pesticide occurrence and contamination levels in a large-scale watershed. Sci Total Environ 651:684-695. https://doi.org/10.1016/j. scitotenv.2018.09.202

Berton A, Brugnera MF, Dores EFGC (2018) Grab and passive sampling applied to pesticide analysis in the São Lourenço river headwater in Campo Verde-MT, Brazil. J Environ Sci Heal Part B Pestic Food Contam Agric Wastes 53:237-245. https://doi. org/10.1080/03601234.2017.1410412

Björlenius B, Ripszám M, Haglund P et al (2018) Pharmaceutical residues are widespread in Baltic Sea coastal and offshore waters screening for pharmaceuticals and modelling of environmental concentrations of carbamazepine. Sci Total Environ 633:14961509. https://doi.org/10.1016/j.scitotenv.2018.03.276

Boles TH, Wells MJM (2014) Pilot survey of methamphetamine in sewers using a polar organic chemical integrative sampler. Sci Total Environ 472:9-12. https://doi.org/10.1016/j.scito tenv.2013.10.122

Booij K, Chen S (2018) Review of atrazine sampling by polar organic chemical integrative samplers and chemcatcher. Environ Toxicol Chem 37:1786-1798. https://doi.org/10.1002/etc.4160

Booij P, Sjollema SB, Leonards PEG et al (2013) Extraction tools for identification of chemical contaminants in estuarine and coastal waters to determine toxic pressure on primary producers. Chemosphere 93:107-114. https://doi.org/10.1016/j.chemospher e.2013.04.095

Bopp S, Weiß H, Schirmer K (2005) Time-integrated monitoring of polycyclic aromatic hydrocarbons (PAHs) in groundwater using the ceramic dosimeter passive sampling device. J Chromatogr A 1072:137-147. https://doi.org/10.1016/j.chroma.2004.12.049

Branchet P, Cadot E, Fenet H et al (2018) Polar pesticide contamination of an urban and peri-urban tropical watershed affected by agricultural activities (Yaoundé, Center Region, Cameroon). Environ Sci Pollut Res 25:17690-17715. https://doi.org/10.1007/ s11356-018-1798-4

Brophy MJ, Mackie AL, Park Y, Gagnon GA (2019) Exploring the detection of microcystin-LR using polar organic chemical integrative samplers (POCIS). Environ Sci Process Impacts 21:659666. https://doi.org/10.1039/c8em00569a

Brown D, Snow D, Hunt GA, Bartelt-Hunt SL (2015) Persistence of pharmaceuticals in effluent-dominated surface waters. J Environ Qual 44:299-304. https://doi.org/10.2134/jeq2014.08.0334

Brumbaugh WG, Petty JD, May TW, Huckins JN (2000) A passive integrative sampler for mercury vapor in air and neutral mercury species in water. Chemosph Glob Change Sci 2:1-9. https://doi. org/10.1016/S1465-9972(99)00055-0

Buzier R, Guibal R, Lissalde S, Guibaud G (2019) Limitation of flow effect on passive sampling accuracy using POCIS with the PRC approach or o-DGT : a pilot-scale evaluation for pharmaceutical compounds. Chemosphere 222:628-636. https://doi. org/10.1016/j.chemosphere.2019.01.181

Caban M, Mẹczykowska H, Stepnowski P (2016) Application of the PASSIL technique for the passive sampling of exemplary polar contaminants (pharmaceuticals and phenolic derivatives) from water. Talanta 155:185-192. https://doi.org/10.1016/j.talan ta.2016.04.035

Camilleri J, Morin N, Miège C et al (2012) Determination of the uptake and release rates of multifamilies of endocrine disruptor compounds on the polar $\mathrm{C} 18$ chemcatcher. Three potential performance reference compounds to monitor polar pollutants in surface water by integrative sampling. J Chromatogr A 1237:37-45. https://doi.org/10.1016/j.chroma.2012.03.025

Camotti Bastos M, Rheinheimer dos Santos D, de Castro M, Lima JA et al (2018) Presence of anthropogenic markers in water: a case study of the Guaporé River Watershed, Brazil. Clean Soil Air Water. https://doi.org/10.1002/clen.201700019

Cao F, Wang L, Ren X et al (2018) The application of molecularly imprinted polymers in passive sampling for selective sampling perfluorooctanesulfonic acid and perfluorooctanoic acid in water environment. Environ Sci Pollut Res 25:33309-33321. https:// doi.org/10.1007/s11356-018-3302-6

Carpinteiro I, Schopfer A, Estoppey N et al (2016) Evaluation of performance reference compounds (PRCs) to monitor emerging polar contaminants by polar organic chemical integrative samplers (POCIS) in rivers. Anal Bioanal Chem 408:1067-1078. https://doi.org/10.1007/s00216-015-9199-8

Černoch I, Fránek M, Diblíková I et al (2011) Determination of atrazine in surface waters by combination of POCIS passive sampling and ELISA detection. J Environ Monit 13:2582. https://doi. org/10.1039/c1em10112a

Černoch I, Fránek M, Diblíková I et al (2012) POCIS sampling in combination with ELISA: screening of sulfonamide residues in surface and waste waters. J Environ Monit 14:250-257. https:// doi.org/10.1039/c1em10652j

Cerveny D, Grabic R, Fedorova G et al (2016) Perfluoroalkyl substances in aquatic environment-comparison of fish and passive sampling approaches. Environ Res 144:92-98. https://doi. org/10.1016/j.envres.2015.11.010

Cerveny D, Grabic R, Fedorova G et al (2018) Fate of perfluoroalkyl substances within a small stream food web affected by sewage effluent. Water Res 134:226-233. https://doi.org/10.1016/j.watre s.2018.01.066

Challis JK, Cuscito LD, Joudan S et al (2018a) Inputs, source apportionment, and transboundary transport of pesticides and other polar organic contaminants along the lower Red River, Manitoba, Canada. Sci Total Environ 635:803-816. https://doi. org/10.1016/j.scitotenv.2018.04.128

Challis JK, Stroski KM, Luong KH et al (2018b) Field evaluation and in situ stress testing of the organic-diffusive gradients in thinfilms passive sampler. Environ Sci Technol 52:12573-12582. https://doi.org/10.1021/acs.est.8b03622

Challis JK, Almirall XO, Helm PA, Wong CS (2020) Performance of the organic-diffusive gradients in thin-films passive sampler for measurement of target and suspect wastewater contaminants. Environ Pollut 261:114092. https://doi.org/10.1016/j.envpo 1.2020 .114092

Charlestra L, Amirbahman A, Courtemanch DL et al (2012) Estimating pesticide sampling rates by the polar organic chemical integrative sampler (POCIS) in the presence of natural organic matter and varying hydrodynamic conditions. Environ Pollut 169:98-104. https://doi.org/10.1016/j.envpol.2012.05.001

Chaves-Barquero LG, Luong KH, Rudy MD et al (2018) Attenuation of pharmaceuticals, nutrients and toxicity in a rural sewage lagoon system integrated with a subsurface filtration technology. Chemosphere 209:767-775. https://doi.org/10.1016/j.chemospher e.2018.06.119

Coes AL, Paretti NV, Foreman WT et al (2014) Sampling trace organic compounds in water: a comparison of a continuous active sampler to continuous passive and discrete sampling methods. Sci 
Total Environ 473-474:731-741. https://doi.org/10.1016/j.scito tenv.2013.12.082

Corcoran S, Metcalfe CD, Sultana T et al (2020) Pesticides in surface waters in argentina monitored using polar organic chemical integrative samplers. Bull Environ Contam Toxicol 104:21-26. https ://doi.org/10.1007/s00128-019-02758-z

Creusot N, Tapie N, Piccini B et al (2013) Distribution of steroid- and dioxin-like activities between sediments, POCIS and SPMD in a French river subject to mixed pressures. Environ Sci Pollut Res 20:2784-2794. https://doi.org/10.1007/s11356-012-1452-5

Criquet J, Dumoulin D, Howsam M et al (2017) Comparison of POCIS passive samplers versus composite water sampling: a case study. Sci Total Environ 609:982-991. https://doi.org/10.1016/j.scito tenv.2017.07.227

Dalton RL, Pick FR, Boutin C, Saleem A (2014) Atrazine contamination at the watershed scale and environmental factors affecting sampling rates of the polar organic chemical integrative sampler (POCIS). Environ Pollut 189:134-142. https://doi.org/10.1016/j. envpol.2014.02.028

De Baat ML, Kraak MHS, Van der Oost R et al (2019) Effect-based nationwide surface water quality assessment to identify ecotoxicological risks. Water Res 159:434-443. https://doi. org/10.1016/j.watres.2019.05.040

de Castro Lima JAM, Labanowski J, Bastos MC et al (2020) "Modern agriculture" transfers many pesticides to watercourses: a case study of a representative rural catchment of southern Brazil. Environ Sci Pollut Res. https://doi.org/10.1007/s11356-01906550-8

Denney S, Sherwood J, Leyden J (1999) In situ measurements of labile $\mathrm{Cu}, \mathrm{Cd}$ and $\mathrm{Mn}$ in river waters using DGT. Sci Total Environ 239:71-80. https://doi.org/10.1016/S0048-9697(99)00304-6

Di Carro M, Bono L, Magi E (2014) A simple recirculating flow system for the calibration of polar organic chemical integrative samplers (POCIS): effect of flow rate on different water pollutants. Talanta 120:30-33. https://doi.org/10.1016/j.talanta.2013.11.088

Di Carro M, Magi E, Massa F et al (2018) Untargeted approach for the evaluation of anthropic impact on the sheltered marine area of Portofino (Italy). Mar Pollut Bull 131:87-94. https://doi. org/10.1016/j.marpolbul.2018.03.059

Diamond SR, Sultana T, Servos MR, Metcalfe CD (2016) Biological responses to contaminants in darters (Etheostoma spp.) collected from rural and urban regions of the Grand River, ON, Canada. Comp Biochem Physiol Part B Biochem Mol Biol 199:126-135. https://doi.org/10.1016/j.cbpb.2016.02.005

Djomte VT, Taylor RB, Chen S et al (2018) Effects of hydrodynamic conditions and temperature on polar organic chemical integrative sampling rates. Environ Toxicol Chem 37:2331-2339. https:// doi.org/10.1002/etc. 4225

Djomte VT, Chen S, Chambliss CK (2020) Effects of suspended sediment on POCIS sampling rates. Chemosphere 241:124972. https ://doi.org/10.1016/j.chemosphere.2019.124972

Dougherty JA, Swarzenski PW, Dinicola RS, Reinhard M (2010) Occurrence of herbicides and pharmaceutical and personal care products in surface water and groundwater around liberty bay, puget sound, Washington. J Environ Qual 39:1173. https://doi. org/10.2134/jeq2009.0189

Estoppey N, Mathieu J, Gascon Diez E et al (2019) Monitoring of explosive residues in lake-bottom water using polar organic chemical integrative sampler (POCIS) and chemcatcher: determination of transfer kinetics through polyethersulfone (PES) membrane is crucial. Environ Pollut 252:767-776. https://doi. org/10.1016/j.envpol.2019.04.087

Fauvelle V, Mazzella N, Delmas F et al (2012) Use of mixed-mode ion exchange sorbent for the passive sampling of organic acids by polar organic chemical integrative sampler (POCIS). Environ Sci Technol 46:13344-13353. https://doi.org/10.1021/es3035279
Fauvelle V, Mazzella N, Belles A et al (2014) Optimization of the polar organic chemical integrative sampler for the sampling of acidic and polar herbicides. Anal Bioanal Chem 406:3191-3199. https ://doi.org/10.1007/s00216-014-7757-0

Fauvelle V, Belles A, Budzinski H et al (2018) Simulated conservative tracer as a proxy for S-metolachlor concentration predictions compared to POCIS measurements in Arcachon Bay. Mar Pollut Bull 133:423-427. https://doi.org/10.1016/j.marpo lbul.2018.06.005

Fedorova G, Golovko O, Randak T, Grabic R (2013) Passive sampling of perfluorinated acids and sulfonates using polar organic chemical integrative samplers. Environ Sci Pollut Res 20:1344-1351. https://doi.org/10.1007/s11356-012-1003-0

Fedorova G, Randak T, Golovko O et al (2014) A passive sampling method for detecting analgesics, psycholeptics, antidepressants and illicit drugs in aquatic environments in the Czech Republic. Sci Total Environ 487:681-687. https://doi.org/10.1016/j.scito tenv.2013.12.091

Fox JT, Adams G, Sharum M, Steelman KL (2010) Passive sampling of bioavailable organic chemicals in Perry County, Missouri cave streams. Environ Sci Technol 44:8835-8841. https://doi. org/10.1021/es1019367

Gallé T, Koehler C, Plattes M et al (2019a) Large-scale determination of micropollutant elimination from municipal wastewater by passive sampling gives new insights in governing parameters and degradation patterns. Water Res 160:380-393. https://doi. org/10.1016/j.watres.2019.05.009

Gallé T, Pittois D, Bayerle M, Braun C (2019b) An immission perspective of emerging micropollutant pressure in Luxembourgish surface waters: a simple evaluation scheme for wastewater impact assessment. Environ Pollut 253:992-999. https://doi. org/10.1016/j.envpol.2019.07.080

Gallé T, Bayerle M, Pittois D, Huck V (2020) Allocating biocide sources and flow paths to surface waters using passive samplers and flood wave chemographs. Water Res 173:115533. https://doi. org/10.1016/j.watres.2020.115533

Gautam P, Carsella JS, Kinney CA (2014) Presence and transport of the antimicrobials triclocarban and triclosan in a wastewaterdominated stream and freshwater environment. Water Res 48:247-256. https://doi.org/10.1016/j.watres.2013.09.032

Gobelius L, Persson C, Wiberg K, Ahrens L (2019) Calibration and application of passive sampling for per- and polyfluoroalkyl substances in a drinking water treatment plant. J Hazard Mater 362:230-237. https://doi.org/10.1016/j.jhazmat.2018.09.005

Gong X, Li K, Wu C et al (2018) Passive sampling for monitoring polar organic pollutants in water by three typical samplers. Trends Environ Anal Chem 17:23-33. https://doi.org/10.1016/j. teac.2018.01.002

Gonzalez-Rey M, Tapie N, Le Menach K et al (2015) Occurrence of pharmaceutical compounds and pesticides in aquatic systems. Mar Pollut Bull 96:384-400. https://doi.org/10.1016/j.marpo lbul.2015.04.029

Grabicová K, Grabic R, Fedorova G et al (2020) Psychoactive pharmaceuticals in aquatic systems: a comparative assessment of environmental monitoring approaches for water and fish. Environ Pollut. https://doi.org/10.1016/j.envpol.2020.114150

Guibal R, Lissalde S, Charriau A et al (2015a) Coupling passive sampling and time of flight mass spectrometry for a better estimation of polar pesticide freshwater contamination: simultaneous target quantification and screening analysis. J Chromatogr A 1387:75-85. https://doi.org/10.1016/j.chroma.2015.02.014

Guibal R, Lissalde S, Charriau A, Guibaud G (2015b) Improvement of POCIS ability to quantify pesticides in natural water by reducing polyethylene glycol matrix effects from polyethersulfone membranes. Talanta 144:1316-1323. https://doi.org/10.1016/j.talan ta.2015.08.008 
Guibal R, Lissalde S, Leblanc J et al (2017) Two sampling strategies for an overview of pesticide contamination in an agriculture-extensive headwater stream. Environ Sci Pollut Res 25:14280-14293. https://doi.org/10.1007/s11356-017-9883-7

Guibal R, Lissalde S, Brizard Y, Guibaud G (2018) Semi-continuous pharmaceutical and human tracer monitoring by POCIS sampling at the watershed-scale in an agricultural rural headwater river. J Hazard Mater 360:106-114. https://doi.org/10.1016/j.jhazm at.2018.07.106

Harman C, Bøyum O, Erik Tollefsen K et al (2008a) Uptake of some selected aquatic pollutants in semipermeable membrane devices (SPMDs) and the polar organic chemical integrative sampler (POCIS). J Environ Monit 10:239-247. https://doi.org/10.1039/ b714725b

Harman C, Tollefsen KE, Bøyum O et al (2008b) Uptake rates of alkylphenols, PAHs and carbazoles in semipermeable membrane devices (SPMDs) and polar organic chemical integrative samplers (POCIS). Chemosphere 72:1510-1516. https://doi. org/10.1016/j.chemosphere.2008.04.091

Harman C, Bøyum O, Thomas KV, Grung M (2009) Small but different effect of fouling on the uptake rates of semipermeable membrane devices and polar organic chemical integrative samplers. Environ Toxicol Chem 28:2324-2332. https://doi.org/10.1897/09-090.1

Harman C, Brooks S, Sundt RC et al (2011a) Field comparison of passive sampling and biological approaches for measuring exposure to PAH and alkylphenols from offshore produced water discharges. Mar Pollut Bull 63:141-148. https://doi.org/10.1016/j. marpolbul.2010.12.023

Harman C, Reid M, Thomas KV (2011b) In situ calibration of a passive sampling device for selected illicit drugs and their metabolites in wastewater, and subsequent year-long assessment of community drug usage. Environ Sci Technol 45:5676-5682. https://doi. org/10.1021/es201124j

Harman C, Allan IJ, Vermeirssen ELM (2012) Calibration and use of the polar organic chemical integrative sampler-a critical review. Environ Toxicol Chem 31:2724-2738. https://doi.org/10.1002/ etc. 2011

Helm PA, Howell ET, Li H et al (2012) Influence of nearshore dynamics on the distribution of organic wastewater-associated chemicals in Lake Ontario determined using passive samplers. J Great Lakes Res 38:105-115. https://doi.org/10.1016/j. jglr.2012.01.005

Huckins JN, Petty JD, Orazio CE et al (1999) Determination of uptake kinetics (sampling rates) by lipid-containing semipermeable membrane devices (SPMDs) for polycyclic aromatic hydrocarbons (PAHs) in water. Environ Sci Technol 33:3918-3923. https ://doi.org/10.1021/es990440u

Huckins JN, Petty JD, Prest HF et al (2000) A guide for the use of semipermeable membrane devices (SPMDs) as samplers of waterborne hydrophobic organic contaminants. Report for the American Petroleum Institute (API)

Ibrahim I, Togola A, Gonzalez C (2013a) Polar organic chemical integrative sampler (POCIS) uptake rates for 17 polar pesticides and degradation products: laboratory calibration. Environ Sci Pollut Res 20:3679-3687. https://doi.org/10.1007/s11356-012-1284-3

Ibrahim I, Togola A, Gonzalez C (2013b) In-situ calibration of POCIS for the sampling of polar pesticides and metabolites in surface water. Talanta 116:495-500. https://doi.org/10.1016/j.talan ta.2013.07.028

Iparraguirre A, Prieto A, Vallejo A et al (2017) Tetraphasic polar organic chemical integrative sampler for the determination of a wide polarity range organic pollutants in water. The use of performance reference compounds and in-situ calibration. Talanta 164:314-322. https://doi.org/10.1016/j.talanta.2016.11.034

Iwanowicz LR, Pinkney AE, Guy CP et al (2019) Temporal evaluation of estrogenic endocrine disruption markers in smallmouth bass
(Micropterus dolomieu) reveals seasonal variability in intersex. Sci Total Environ 646:245-256. https://doi.org/10.1016/j.scito tenv.2018.07.167

Jacquet R, Miège C, Bados P et al (2012) Evaluating the polar organic chemical integrative sampler for the monitoring of beta-blockers and hormones in wastewater treatment plant effluents and receiving surface waters. Environ Toxicol Chem 31:279-288. https:// doi.org/10.1002/etc.737

Jaimes-Correa JC, Snow DD, Bartelt-Hunt SL (2015) Seasonal occurrence of antibiotics and a beta agonist in an agriculturallyintensive watershed. Environ Pollut 205:87-96. https://doi. org/10.1016/j.envpol.2015.05.023

Jakubus A, Tyma M, Stepnowski P, Paszkiewicz M (2016) Application of passive sampling devices based on multi-walled carbon nanotubes for the isolation of selected pharmaceuticals and phenolic compounds in water samples-possibilities and limitations. Talanta 164:700-707. https://doi.org/10.1016/j.talanta.2016.09.052

Jakubus A, Godlewska K, Gromelski M et al (2019a) The possibility to use multi-walled carbon nanotubes as a sorbent for dispersive solid phase extraction of selected pharmaceuticals and their metabolites: effect of extraction condition. Microchem J 146:1113-1125. https://doi.org/10.1016/j.microc.2019.02.051

Jakubus A, Gromelski M, Jagiello K et al (2019b) Dispersive solidphase extraction using multi-walled carbon nanotubes combined with liquid chromatography - mass spectrometry for the analysis of $\beta$-blockers: experimental and theoretical studies. Microchem J 146:258-269. https://doi.org/10.1016/j.microc.2018.12.063

Jaša L, Sadílek J, Kohoutek J et al (2019) Application of passive sampling for sensitive time-integrative monitoring of cyanobacterial toxins microcystins in drinking water treatment plants. Water Res 153:108-120. https://doi.org/10.1016/j.watres.2018.12.059

Jeong Y, Schäffer A, Smith K (2018a) Comparison of the sampling rates and partitioning behaviour of polar and non-polar contaminants in the polar organic chemical integrative sampler and a monophasic mixed polymer sampler for application as an equilibrium passive sampler. Sci Total Environ 627:905-915. https ://doi.org/10.1016/j.scitotenv.2018.01.273

Jeong Y, Schäffer A, Smith K (2018b) A comparison of equilibrium and kinetic passive sampling for the monitoring of aquatic organic contaminants in German rivers. Water Res 145:248-258. https://doi.org/10.1016/j.watres.2018.08.016

Jones L, Ronan J, McHugh B, Regan F (2019) Passive sampling of polar emerging contaminants in Irish catchments. Water Sci Technol 79:218-230. https://doi.org/10.2166/wst.2019.021

Jones-Lepp TL, Alvarez DA, Petty JD, Huckins JN (2004) Polar organic chemical integrative sampling and liquid chromatography- electrospray/ion-trap mass spectrometry for assessing selected prescription and illicit drugs in treated sewage effluents. Arch Environ Contam Toxicol 47:427-439. https://doi. org/10.1007/s00244-004-3146-6

Jorgenson ZG, Thomas LM, Elliott SM et al (2018) Contaminants of emerging concern presence and adverse effects in fish: a case study in the Laurentian Great Lakes. Environ Pollut 236:718 733. https://doi.org/10.1016/j.envpol.2018.01.070

Kaserzon SL, Kennedy K, Hawker DW et al (2012) Development and calibration of a passive sampler for perfluorinated alkyl carboxylates and sulfonates in water. Environ Sci Technol 46:4985-4993. https://doi.org/10.1021/es300593a

Kaserzon SL, Vermeirssen ELM, Hawker DW et al (2013) Passive sampling of perfluorinated chemicals in water: flow rate effects on chemical uptake. Environ Pollut 177:58-63. https://doi. org/10.1016/j.envpol.2013.02.002

Kaserzon SL, Hawker DW, Booij K et al (2014a) Passive sampling of perfluorinated chemicals in water: in-situ calibration. Environ Pollut 186:98-103. https://doi.org/10.1016/j.envpo 1.2013.11.030 
Kaserzon SL, Hawker DW, Kennedy K et al (2014b) Characterisation and comparison of the uptake of ionizable and polar pesticides, pharmaceuticals and personal care products by POCIS and Chemcatchers. Environ Sci Process Impacts 16:2517-2526. https://doi.org/10.1039/c4em00392f

Kim Tiam S, Morin S, Pesce S et al (2014) Environmental effects of realistic pesticide mixtures on natural biofilm communities with different exposure histories. Sci Total Environ 473474:496-506. https://doi.org/10.1016/j.scitotenv.2013.12.060

Kim Tiam S, Morin S, Bonet B et al (2015) Is the toxicity of pesticide mixtures on river biofilm accounted for solely by the major compounds identified? Environ Sci Pollut Res 22:40094024. https://doi.org/10.1007/s11356-014-3373-y

Kohoutek J, Babica P, Bláha L, Maršálek B (2008) A novel approach for monitoring of cyanobacterial toxins: development and evaluation of the passive sampler for microcystins. Anal Bioanal Chem 390:1167-1172. https://doi.org/10.1007/s0021 6-007-1785-y

Kohoutek J, Maršálek B, Bláha L (2010) Evaluation of the novel passive sampler for cyanobacterial toxins microcystins under various conditions including field sampling. Anal Bioanal Chem 397:823-828. https://doi.org/10.1007/s00216-010-3578-y

Kot-Wasik A, Zabiegała B, Urbanowicz M et al (2007) Advances in passive sampling in environmental studies. Anal Chim Acta 602:141-163. https://doi.org/10.1016/j.aca.2007.09.013

Larner BL, Seen AJ, Snape I (2006) Evaluation of diffusive gradients in thin film (DGT) samplers for measuring contaminants in the Antarctic marine environment. Chemosphere 65:811-820. https ://doi.org/10.1016/j.chemosphere.2006.03.028

Lehmann E, Fargues M, Nfon Dibié JJ et al (2018) Assessment of water resource contamination by pesticides in vegetable-producing areas in Burkina Faso. Environ Sci Pollut Res 25:3681-3694. https://doi.org/10.1007/s11356-017-0665-z

Lhotský O, Krákorová E, Linhartová L et al (2017) Assessment of biodegradation potential at a site contaminated by a mixture of BTEX, chlorinated pollutants and pharmaceuticals using passive sampling methods-case study. Sci Total Environ 607608:1451-1465. https://doi.org/10.1016/j.scitotenv.2017.06.193

Li H, Helm PA, Metcalfe CD (2010a) Sampling in the great lakes for pharmaceuticals, personal care products, and endocrinedisrupting substances using the passive polar organic chemical integrative sampler. Environ Toxicol Chem 29:751-762. https:// doi.org/10.1002/etc.104

Li H, Vermeirssen ELM, Helm PA, Metcalfe CD (2010b) Controlled field evaluation of water flow rate effects on sampling polar organic compounds using polar organic chemical integrative samplers. Environ Toxicol Chem 29:2461-2469. https://doi. org/10.1002/etc.305

Li H, Helm PA, Paterson G, Metcalfe CD (2011) The effects of dissolved organic matter and $\mathrm{pH}$ on sampling rates for polar organic chemical integrative samplers (POCIS). Chemosphere 83:271280. https://doi.org/10.1016/j.chemosphere.2010.12.071

Li Y, Yang C, Bao Y et al (2016a) Aquatic passive sampling of perfluorinated chemicals with polar organic chemical integrative sampler and environmental factors affecting sampling rate. Environ Sci Pollut Res 23:16096-16103. https://doi.org/10.1007/ s11356-016-6791-1

Li Z, Sobek A, Radke M (2016b) Fate of pharmaceuticals and their transformation products in four small European rivers receiving treated wastewater. Environ Sci Technol 50:5614-5621. https:// doi.org/10.1021/acs.est.5b06327

Li Y, Yang C, Zha D et al (2018a) In situ calibration of polar organic chemical integrative samplers to monitor organophosphate flame retardants in river water using polyethersulfone membranes with performance reference compounds. Sci Total Environ 610 611:1356-1363. https://doi.org/10.1016/j.scitotenv.2017.08.234
Li Y, Yao C, Zha D et al (2018b) Selection of performance reference compound (PRC) for passive sampling of pharmaceutical residues in an effluent dominated river. Chemosphere 211:884-892. https://doi.org/10.1016/j.chemosphere.2018.07.179

Lis H, Stepnowski P, Caban M (2019) Salinity and pH as factors affecting the passive sampling and extraction of pharmaceuticals from water. J Sep Sci 42:2949-2956. https://doi.org/10.1002/ jssc. 201900346

Liscio C, Magi E, Di Carro M et al (2009) Combining passive samplers and biomonitors to evaluate endocrine disrupting compounds in a wastewater treatment plant by LC/MS/MS and bioassay analyses. Environ Pollut 157:2716-2721. https://doi.org/10.1016/j.envpo 1.2009.04.034

Liscio C, Abdul-Sada A, Al-Salhi R et al (2014) Methodology for profiling anti-androgen mixtures in river water using multiple passive samplers and bioassay-directed analyses. Water Res 57:258-269. https://doi.org/10.1016/j.watres.2014.03.039

Lissalde S, Mazzella N, Mazellier P (2014) Polar organic chemical integrative samplers for pesticides monitoring: impacts of field exposure conditions. Sci Total Environ 488-489:188-196. https ://doi.org/10.1016/j.scitotenv.2014.04.069

Lissalde S, Charriau A, Poulier G et al (2016) Overview of the Chemcatcher ${ }^{\circledR}$ for the passive sampling of various pollutants in aquatic environments Part B: field handling and environmental applications for the monitoring of pollutants and their biological effects. Talanta 148:572-582. https://doi.org/10.1016/j.talan ta.2015.06.076

López-Feria S, Cárdenas S, Valcárcel M (2009) One step carbon nanotubes-based solid-phase extraction for the gas chromatographicmass spectrometric multiclass pesticide control in virgin olive oils. J Chromatogr A 1216:7346-7350. https://doi.org/10.1016/j. chroma.2009.02.060

Lotufo GR, George RD, Belden JB et al (2018) Investigation of polar organic chemical integrative sampler (POCIS) flow rate dependence for munition constituents in underwater environments. Environ Monit Assess. https://doi.org/10.1007/s10661-018-6558-x

Lotufo GR, George RD, Belden JB et al (2019) Release of munitions constituents in aquatic environments under realistic scenarios and validation of polar organic chemical integrative samplers for monitoring. Environ Toxicol Chem 38:2383-2391. https:// doi.org/10.1002/etc.4553

Macleod SL, Mcclure EL, Wong CS (2007) Laboratory calibration and field deployment of the polar organic chemical integrative sampler for pharmaceuticals and personal care products in wastewater and surface water. Environ Toxicol Chem 26:2517-2529. https://doi.org/10.1897/07-238.1

Magi E, Scapolla C, Di Carro M, Liscio C (2010) Determination of endocrine-disrupting compounds in drinking waters by fast liquid chromatography-tandem mass spectrometry. J Mass Spectrom 45:1003-1011. https://doi.org/10.1002/jms.1781

Magi E, Di Carro M, Mirasole C, Benedetti B (2018) Combining passive sampling and tandem mass spectrometry for the determination of pharmaceuticals and other emerging pollutants in drinking water. Microchem J 136:56-60. https://doi.org/10.1016/j. microc.2016.10.029

Martínez Bueno MJ, Hernando MD, Agüera A, Fernández-Alba AR (2009) Application of passive sampling devices for screening of micro-pollutants in marine aquaculture using LC-MS/MS. Talanta 77:1518-1527. https://doi.org/10.1016/j.talanta.2008.09.047

Martínez Bueno MJ, Herrera S, Munaron D et al (2016) POCIS passive samplers as a monitoring tool for pharmaceutical residues and their transformation products in marine environment. Environ Sci Pollut Res 23:5019-5029. https://doi.org/10.1007/s1135 6-014-3796-5

Mazzella N, Dubernet JF, Delmas F (2007) Determination of kinetic and equilibrium regimes in the operation of polar organic chemical 
integrative samplers. Application to the passive sampling of the polar herbicides in aquatic environments. J Chromatogr A 1154:42-51. https://doi.org/10.1016/j.chroma.2007.03.087

Mazzella N, Lissalde S, Moreira S et al (2010) Evaluation of the use of performance reference compounds in an oasis-HLB adsorbent based passive sampler for improving water concentration estimates of polar herbicides in freshwater. Environ Sci Technol 44:1713-1719. https://doi.org/10.1021/es902256m

Męczykowska H, Stepnowski P, Caban M (2018) Effect of salinity and $\mathrm{pH}$ on the calibration of the extraction of pharmaceuticals from water by PASSIL. Talanta 179:271-278. https://doi. org/10.1016/j.talanta.2017.11.012

Męczykowska H, Kobylis P, Stepnowski P, Caban M (2017a) Calibration of passive samplers for the monitoring of pharmaceuticals in water-sampling rate variation. Crit Rev Anal Chem 47:204-222. https://doi.org/10.1080/10408347.2016.1259063

Męczykowska H, Kobylis P, Stepnowski P, Caban M (2017b) Ionic liquids for the passive sampling of sulfonamides from water-applicability and selectivity study. Anal Bioanal Chem 409:39513958. https://doi.org/10.1007/s00216-017-0342-6

Męczykowska H, Stepnowski P, Caban M (2019) Impact of humic acids, temperature and stirring on passive extraction of pharmaceuticals from water by trihexyl(tetradecyl)phosphonium dicyanamide. Microchem J 144:500-505. https://doi.org/10.1016/j. microc.2018.07.023

Metcalfe C, Hoque ME, Sultana T et al (2014) Monitoring for contaminants of emerging concern in drinking water using POCIS passive samplers. Environ Sci Process Impacts 16:473. https:// doi.org/10.1039/c3em00508a

Metcalfe CD, Sultana T, Li H, Helm PA (2016) Current-use pesticides in urban watersheds and receiving waters of western Lake Ontario measured using polar organic chemical integrative samplers (POCIS). J Great Lakes Res 42:1432-1442. https://doi. org/10.1016/j.jglr.2016.08.004

Metcalfe CD, Helm P, Paterson G et al (2019) Pesticides related to land use in watersheds of the Great Lakes basin. Sci Total Environ 648:681-692. https://doi.org/10.1016/j.scitotenv.2018.08.169

Mhadhbi T, Pringault O, Nouri H et al (2019) Evaluating polar pesticide pollution with a combined approach: a survey of agricultural practices and POCIS passive samplers in a Tunisian lagoon watershed. Environ Sci Pollut Res 26:342-361. https:// doi.org/10.1007/s11356-018-3552-3

Miège C, Budzinski H, Jacquet R et al (2012) Polar organic chemical integrative sampler (POCIS): application for monitoring organic micropollutants in wastewater effluent and surface water. J Environ Monit 14:626-635. https://doi.org/10.1039/C1EM10730E

Mijangos L, Ziarrusta H, Prieto A et al (2018a) Evaluation of polar organic chemical integrative and hollow fibre samplers for the determination of a wide variety of organic polar compounds in seawater. Talanta 185:469-476. https://doi.org/10.1016/j.talan ta.2018.03.103

Mijangos L, Ziarrusta H, Ros O et al (2018b) Occurrence of emerging pollutants in estuaries of the Basque Country: analysis of sources and distribution, and assessment of the environmental risk. Water Res 147:152-163. https://doi.org/10.1016/j.watres.2018.09.033

Miller TH, Baz-Lomba JA, Harman C et al (2016) The first attempt at non-linear in silico prediction of sampling rates for polar organic chemical integrative samplers (POCIS). Environ Sci Technol 50:7973-7981. https://doi.org/10.1021/acs.est.6b01407

Mirasole C, Di Carro M, Tanwar S, Magi E (2016) Liquid chromatography-tandem mass spectrometry and passive sampling: powerful tools for the determination of emerging pollutants in water for human consumption. J Mass Spectrom. https://doi.org/10.1002/ jms.3813

Morin N, Miège C, Coquery M, Randon J (2012a) Chemical calibration, performance, validation and applications of the polar organic chemical integrative sampler (POCIS) in aquatic environments. TrAC Trends Anal Chem 36:144-175. https://doi. org/10.1016/j.trac.2012.01.007

Morin S, Pesce S, Kim-Tiam S et al (2012b) Use of polar organic chemical integrative samplers to assess the effects of chronic pesticide exposure on biofilms. Ecotoxicology 21:1570-1580. https://doi.org/10.1007/s10646-012-0910-7

Morin N, Camilleri J, Cren-Olivé C et al (2013) Determination of uptake kinetics and sampling rates for 56 organic micropollutants using "pharmaceutical” POCIS. Talanta 109:61-73. https:// doi.org/10.1016/j.talanta.2013.01.058

Morin NAO, Mazzella N, Arp HPH et al (2018) Kinetic accumulation processes and models for 43 micropollutants in "pharmaceutical" POCIS. Sci Total Environ 615:197-207. https://doi org/10.1016/j.scitotenv.2017.08.311

Morrison SA, Belden JB (2016a) Calibration of nylon organic chemical integrative samplers and sentinel samplers for quantitative measurement of pulsed aquatic exposures. J Chromatogr A 1449:109-117. https://doi.org/10.1016/j.chroma.2016.04.072

Morrison SA, Belden JB (2016b) Characterization of performance reference compound kinetics and analyte sampling rate corrections under three flow regimes using nylon organic chemical integrative samplers. J Chromatogr A 1466:1-11. https://doi. org/10.1016/j.chroma.2016.08.061

Müller AK, Leser K, Kämpfer D et al (2019) Bioavailability of estrogenic compounds from sediment in the context of flood events evaluated by passive sampling. Water Res 161:540-548. https:// doi.org/10.1016/j.watres.2019.06.020

Munaron D, Tapie N, Budzinski H et al (2012) Pharmaceuticals, alkylphenols and pesticides in Mediterranean coastal waters: results from a pilot survey using passive samplers. Estuar Coast Shelf Sci 114:82-92. https://doi.org/10.1016/j.ecss.2011.09.009

Neher TP, Ma L, Moorman TB et al (2020) Catchment-scale export of antibiotic resistance genes and bacteria from an agricultural watershed in central Iowa. PLoS ONE 15:1-18. https://doi. org/10.1371/journal.pone.0227136

Nyoni H, Mamba BB, Msagati TAM (2015) Calibration of a passive, in situ, integrative sampler for monitoring of microbial biotoxins in aquatic environments. Water Sci Technol Water Supply 15:1353-1367. https://doi.org/10.2166/ws.2015.080

Ory J, Bricheux G, Togola A et al (2016) Ciprofloxacin residue and antibiotic-resistant biofilm bacteria in hospital effluent. Environ Pollut 214:635-645. https://doi.org/10.1016/j.envpo 1.2016 .04 .033

Paszkiewicz M, Sikorska C, Leszczyńska D, Stepnowski P (2018) Helical multi-walled carbon nanotubes as an efficient material for the dispersive solid-phase extraction of low and high molecular weight polycyclic aromatic hydrocarbons from water samples : theoretical study. Water Air Soil Polluta 229:253

Pesce S, Lissalde S, Lavieille D et al (2010) Evaluation of single and joint toxic effects of diuron and its main metabolites on natural phototrophic biofilms using a pollution-induced community tolerance (PICT) approach. Aquat Toxicol 99:492-499. https://doi. org/10.1016/j.aquatox.2010.06.006

Pesce S, Morin S, Lissalde S et al (2011) Combining polar organic chemical integrative samplers (POCIS) with toxicity testing to evaluate pesticide mixture effects on natural phototrophic biofilms. Environ Pollut 159:735-741. https://doi.org/10.1016/j. envpol.2010.11.034

Petty JD, Huckins JN, Alvarez DA et al (2004) A holistic passive integrative sampling approach for assessing the presence and potential impacts of waterborne environmental contaminants. Chemosphere 54:695-705. https://doi.org/10.1016/j.chemospher e.2003.08.015

Pickford DB, Jones A, Velez-Pelez A et al (2015) Screening breeding sites of the common toad (Bufo bufo) in England and Wales for 
evidence of endocrine disrupting activity. Ecotoxicol Environ Saf 117:7-19. https://doi.org/10.1016/j.ecoenv.2015.03.006

Pignatello JJ, Katz BG, Li H (2010) Sources, interactions, and ecological impacts of organic contaminants in water, soil, and sediment: an introduction to the special series. J Environ Qual 39:11331138. https://doi.org/10.2134/jeq2010.0099

Pintado-Herrera MG, Lara-Martín PA, González-Mazo E, Allan IJ (2016) Determination of silicone rubber and low-density polyethylene diffusion and polymer/water partition coefficients for emerging contaminants. Environ Toxicol Chem 35:2162-2172. https://doi.org/10.1002/etc.3390

Poulier G, Lissalde S, Charriau A et al (2014) Can POCIS be used in Water Framework Directive (2000/60/EC) monitoring networks? A study focusing on pesticides in a French agricultural watershed. Sci Total Environ 497-498:282-292. https://doi. org/10.1016/j.scitotenv.2014.08.001

Poulier G, Lissalde S, Charriau A et al (2015) Estimates of pesticide concentrations and fluxes in two rivers of an extensive French multi-agricultural watershed: application of the passive sampling strategy. Environ Sci Pollut Res 22:8044-8057. https:// doi.org/10.1007/s11356-014-2814-y

Puls RW, Paul CJ (1997) Multi-layer sampling in conventional monitoring wells for improved estimation of vertical contaminant distributions and mass. J Contam Hydrol 25:85-111. https://doi. org/10.1016/S0169-7722(96)00026-5

Rico A, Arenas-Sánchez A, Alonso-Alonso C et al (2019) Identification of contaminants of concern in the upper Tagus river basin (central Spain). Part 1: screening, quantitative analysis and comparison of sampling methods. Sci Total Environ 666:1058-1070. https://doi.org/10.1016/j.scitotenv.2019.02.250

Rosen MR, Alvarez DA, Goodbred SL et al (2010) Sources and distribution of organic compounds using passive samplers in lake mead national recreation area, Nevada and Arizona, and their implications for potential effects on aquatic biota. J Environ Qual 39:1161. https://doi.org/10.2134/jeq2009.0095

Rosen G, Lotufo GR, George RD et al (2018) Field validation of POCIS for monitoring at underwater munitions sites. Environ Toxicol Chem 37:2257-2267. https://doi.org/10.1002/etc.4159

Rotter S, Sans-Piché F, Streck G et al (2011) Active bio-monitoring of contamination in aquatic systems - an in situ translocation experiment applying the PICT concept. Aquat Toxicol 101:228-236. https://doi.org/10.1016/j.aquatox.2010.10.001

Rujiralai T, Bull ID, Llewellyn N, Evershed RP (2011) In situ polar organic chemical integrative sampling (POCIS) of steroidal estrogens in sewage treatment works discharge and river water. J Environ Monit 13:1427. https://doi.org/10.1039/c0em00537a

Schäfer RB, Paschke A, Liess M (2008) Aquatic passive sampling of a short-term thiacloprid pulse with the chemcatcher: impact of biofouling and use of a diffusion-limiting membrane on the sampling rate. J Chromatogr A 1203:1-6. https://doi.org/10.1016/j. chroma.2008.05.098

Schintu M, Durante L, Maccioni A et al (2008) Measurement of environmental trace-metal levels in Mediterranean coastal areas with transplanted mussels and DGT techniques. Mar Pollut Bull 57:832-837. https://doi.org/10.1016/j.marpolbul.2008.02.038

Schopfer A, Estoppey N, Omlin J et al (2014) The use of passive samplers to reveal industrial and agricultural pollution trends in Swiss rivers. Chim Int J Chem 68:778-782. https://doi. org/10.2533/chimia.2014.778

Sharpe AJ, Nichols EG (2007) Use of stable nitrogen isotopes and permeable membrane devices to study what factors influence freshwater mollusk survival in the Conasauaga River. Environ Monit Assess 132:275-295. https://doi.org/10.1007/s10661-006-9533-x

Shi X, Zhou JL, Zhao H et al (2014) Application of passive sampling in assessing the occurrence and risk of antibiotics and endocrine disrupting chemicals in the Yangtze Estuary, China.
Chemosphere 111:344-351. https://doi.org/10.1016/j.chemo sphere.2014.03.139

Silvani L, Riccardi C, Eek E et al (2017) Monitoring alkylphenols in water using the polar organic chemical integrative sampler (POCIS): determining sampling rates via the extraction of PES membranes and Oasis beads. Chemosphere 184:1362-1371. https://doi.org/10.1016/j.chemosphere.2017.06.083

Škodová A, Prokeš R, Šimek Z, Vrana B (2016) In situ calibration of three passive samplers for the monitoring of steroid hormones in wastewater. Talanta 161:405-412. https://doi.org/10.1016/j. talanta.2016.08.068

Smedes F (2018) Silicone-water partition coefficients determined by cosolvent method for chlorinated pesticides, musks, organo phosphates, phthalates and more. Chemosphere 210:662-671. https ://doi.org/10.1016/j.chemosphere.2018.07.054

Solagaistua L, de Guzmán I, Barrado M et al (2018) Testing wastewater treatment plant effluent effects on microbial and detritivore performance: a combined field and laboratory experiment. Aquat Toxicol 203:159-171. https://doi.org/10.1016/j.aquat ox.2018.08.006

Sonavane M, Creusot N, Maillot-Maréchal E et al (2016) Zebrafishbased reporter gene assays reveal different estrogenic activities in river waters compared to a conventional human-derived assay. Sci Total Environ 550:934-939. https://doi.org/10.1016/j.scito tenv.2016.01.187

Soulier C, Coureau C, Togola A (2016) Environmental forensics in groundwater coupling passive sampling and high resolution mass spectrometry for screening. Sci Total Environ 563-564:845-854. https://doi.org/10.1016/j.scitotenv.2016.01.056

Spirhanzlova P, Fini JB, Demeneix B et al (2019) Composition and endocrine effects of water collected in the Kibale national park in Uganda. Environ Pollut 251:460-468. https://doi.org/10.1016/j. envpol.2019.05.006

Sultana T, Murray C, Ehsanul Hoque M, Metcalfe CD (2016) Monitoring contaminants of emerging concern from tertiary wastewater treatment plants using passive sampling modelled with performance reference compounds. Environ Monit Assess. https://doi. org/10.1007/s10661-016-5706-4

Sultana T, Murray C, Kleywegt S, Metcalfe CD (2018) Neonicotinoid pesticides in drinking water in agricultural regions of southern Ontario, Canada. Chemosphere 202:506-513. https://doi. org/10.1016/j.chemosphere.2018.02.108

Taniyasu S, Kannan K, Ka M et al (2005) Analysis of fluorotelomer alcohols, fluorotelomer acids, and short- and long-chain perfluorinated acids in water and biota. J Chromatogr A 1093:89-97. https://doi.org/10.1016/j.chroma.2005.07.053

Tanwar S, Di Carro M, Magi E (2015) Innovative sampling and extraction methods for the determination of nonsteroidal anti-inflammatory drugs in water. J Pharm Biomed Anal 106:100-106. https ://doi.org/10.1016/j.jpba.2014.10.027

Tapie N, Devier MH, Soulier C et al (2011) Passive samplers for chemical substance monitoring and associated toxicity assessment in water. Water Sci Technol 63:2418-2426. https://doi.org/10.2166/ wst.2011.129

Terzopoulou E, Voutsa D (2016) Active and passive sampling for the assessment of hydrophilic organic contaminants in a river basin-ecotoxicological risk assessment. Environ Sci Pollut Res 23:5577-5591. https://doi.org/10.1007/s11356-015-5760-4

Thomatou AA, Zacharias I, Hela D, Konstantinou I (2011) Passive sampling of selected pesticides in aquatic environment using polar organic chemical integrative samplers. Environ Sci Pollut Res 18:1222-1233. https://doi.org/10.1007/s11356-010-0436-6

Thomatou AA, Antonopoulou M, Michail F, Konstantinou I (2015) Laboratory calibration of twelve pesticides using polar organic chemical integrative samplers. Int J Environ Anal Chem 95:1230-1241. https://doi.org/10.1080/03067319.2015.1070405 
Togola A, Budzinski H (2007) Development of polar organic integrative samplers for analysis of pharmaceuticals in aquatic systems. Anal Chem 79:6734-6741. https://doi.org/10.1021/ac070559i

Toušová Z, Vrana B, Smutná M et al (2019) Analytical and bioanalytical assessments of organic micropollutants in the Bosna River using a combination of passive sampling, bioassays and multiresidue analysis. Sci Total Environ 650:1599-1612. https://doi. org/10.1016/j.scitotenv.2018.08.336

Tumova J, Grabicova K, Golovko O et al (2017) Comparison of passive sampling and biota for monitoring of tonalide in aquatic environment. Environ Sci Pollut Res 24:22251-22257. https:// doi.org/10.1007/s11356-017-9850-3

Vallejo A, Prieto A, Moeder M et al (2013) Calibration and field test of the polar organic chemical integrative samplers for the determination of 15 endocrine disrupting compounds in wastewater and river water with special focus on performance reference compounds (PRC). Water Res 47:2851-2862. https://doi. org/10.1016/j.watres.2013.02.049

Van Metre PC, Alvarez DA, Mahler BJ et al (2017) Complex mixtures of pesticides in midwest U.S. streams indicated by POCIS timeintegrating samplers. Environ Pollut 220:431-440. https://doi. org/10.1016/j.envpol.2016.09.085

Vercraene-Eairmal M, Lauga B, Saint Laurent S et al (2010) Diuron biotransformation and its effects on biofilm bacterial community structure. Chemosphere 81:837-843. https://doi.org/10.1016/j. chemosphere.2010.08.014

Vermeirssen ELM, Körner O, Schönenberger R et al (2005) Characterization of environmental estrogens in river water using a three pronged approach: active and passive water sampling and the analysis of accumulated estrogens in the bile of caged fish. Environ Sci Technol 39:8191-8198. https://doi.org/10.1021/ es050818q

Vermeirssen ELM, Dietschweiler C, Escher BI et al (2012) Transfer kinetics of polar organic compounds over polyethersulfone membranes in the passive samplers pocis and chemcatcher. Environ Sci Technol 46:6759-6766. https://doi.org/10.1021/es3007854

Vičkačkaite V, Padarauskas A (2012) Ionic liquids in microextraction techniques. Cent Eur J Chem 10:652-674. https://doi. org/10.2478/s11532-012-0023-4

Vrana B, Allan IJ, Greenwood R et al (2005) Passive sampling techniques for monitoring pollutants in water. TrAC Trends Anal Chem 24:845-868. https://doi.org/10.1016/j.trac.2005.06.006

Vrana B, Mills GA, Dominiak E, Greenwood R (2006) Calibration of the chemcatcher passive sampler for the monitoring of priority organic pollutants in water. Environ Pollut 142:333-343. https ://doi.org/10.1016/j.envpol.2005.10.033

Vrana B, Mills GA, Kotterman M et al (2007) Modelling and field application of the chemcatcher passive sampler calibration data for the monitoring of hydrophobic organic pollutants in water. Environ Pollut 145:895-904. https://doi.org/10.1016/j.envpo 1.2006.04.030

Vrana B, Smedes F, Prokeš R et al (2016) An interlaboratory study on passive sampling of emerging water pollutants. TrAC Trends Anal Chem 76:153-165. https://doi.org/10.1016/j. trac.2015.10.013

Vroblesky DA (2001) User's guide for polyethylene-based passive diffusion bag samplers to obtain volatile organic compound concentrations in wells, part 1: deployment, recovery, data interpretation, and quality control and assurance

Vystavna Y, Huneau F, Grynenko V et al (2012) Pharmaceuticals in rivers of two regions with contrasted socio-economic conditions: occurrence, accumulation, and comparison for Ukraine and France. Water Air Soil Pollut 223:2111-2124. https://doi. org/10.1007/s11270-011-1008-1

Vystavna Y, Frkova Z, Marchand L et al (2017) Removal efficiency of pharmaceuticals in a full scale constructed wetland in East
Ukraine. Ecol Eng 108:50-58. https://doi.org/10.1016/j.ecole ng.2017.08.009

Wang L, Gong X, Wang R et al (2017) Application of an immobilized ionic liquid for the passive sampling of perfluorinated substances in water. J Chromatogr A 1515:45-53. https://doi.org/10.1016/j. chroma.2017.08.001

Wennrich L, Vrana B, Popp P, Lorenz W (2003) Development of an integrative passive sampler for the monitoring of organic water pollutants. J Environ Monit 5:813-822. https://doi.org/10.1039/ b303497f

Writer JH, Barber LB, Brown GK et al (2010) Anthropogenic tracers, endocrine disrupting chemicals, and endocrine disruption in Minnesota lakes. Sci Total Environ 409:100-111. https://doi. org/10.1016/j.scitotenv.2010.07.018

Xiong J, Wang Z, Ma X et al (2019) Occurrence and risk of neonicotinoid insecticides in surface water in a rapidly developing region: application of polar organic chemical integrative samplers. Sci Total Environ 648:1305-1312. https://doi.org/10.1016/j.scito tenv.2018.08.256

Yabuki Y, Nagai T, Inao K et al (2016) Temperature dependence on the pesticide sampling rate of polar organic chemical integrative samplers (POCIS). Biosci Biotechnol Biochem 80:2069-2075. https://doi.org/10.1080/09168451.2016.1191329

Yabuki Y, Ono J, Nagai T et al (2018) Determining the suitability of a polar organic chemical integrated sampler (POCIS) for the detection of pesticide residue in the Ishikawa River and its tributary in Osaka, Japan. J Pestic Sci 43:1-6. https://doi.org/10.1584/JPEST ICS.D17-063

Yang C, Li Y, Zha D et al (2017) A passive sampling method for assessing the occurrence and risk of organophosphate flame retardants in aquatic environments. Chemosphere 167:1-9. https ://doi.org/10.1016/j.chemosphere.2016.09.141

Yates K, Davies I, Webster L et al (2007) Passive sampling: PARTITION coefficients for a silicone rubber reference phase. J Environ Monit 9:1116-1121. https://doi.org/10.1039/b706716j

Zenker A, Schmutz H, Fent K (2008) Simultaneous trace determination of nine organic UV-absorbing compounds (UV filters) in environmental samples. J Chromatogr A 1202:64-74. https://doi. org/10.1016/j.chroma.2008.06.041

Zha D, Li Y, Wang L et al (2017) Occurrence and attenuation of pharmaceuticals and their transformation products in rivers impacted by sewage treatment plants. RSC Adv 7:40905-40913. https:// doi.org/10.1039/c7ra06852b

Zha D, Li Y, Yang C, Yao C (2018) Assessment of organophosphate flame retardants in surface water and sediment from a freshwater environment (Yangtze River, China). Environ Monit Assess. https://doi.org/10.1007/s10661-018-6587-5

Zhang Z, Hibberd A, Zhou JL (2008) Analysis of emerging contaminants in sewage effluent and river water: comparison between spot and passive sampling. Anal Chim Acta 607:37-44. https:// doi.org/10.1016/j.aca.2007.11.024

Zhang Z, Troldborg M, Yates K et al (2016) Evaluation of spot and passive sampling for monitoring, flux estimation and risk assessment of pesticides within the constraints of a typical regulatory monitoring scheme. Sci Total Environ 569-570:1369-1379. https ://doi.org/10.1016/j.scitotenv.2016.06.219

Zhang Z, Lebleu M, Osprey M et al (2018) Risk estimation and annual fluxes of emerging contaminants from a Scottish priority catchment to the estuary and North Sea. Environ Geochem Health 40:1987-2005. https://doi.org/10.1007/s10653-017-0002-y

Publisher's Note Springer Nature remains neutral with regard to jurisdictional claims in published maps and institutional affiliations. 